International Scientific-Technical and Production Journal

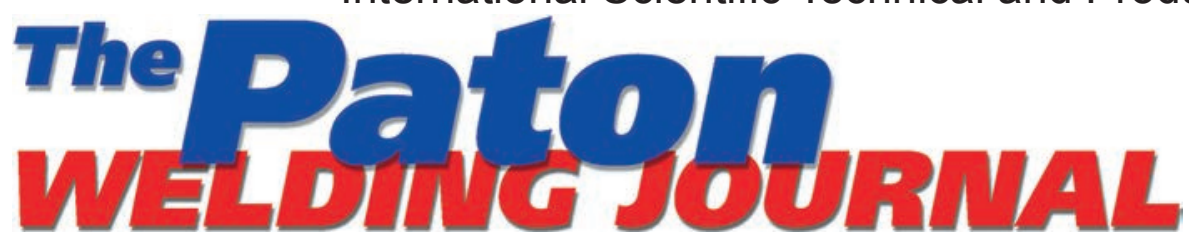

English Translation of the Monthly «Avtomatychne Zvaryuvannya»

(Avtomaticheskaya Svarka/Automatic Welding) Journal Published in Ukrainian and Russian Since 1948

\section{EDITORIAL BOARD}

E.O. Paton Electric Welding Institute, Kyiv, Ukraine: B.E. Paton (Editor-in-Chief),

S.I. Kuchuk-Yatsenko (Deputy Editor-in-Chief),

V.M. Lipodaev (Deputy Editor-in-Chief),

O.M. Berdnikova, Yu.S. Borisov,

V.V. Knysh, V.M. Korzhyk, I.V. Krivtsun,

Yu.M. Lankin, L.M. Lobanov, S.Yu. Maksimov,

M.O. Pashchin, V.D. Poznyakov,

I.O. Ryabtsev, K.A. Yushchenko; V.V. Dmitrik, NTUU

«Kharkiv Polytechnic Institute», Kharkiv, Ukraine;

E.P. Chvertko, V.V. Kvasnitsky, NTUU

«Igor Sikorsky Kyiv Polytechnic Institute», Kyiv, Ukraine;

M.M. Student, Karpenko Physico-Mechanical Institute, Lviv, Ukraine;

M. Zinigrad, Ariel University, Israel;

Ya. Pilarczyk, Welding Institute, Gliwice, Poland;

U. Reisgen, Welding and Joining Institute, Aachen, Germany

\section{Founders}

E.O. Paton Electric Welding Institute International Association «Welding» Publisher

International Association «Welding» Translators

A.O. Fomin, I.M. Kutianova Editor

N.G. Khomenko Electron galley

D.I. Sereda, T.Yu. Snegiryova

$$
\text { Address }
$$

E.O. Paton Electric Welding Institute,

International Association «Welding»

11 Kazymyr Malevych Str. (former Bozhenko), 03150, Kyiv, Ukraine

Tel.:/Fax: (38044) 2008277

E-mail: journal@paton.kiev.ua

www://patonpublishinghouse.com/eng/journals/tpw]

State Registration Certificate

KV 4790 of 09.01.2001

ISSN 0957-798X

DOI: http://dx.doi.org/10.37434/tpwj Subscriptions

12 issues per year, back issues available $\$ 384$, subscriptions for the printed (hard copy) version, air postage and packaging included.

$\$ 312$, subscriptions for the electronic version (sending issues of Journal in pdf format or providing access to IP addresses). Institutions with current subscriptions on printed version can purchase online access to the electronic versions

of any back issues that they have not subscribed to.

Issues of the Journal (more than two years old)

are available at a substantially reduced price.

All rights reserved.

This publication and each of the articles contained herein are protected by copyright.

Permission to reproduce material contained in this

journal must be obtained in writing from the Publisher.

\section{CONTENTS}

\section{SCIENTIFIC AND TECHNICAL}

Berdnikova O.M., Kostin V.A., Poznyakov V.D., Gaivoronskii O.A., Alekseenko T.O. and Alekseenko I.I. Structure and crack resistance of special steels with $0.25-0.31 \%$ carbon under the conditions of simulation of thermal cycles of welding

Skryabinskyi V.V., Nesterenkov V.M., Rusynyk M.O. and Strashko V.R. Effect of mode of electron beam welding, heat treatment and plastic deformation on strength of joints of aluminium 1570 alloy

Babinets A.A., Ryabtsev I.O., Lentyugov I.P., Ryabtsev I.I.,

Demchenko Yu.V. and Panfilov A.I. Problems and prospects of

surfacing of copper and copper parts by wear-resistant layers

(Review)

Shchetynin S.V., Shchetynina V.I. and Desyatskii S.P. Improvement of crack resistance of banded support rolls at high-speed surfacing with low energy input

\section{INDUSTRIAL}

Nesterenkov V.M., Rusynyk M.O., Berdnikova O.M., Matviichuk V.A. and Strashko V.R. Microstructure of titanium alloys produced by the method of layer-by-layer electron beam surfacing using the wire of grade Ti6Al4V

Lobanov L.M., Makhlin N.M., Popov V.Ye., Oliyanenko D.S. and Kovalyuk O.V. Automatic arc welding in manufacture and renovation repair of pipe elements of spirals of high-pressure heaters of NPP power units

Prokofiev O.S., Gubatyuk R.S., Pismennyi O.S., Rymar S.V. and Panteleymonov Ye.O. Development of inductors for bulk and surface heat treatment of welded butt joints of railway rails

Masiouchok O.P., Iurzhenko M.V., Kolisnyk R.V. and Korab M.G.

Additive technologies of polymer materials (Review)

\section{BRIEF INFORMATION}

EBW installations for granular metallurgy 


\title{
STRUCTURE AND CRACK RESISTANCE OF SPECIAL STEELS WITH $0.25-0.31 \%$ CARBON UNDER THE CONDITIONS OF SIMULATION OF THERMAL CYCLES OF WELDING
}

\author{
O.M. Berdnikova, V.A. Kostin, V.D. Poznyakov, \\ O.A. Gaivoronskii, T.O. Alekseenko and I.I. Alekseenko \\ E.O. Paton Electric Welding Institute of the NAS of Ukraine \\ 11 Kazymyr Malevych Str., 03150, Kyiv, Ukraine. E-mail: office@paton.kiev.ua
}

\begin{abstract}
The impact of thermodeformational cycle of welding on structural-phase transformations in the HAZ metal of armour steel of $30 \mathrm{Kh} 2 \mathrm{NMF}$ type with different carbon content $(0.25 ; 0.29$ and $0.31 \%)$ was studied. At the next stage, structural changes in model samples-simulators with $0.31 \%$ carbon at different cooling rates $\left(3.8 ; 12.5\right.$ and $\left.21{ }^{\circ} \mathrm{C} / \mathrm{s}\right)$ and their fracture mode after bend testing were studied. As a result of the performed studies, it was established that the structure ensuring the optimum level of strength and fracture toughness, forms when low cooling rates are used (below $3.8^{\circ} \mathrm{C} / \mathrm{s}$ ). 13 Ref., 3 Tables, 6 Figures.
\end{abstract}

Ke ywords: special high-strength steel, thermodeformational welding cycle, thermokinetic transformation diagrams, heat-affected zone, microstructure, fracture mode, crack resistance

In the middle of the previous century, special armoured vehicles were made predominantly from steels of the following alloying systems: $\mathrm{Cr}-\mathrm{Mn}-\mathrm{Mo}$; $\mathrm{Cr}-\mathrm{Ni}-\mathrm{Mn}-\mathrm{V}, \mathrm{Cr}-\mathrm{Ni}-\mathrm{Mn}-\mathrm{Mo}$, etc., which had 0.7$1.5 \% \mathrm{Mn}, 0.7-2.5 \% \mathrm{Cr}, 1.1-3.0 \% \mathrm{Ni}, 0.1-0.2 \% \mathrm{~V}$, $0.2-0.6 \%$ Mo and $0.25-0.5 \%$ carbon [1]. Further development of special steels followed the path of optimization of their chemical composition and application of special heat treatment modes that allowed increasing the hardness, ultimate strength and decreasing the content of carbon and sulphur, lowering the risks of cold cracking. Tempered martensite structure is the main structural component of these steels. Such steels are high-strength steels with $\sigma_{0.2} \geq$ $1300 \mathrm{MPa}$ and $\sigma_{t} \geq \geq 1500 \mathrm{MPa}$.

Nowadays, heat-hardened high-strength steels alloyed by $\mathrm{Cr}, \mathrm{Ni}, \mathrm{Mn}$ and $\mathrm{Mo}$ with carbon content from 0.25 to $0.50 \%$ which are additionally alloyed with $\mathrm{V}, \mathrm{Al}$, and $\mathrm{B}$, are widely used during manufacture of welded components and bodies of wheeled armoured vehicles. Depending on their purpose, special steels can have medium $\geq 2850 \mathrm{MPa}$, increased $\geq 3350 \mathrm{MPa}$ and high $\geq 3630 \mathrm{MPa}$ hardness, which they develop after the respective heat treatment $[2,3]$.

One of the main requirements made of the welded joints of special steels, consists in that the hardness of metal in the joint HAZ should not be lower than that of base metal hardness. As structures from the mentioned steels are not hardened after welding, but are subjected to low-temperature tempering, it becomes obvious that the required values of HAZ metal hardness should be formed after welding.

It is known $[4,5]$ that the mechanical properties of metal are determined by its structural composition. Moreover, formation of the structure in the metal of welded joint HAZ depends not only on the chemical composition of steels, but also on the temperature-time cooling modes - thermal cycles of welding. Under certain conditions, when the metal is cooling down at a low rate after heating, it can be softened. And with increase of the cooling rate, its hardness and static strength usually increase.

However, welded joints of high-strength medium-carbon alloyed steels are prone to cold cracking. This is associated with formation of hardening structures and residual stresses in the HAZ metal [6-9]. Local preheating is used, in order to reduce the risk of cold cracking in the welded joints of these steels. On the one hand, it allows controlling the kinetics of phase transformations and forming structures with higher cold cracking resistance, and on the other hand - creating the conditions for active desorption of hydrogen from the welded joint metal. In a number of cases, however, welding high-strength special

O.M. Berdnikova — https://orcid.org/0000-0001-9754-9478, V.A. Kostin — https://orcid.org/0000-0002-2677-4667

V.D. Poznyakov — https://orcid.org/0000-0001-8581-3526, O.A. Gaivoronskii — https://orcid.org/0000-0002-8146-7790

T.O. Alekseenko — https://orcid.org/0000-0001-8492-753X, I.I. Alekseenko — https://orcid.org/0000-0002-2595-1684 
steels with more than $0.25 \% \mathrm{C}$ content becomes an insoluble problem for many developers of armoured vehicle design.

On the other hand, the problems in development of new high-strength steels for armoured vehicles still remains urgent. So, presence of defects in the welded joint zone was found recently in a number of cases at manufacture of armoured vehicle bodies from steel of $30 \mathrm{Kh} 2 \mathrm{~N} 2 \mathrm{MF}$ type, even before their use [10]. This points to the fact that the problem of producing sound welded joints can be related not only to technological features of armoured welding, but also to the quality of the steel proper, namely uniformity of its structure, chemical composition and presence of defects.

In order to clarify the possible circumstances of appearance of low-quality welded joints of the bodies of armoured vehicles for the Ukrainian army, it is necessary to precisely determine the structural state of steel, applied in production, in as-delivered condition and possible structural-phase changes, occurring during welding of this steel. It is also necessary to take into account the rather broad range of carbon content (from 0.25 to $0.35 \%$ ), characteristic for this steel.

Brittle fracture resistance that is usually assessed by fracture mechanics criteria, also is a significant factor, determining the reliability of technical means from armoured steels.

Therefore, the main objective of the work, was evaluation of the impact of thermal-deformational cycles of welding (TDCW) on structural-phase transformations in the HAZ metal of armoured steel, determination of their structural inhomogeneity and establishing the relationship between the structure that forms and brittle cracking susceptibility (crack resistance) of this steel with different carbon content.

Materials and experimental procedures. At the first stage of the work, the structure-phase transformations in the HAZ metal of armoured steel of 30Kh2N2MF type with different content of carbon (Table 1) was studied at simulation of TDCW, using Gleeble 3800 complex $[11,12]$. In keeping with the method, cylindrical steel samples of $6.0 \mathrm{~mm}$ diameter and $80 \mathrm{~mm}$ length were used, which were heated up to the temperature of $1250{ }^{\circ} \mathrm{C}$ in vacuum. Simulation cycles were selected in keeping with the established parameters of the thermal cycle in the HAZ of welded joints of $20 \mathrm{~mm}$ thickness at mechanized welding in shielding gas atmosphere. Accordingly, the rate of sample heating in Gleeble 3800 complex was equal to approximately $210{ }^{\circ} \mathrm{C} / \mathrm{s}$ in the temperature range of $20-1200{ }^{\circ} \mathrm{C}$, cooling rate was $w_{6 / 5}=2.5-30{ }^{\circ} \mathrm{C} / \mathrm{s}$ in the temperature range of $600-500^{\circ} \mathrm{C}$. When studying the kinetics of austenite decomposition the temperature of the start and end of transformation was determined by the tangent to the dilatometric curve, and the ratio of phases that formed as a result of transformation, was established by the random linear intercept method [13].

At the second stage, the structural changes and fracture mode of armoured steel with $0.31 \%$ carbon were studied, depending on the cooling rate $\left(w_{6 / 5}=3.8,12.5\right.$ and $21{ }^{\circ} \mathrm{C} / \mathrm{s}$ ), using a complex of light metallography research methods (Versamet-2, Neophot-32) and analytical scanning microscopy (SEM-515, PHILIPS Company, Netherlands). The images were recorded, using Olympus digital camera. Microhardness of the structural components and integral microhardness of the HAZ metal were measured in the microhardness meter M-400 of LECO Company at the load of $100 \mathrm{~g}$ (HV 0.1) and $1 \mathrm{~kg}$ (HV 1) to GOST 2999-75).

Experimental results and their analysis. Base metal of armoured steel with $0.25 \%$ carbon content in as-delivered condition without heat treatment (HT) is characterized by the rolled texture; its structure is mainly represented by upper bainite (Figure $1, a$ ). Integral hardness of metal is $H V_{1}=2830-2960 \mathrm{MPa}$.

The metal structure changes under the impact of TDCW. Generalized results of the studying the impact of the cooling rate on the structural-phase transformations in the HAZ metal of welded joints of armoured steel with $0.25 \%$ carbon, are shown in Figure 2, $a$ in the form of a thermokinetic diagram of transformation of overcooled austenite. As shown by the conducted studies, in the range of cooling rates $w_{6 / 5}=2.5$ $30^{\circ} \mathrm{C} / \mathrm{s}$ the transformation of overcooled austenite in the HAZ metal of steel with $0.25 \%$ carbon occurs exclusively in the martensite region. The temperature of the start of martensite transformation is equal to $360{ }^{\circ} \mathrm{C}$, the temperature of its end is $150{ }^{\circ} \mathrm{C}$ (Figure 2). It should be also noted that at increase of the cooling rate the size of martensite packets is reduced from 34 to $12.5 \mathrm{~mm}$, and integral hardness $H V_{1}$ rises from 3680 to $5070 \mathrm{MPa}$.

Studies of armoured steel with $0.29 \%$ carbon content (after heat treatment) showed that the rolled texture in the metal is not as clearly manifested as in steel

Table 1. Chemical composition of armoured steel with different content of carbon, wt.\%

\begin{tabular}{|c|c|c|c|c|c|c|c|c|c|c|c|c|}
\hline Material & $\mathrm{C}$ & $\mathrm{Si}$ & Mn & $\mathrm{Cr}$ & $\mathrm{Ni}$ & Mo & $\mathrm{Cu}$ & V & $\mathrm{Al}$ & $\mathrm{Ti}$ & $\mathrm{S}$ & $\mathrm{P}$ \\
\hline \multirow{3}{*}{ Armoured steel } & 0.25 & 1.24 & 0.71 & 1.68 & 2.20 & 0.24 & $<0.02$ & 0.18 & 0.032 & 0.019 & 0.007 & 0.01 \\
\hline & 0.29 & 0.78 & 0.73 & 1.68 & 2.0 & 0.30 & $<0.02$ & 0.18 & 0.036 & 0.016 & 0.009 & 0.012 \\
\hline & 0.31 & 93.3 & 1.16 & 0.74 & 1.16 & 2.26 & 0.3 & 0.2 & 0.04 & 0.024 & 0.01 & 0.016 \\
\hline
\end{tabular}




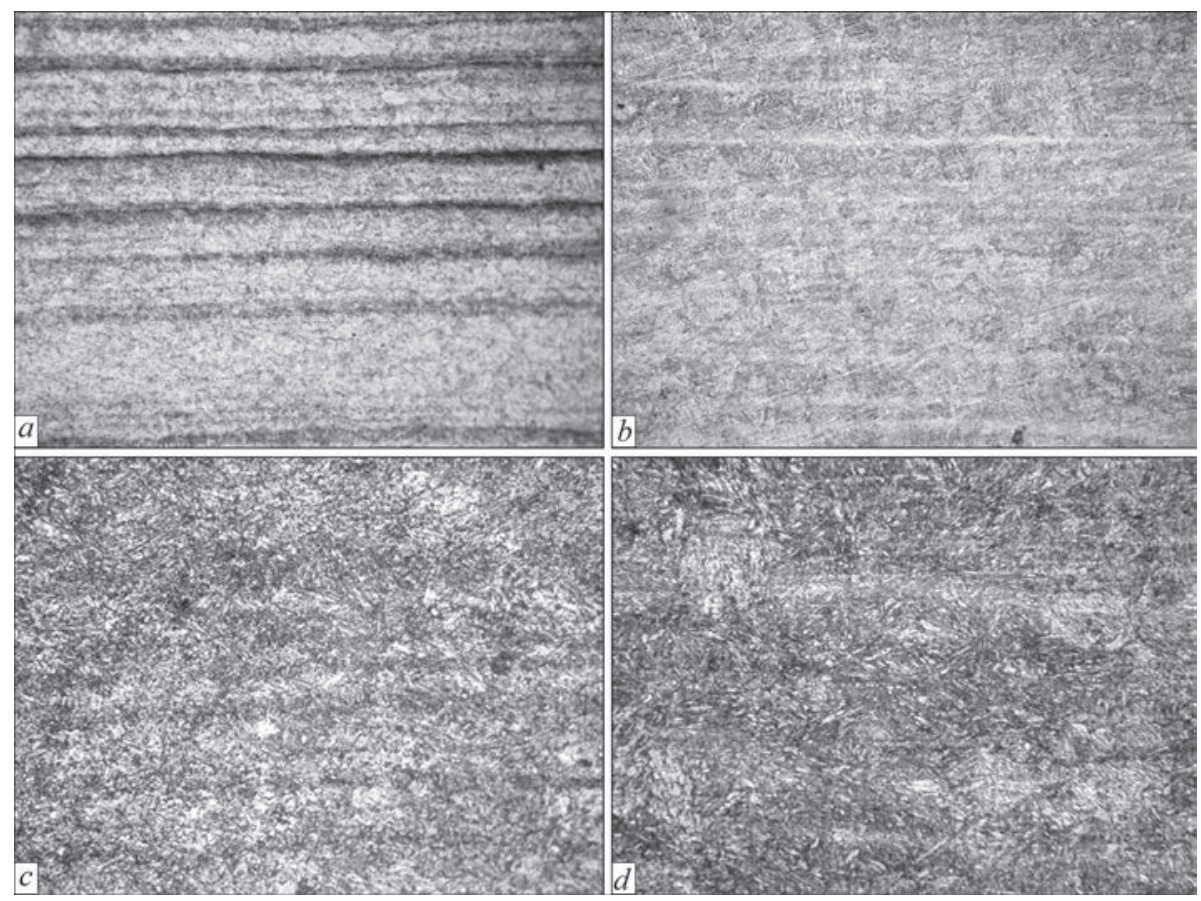

Figure 1. Structure of base metal of armoured steel with different carbon content, $\% \mathrm{C}: a-0.25 ; b-0.29 ; c, d-0.31(\times 200$, reduced two times at printing)
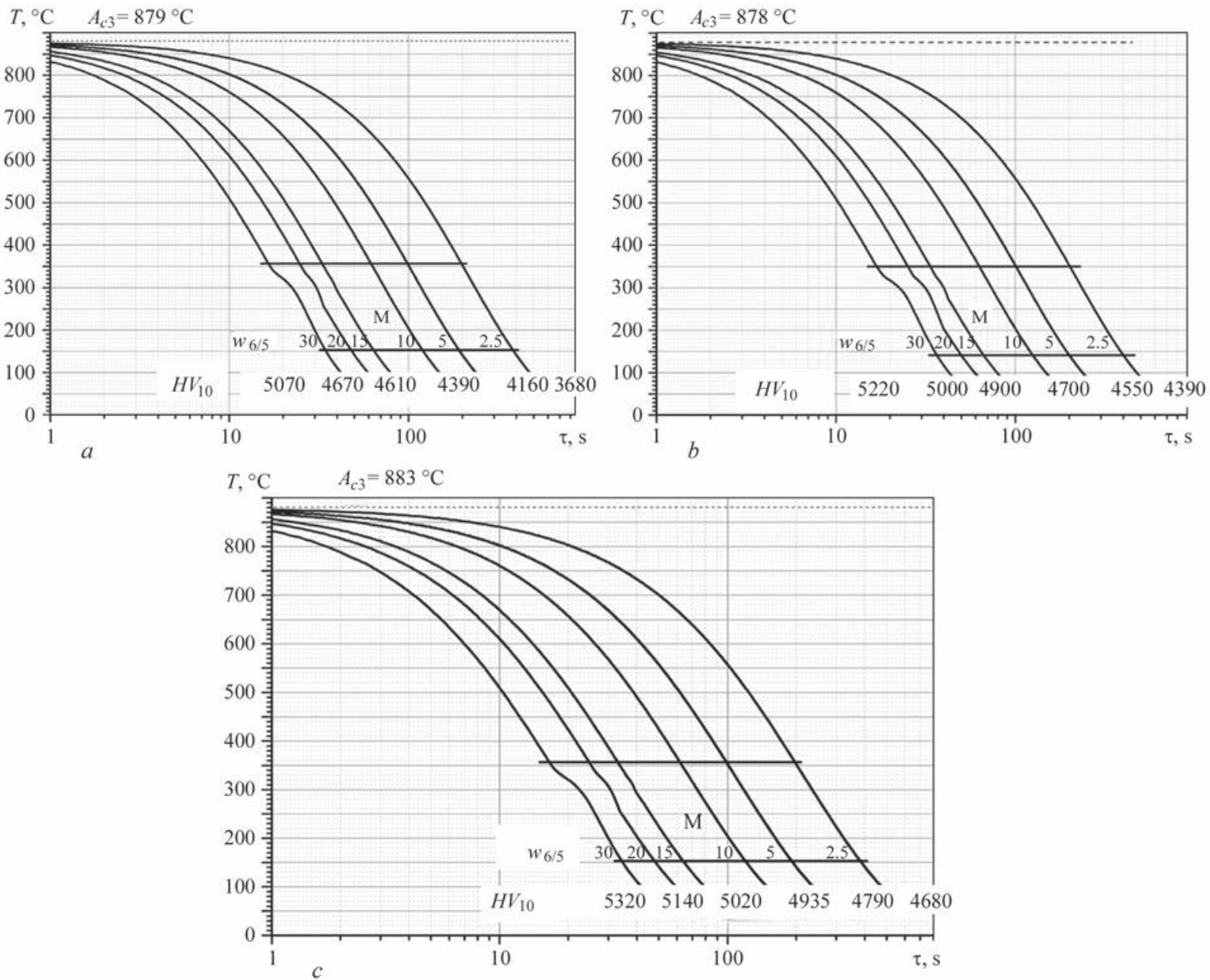

Figure 2. Thermokinetic diagram of transformation of overcooled austenite in the HAZ metal of armoured steel with carbon content, \%: $a-0.25 ; b-0.29$; $c-0.31$ 
Table 2. Structural parameters: packet size $\left(D_{\mathrm{p}}\right)$; volume fraction $\left(V_{\mathrm{fr}}, \%\right)$; microhardness $(H V)$ of structural components in the HAZ metal of samples of armoured steel $(0.31 \% \mathrm{C})$ at different cooling rates $\left(w_{6 / 5}\right)$

\begin{tabular}{|c|c|c|c|}
\hline \multirow{2}{*}{ Parameter } & \multicolumn{3}{|c|}{ Cooling rate $w_{6 / 5},{ }^{\circ} \mathrm{C} / \mathrm{s}$} \\
\hline & 3.8 & 12.5 & 21 \\
\hline$V_{\mathrm{fr}}, \%^{*}$ & $\begin{array}{l}88-90 \% \mathrm{M} \\
10-12 \% \mathrm{~B}_{1} \\
\end{array}$ & $\begin{array}{c}93-95 \% \mathrm{M} \\
5-7 \% \mathrm{~B}_{1}\end{array}$ & $\begin{array}{c}95-98 \% \mathrm{M} \\
3-5 \% \mathrm{~B}_{1}\end{array}$ \\
\hline$D_{\mathrm{p}}, \mu \mathrm{m}$ & $35-80$ & $20-70$ & $15-50$ \\
\hline$H V, \mathrm{MPa}$ & $\begin{array}{c}4420\left(\mathrm{~B}_{1}\right) \\
4980-5600(\mathrm{M})\end{array}$ & $\begin{array}{c}4880\left(\mathrm{~B}_{1}\right) \\
5030-6060(\mathrm{M})\end{array}$ & $\begin{array}{c}4800\left(\mathrm{~B}_{1}\right) \\
5360-6810(\mathrm{M})\end{array}$ \\
\hline
\end{tabular}

without HT. Metal structure is more uniform, and consists of dispersed martensite (Figure 1,b), integral hardness of metal is $H V_{1}=4420-4560 \mathrm{MPa}$. Figure 2, $b$ shows the generalized results of studying the impact of cooling rate on structural-phase transformations in the HAZ metal of welded joints with $0.29 \%$ carbon, in the form of thermokinetic diagram of transformation of overcooled austenite.

In the HAZ metal of armoured steel with $0.29 \%$ carbon, the overcooled austenite transformations in the range of cooling rates $w_{6 / 5}=2.5-30{ }^{\circ} \mathrm{C} / \mathrm{s}$ occurs also in the martensite region, similar to the previous case. Unlike steel with $0.25 \%$ carbon, in steel with $0.29 \%$ carbon the temperature of the start of martensite transformation is somewhat lower and is equal to $350{ }^{\circ} \mathrm{C}$, that of the end of transformation is $140{ }^{\circ} \mathrm{C}$ (Figure 2, $a, b$ ). At increase of the cooling rate, the size of martensite packets decreases from 35.6 to $12.5 \mu \mathrm{m}$ on average, integral value of microhardness increases from 4390 up to $5420 \mathrm{MPa}$.

Results of the conducted studies show that unlike steel, where carbon content is equal to $0.25 \%$, in the HAZ metal of steel with $0.29 \%$ carbon, a martensitic structure of higher hardness and strength forms at cooling rate $w_{6 / 5} \geq 15^{\circ} \mathrm{C} / \mathrm{s}$.

Investigations of armoured steel with $0.31 \%$ carbon in as-delivered condition (without HT) showed that the structure of predominantly upper bainite forms at a small amount of lower bainite (Figure 1, c).
After HT (quenching and high-temperature tempering) the steel structure changes and consists of martensite and lower bainite (Figure 1, $d$ ).

Thus, in the considered range of cooling rates, the transformations of overcooled austenite in the HAZ metal of steel with $0.31 \%$ carbon occur exclusively in the martensite region. Irrespective of the sample cooling rate, martensite transformation starts from the temperature of $360{ }^{\circ} \mathrm{C}$, and ends at the temperature of $150^{\circ} \mathrm{C}$ (Figure $2, c$ ). With increase of the cooling rate, the size of martensite packets decreases, similar to the previous cases, from 34 to $12.5 \mu \mathrm{m}$ on average.

With the purpose of further studying the structural-phase changes in the model samples-simulators from armoured steel, depending on the cooling rate $\left(w_{6 / 5}=3.8 ; 12.5\right.$ and $\left.21^{\circ} \mathrm{C} / \mathrm{s}\right)$, investigations of steel with $0.31 \% \mathrm{C}$ were conducted by the methods of light and scanning electron microscopy. At metallographic investigations the following structures: bainite, martensite, and their parameters: packet size $\left(D_{\mathrm{p}}\right)$, volume fraction of the structures $\left(V_{\mathrm{fr}}, \%\right)$, which form in the metal of HAZ overheated zone, were studied, as well as the respective microhardness changes (Table 2).

It was established that at increase of the cooling rate from $w_{6 / 5}=3.8$ up to $12.5^{\circ} \mathrm{C} / \mathrm{s}$ and $w_{6 / 5}=21^{\circ} \mathrm{C} / \mathrm{s}$, the volume fraction of martensite becomes greater at reduction of the fraction of the bainite component, structure refinement (packet size is reduced 2 times)
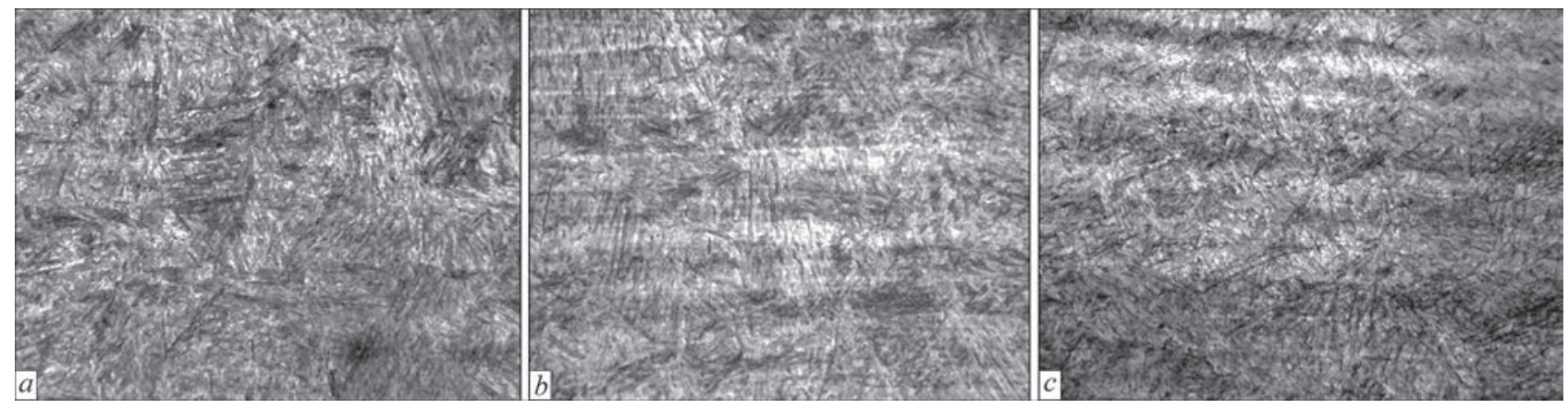

Figure 3. Microstructure $(\times 500)$ of HAZ metal of model samples of armoured steel, cooled at different rates $w_{6 / 5},{ }^{\circ} \mathrm{C} / \mathrm{s}: a-3.8$; $b-12.5 ; c-21$ 
Table 3. Results of fracture toughness testing of armoured steel $(0.31 \% \mathrm{C})$ at different cooling rates $\left(w_{6 / 5}\right)$

\begin{tabular}{|c|c|c|c|}
\hline \multirow{2}{*}{$\begin{array}{c}\text { Critical coefficient } \\
\text { of stress intensity }\end{array}$} & \multicolumn{3}{|c|}{ Cooling rate $w_{6 / 5},{ }^{\circ} \mathrm{C} / \mathrm{s}$} \\
\cline { 2 - 4 } & 3.8 & 12.5 & 21 \\
\hline$K_{1 c}, \mathrm{MPa} \cdot \mathrm{m}^{1 / 2}$ & 110 & 85 & 70 \\
\hline
\end{tabular}

and increase of microhardness (by $13 \%$ on average) (Table 2, Figure 3).

In order to evaluate the crack resistance of the HAZ metal of armoured steel samples at different cooling rates $w_{6 / 5}$, investigations of the impact of structural factors on the fracture mode at three-point bend testing at external load were conducted. Mechanical testing showed that the largest values of fracture toughness, namely the critical coefficient of stress intensity $K_{1 c}=$ $=110 \mathrm{MPa} \cdot \mathrm{m}^{1 / 2}$ of the metal was obtained at cooling rate $w_{6 / 5}=3.8^{\circ} \mathrm{C} / \mathrm{s}$ (Table 3 ). $K_{1 c}$ value decreases at increase of the cooling rate up to $w_{6 / 5}=12.5$ and $21^{\circ} \mathrm{C} / \mathrm{s}$. Such changes of fracture toughness are associated with the impact of the cooling rates on the structural-phase changes in the metal of the studied samples, namely reduction of the amount of lower bainite and increase of the amount of the martensite component.

Mechanical testing was followed by detailed fractographic analysis of the structure of sample fractures, taking into account the fracture modes, and parame- ters of microrelief elements of the fracture surface by the characteristic fracture zones: fatigue crack zone (near the notch); main fracture zone; final fracture zone (Figures 4-6).

Fractographic studies of the sample produced at cooling rate $w_{6 / 5}=3.8^{\circ} \mathrm{C} / \mathrm{s}$, showed the uniform type of quasibrittle fracture in the fatigue crack zone, with quasicleavage facet size $d_{\mathrm{f}}=2-7 \mu \mathrm{m}$, and local areas of the tough component $\left(d_{\text {pit }}=2-5 \mu \mathrm{m}\right)$, Figure $4 a$, $b$. At transition to the main crack zone, the fracture mode is predominantly $\left(V_{\mathrm{fr}}=90 \%\right)$ ductile with pit size $d_{\text {pit }}=2-4 \mu \mathrm{m}$ (Figure $4, c, d$ ). The main crack zone is characterized by the presence of isolated secondary cracks of length $L_{\mathrm{cr}}=10-15 \mu \mathrm{m}$ (Figure 4,e). In the final fracture zone, the fracture mode is also ductile with pit size $d_{\text {pit }}=2-7 \mu \mathrm{m}$ (Figure 4, $f$ ).

At increase of the sample cooling rate up to $w_{6 / 5}=$ $=12.5^{\circ} \mathrm{C} / \mathrm{s}$, quasibrittle fracture with the size of quasicleavage facets $d_{\mathrm{f}}=3-10 \mu \mathrm{m}$ and local areas of the ductile component $\left(d_{\text {pit }}=2-5 \mu \mathrm{m}\right)$ was found in the fatigue crack zone brittle fracture, Figure $5, a, b$. At transition into the main crack zone the fracture mode is predominantly ductile $\left(V_{\mathrm{fr}}=75-80 \%\right)$ with pit size $d_{\text {pit }}=2-6 \mu \mathrm{m}$ (Figure 5, c, d, e) and secondary cracks are absent. In the final fracture zone, fracture mode is ductile with pit size $d_{\text {pit }}=2-8 \mu \mathrm{m}$ (Figure $5, f$ ).
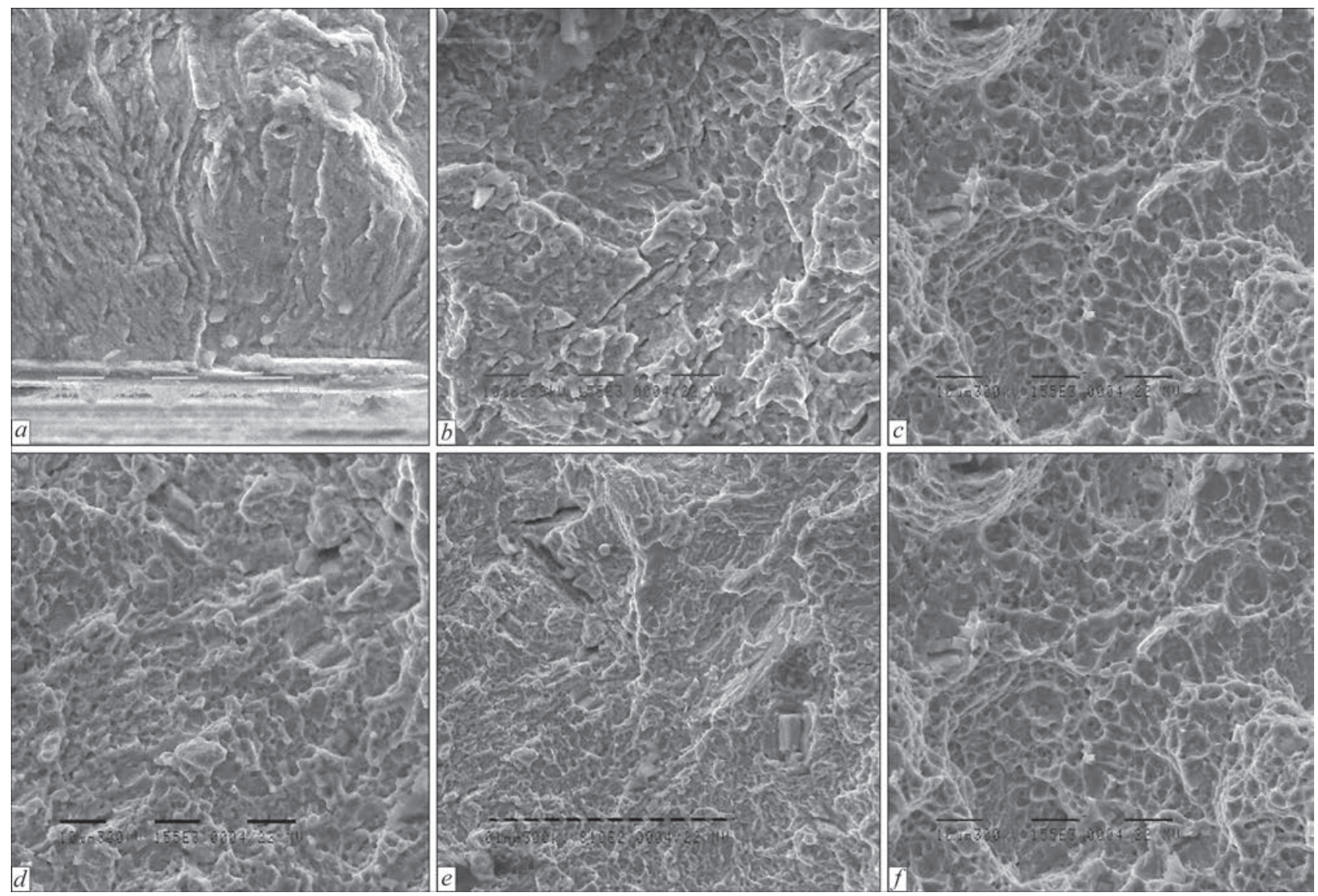

Figure 4. Fracture mode by fracture zones of armoured steel $\left(w_{6 / 5}=3 / 8{ }^{\circ} \mathrm{C} / \mathrm{s}\right): a, b-$ in the fatigue crack zone; $c, d, e-$ in the zone of main crack propagation; $f-$ in the final fracture zone $(a-d, f-\times 1550) ; e-\times 810)$ 

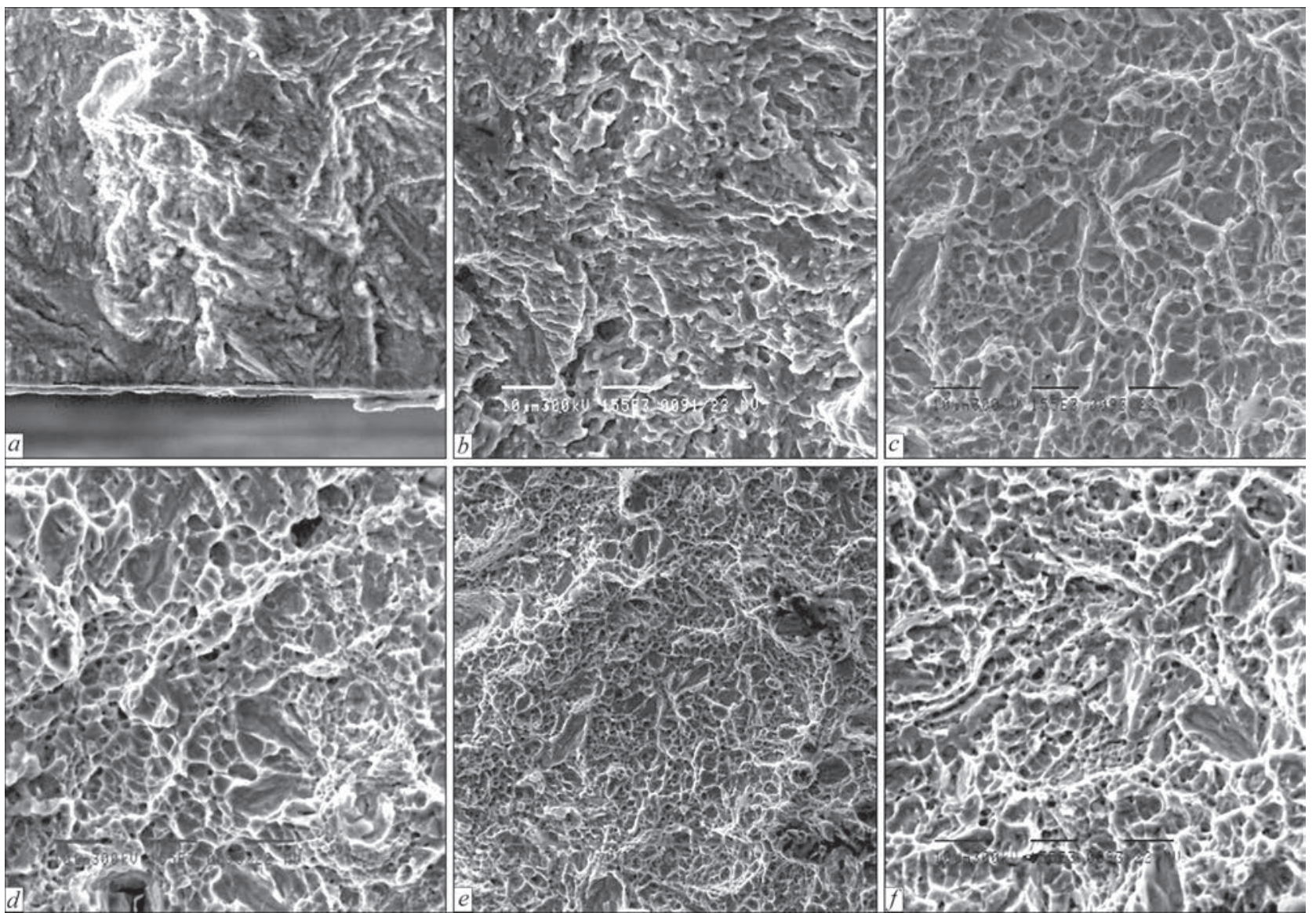

Figure 5. Fracture mode by zones of armoured steel fracture $\left(w_{6,5}=21^{\circ} \mathrm{C} / \mathrm{s}\right): a, b-$ in fatigue crack zone; $c-e-$ in the zone of main crack development; $f-$ in final fracture zone $(a-d, f-\times 1550 ; e-\times 810)$

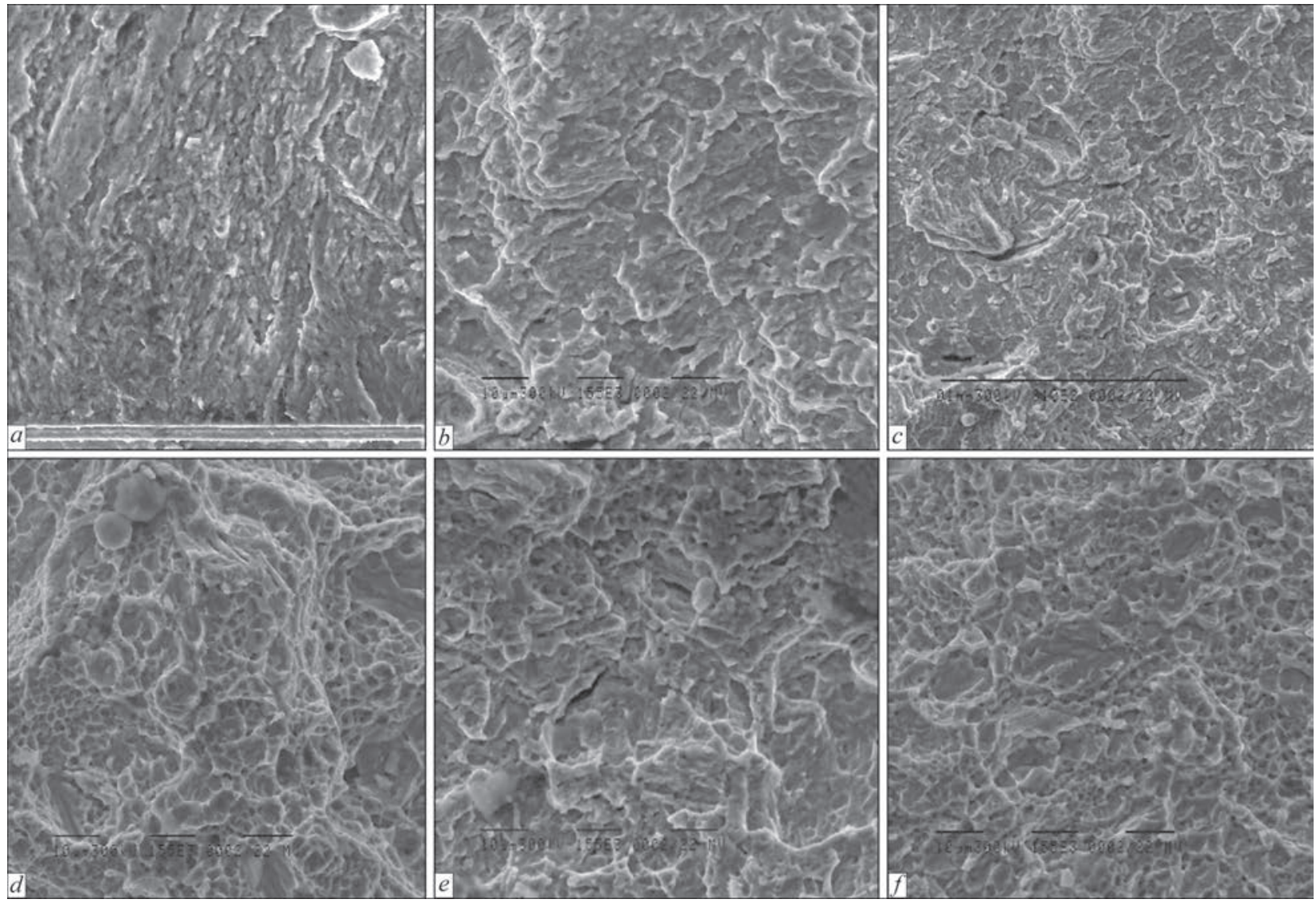

Figure 6. Fracture mode by the zones of armoured steel fracture $\left(w_{6,5}=21^{\circ} \mathrm{C} / \mathrm{s}\right): a-c$ in fatigue crack zone; $d, e-$ in the zone of main crack propagation; $f-$ in final fracture zone $(a, b, d-f-\times 1550 ; a-\times 810)$ 
At $w_{6 / 5}=21{ }^{\circ} \mathrm{C} / \mathrm{s}$, the fatigue crack zone demonstrates a uniform type of quasibrittle fracture with quasicleavage facet size $d_{\mathrm{f}}=3-15 \mu \mathrm{m}$ and secondary cracks of length $L_{\mathrm{cr}}=10-15 \mu \mathrm{m}$, their volume fraction being $V_{\mathrm{fr}}=2 \%$ (Figure 6, $a-c$ ). At transition into the main crack zone, the fracture mode is predominantly ductile $\left(V_{\mathrm{fr}}=70 \%\right)$ with pit size $d_{\text {pit }}=2-6 \mu \mathrm{m}$ (Figure $6, d, e)$. The main crack zone is characterized by presence of isolated secondary cracks of length $L_{\mathrm{cr}}=$ $=8-15 \mu \mathrm{m}$ (Figure $6, e$ ). In the final fracture zone, the fracture mode is also tough with pit size $d_{\text {pit }}=2-8 \mu \mathrm{m}$ (Figure 6, f).

Thus, it was found that at $w_{6 / 5}=3.8-21{ }^{\circ} \mathrm{C} / \mathrm{s}$ the fracture mode in the fatigue crack zone is quasibrittle. However, in the zone of the main crack development, the fracture mode changes at increase of the cooling rate: volume fraction of the ductile fracture becomes smaller $\left(V_{\mathrm{fr}}=90\right.$ to $\left.70 \%\right)$. In the quasibrittle fracture sections $\left(V_{\mathrm{fr}}=10-30 \%\right)$ the size of quasicleavage facets becomes larger in the presence of secondary cracks on the fracture surface.

As a result, fractographic studies showed that the optimum structure of armoured steel of 30Kh2N2MF type, from the view point of phase composition, microhardness and minimum parameters of the fracture surface relief elements, at maximum volume fraction of the ductile component is achieved at cooling of the HAZ metal at the rate $w_{6 / 5}=3.8^{\circ} \mathrm{C}$. This is related to increase of the amount of lower bainite and reduction of the quantity of the martensitic component.

\section{Conclusions}

It is found that under the conditions of simulation of thermal cycles of welding $\left(w_{6 / 5}=2.5-30{ }^{\circ} \mathrm{C} / \mathrm{s}\right)$ of armoured steel of $30 \mathrm{Kh} 2 \mathrm{~N} 2 \mathrm{MF}$ type with $0.25-0.31 \%$ carbon in shielding gas atmosphere, the transformation of overcooled austenite in the HAZ metal occurs exclusively with formation of the bainite-martensite structure.

Increase of the cooling rate (up to $w_{6 / 5}=21^{\circ} \mathrm{C} / \mathrm{s}$ ) in welding with armoured steel $(0.31 \% \mathrm{C})$ leads to lowering of the fracture toughness coefficient from 110 to
$70 \mathrm{MPa} \cdot \mathrm{m}^{1 / 2}$ that is due to increase of the martensitic component (up to 97-98 \%) at increase of metal microhardness.

Optimum fine-grained martensite-bainite structure of the metal of armoured steel $(0.31 \% \mathrm{C})$, from the view point of phase composition, microhardness, and minimum volume fraction of quasibrittle fracture at mechanical testing for fracture toughness, forms at the metal cooling rate $w_{6 / 5}=3.8^{\circ} \mathrm{C} / \mathrm{s}$, that ensures the metal crack resistance.

1. Otroshchenko, B. (2005) Let armour become stronger and tanks be improved. Metall Bulleten, Ukraine, 10 [in Russian].

2. Kashirsky, Yu.V. (2000) Information bank on mechanical engineering materials and modes of treatment. Tyazholoe Mashinostroenie, 4, 12-19 [in Russian].

3. Goldshtejn, M.I., Grachev, S.V., Veksler, Yu.G. (1985) Special steels. Moscow, Metallurgiya [in Russian].

4. Kuchuk-Yatsenko, S.I., Grigorenko, G.M., Novikova, D.P et al. (2007) Effect of energy input on ductile properties of flash butt welded joints in steel X70. The Paton Welding J., 6, 2-6.

5. Gulyaev, A.P. (1960) Heat treatment of steel. Moscow, Mashgiz [in Russian].

6. Seo, J.S., Kim, H.J., Ryoo, H.S. (2008) Microstructure parameter controlling weld metal cold cracking. J. of Achievements in Materials and Manufacturing Eng., 27, 199-202.

7. Sterenbogen, Yu.A. (1986) Some factors determining resistance of HAZ metal of martensitic steels to cold crack formation. Avtomatich. Svarka, 6, 5-8 [in Russian].

8. Skulsky, V.Yu. (2009) Peculiarities of kinetics of delayed fracture of welded joints of hardening steels. The Paton Welding J., 7, 12-17.

9. Gajvoronsky, A.A., Sarzhevsky, V.A., Gordonny, V.G. (1997) Weldability of medium-carbon alloyed steel 38Kh2MYuA. Avtomatich. Svarka, 4, 20-24 [in Russian].

10. Kostin, V.A., Grigorenko, G.M., Poznyakov, V.D. (2019) Peculiarities of HAZ metal structure formation of welded joints of foreign special steels. Svarochn. Proizvodstvo, 12, 50-56 [in Russian].

11. Grigorenko, G.M., Kostin, V.A., Orlovsky, V.Yu. (2008) Current capabilities of simulation of austenite transformations in low-alloyed steel welds. The Paton Welding J., 3, 22-24.

12. Cherepin, V.T. (1968) Experimental technique in physical materials science. Kiev, Tekhnika [in Russian].

13. Krimer, B.I., Panchenko, E.V., Shishko, L.A. et al. (1966) Laboratory practical work on metallography and physical properties of metals and alloys. Moscow, Metallurgiya [in Russian].

\section{INTERNATIONAL CONFERENCES}

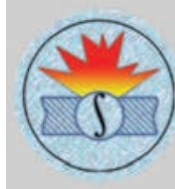

X International Conference

«Mathematical Modeling

and Information Technologies in Welding

and Related Processes»)

Hotel «Arkadia»,

14-18 September, 2020,

Odessa, Ukraine
XXIII International Conference «Non-Destructive Testing and Monitoring of Technical Condition»)

Hotel «Arkadia»,

14-18 September, 2020, Odessa, Ukraine

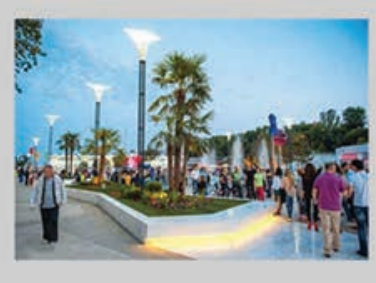

http://pwi-scientists.com/ukr/nktd2020 


\title{
EFFECT OF MODE OF ELECTRON BEAM WELDING, HEAT TREATMENT AND PLASTIC DEFORMATION ON STRENGTH OF JOINTS OF ALUMINIUM 1570 ALLOY
}

\author{
V.V. Skryabinskyi, V.M. Nesterenkov, M.O. Rusynyk and V.R. Strashko \\ E.O. Paton Electric Welding Institute of the NAS of Ukraine \\ 11 Kazymyr Malevych Str., 03150, Kyiv, Ukraine. E-mail: office@paton.kiev.ua
}

\begin{abstract}
The effect of the rate of hardening the weld metal during EBW process and the temperature of the subsequent heat treatment on the strength of welded joints of aluminium 1570 alloy was studied. The rate of «hardening» the weld metal was measured by submerging thermocouple into the molten metal of weld pool. At an increase in welding speed from 2.8 to $16.8 \mathrm{~mm} / \mathrm{s}$, the rate of «hardening» grows from $5 \cdot 10^{2}$ to $1 \cdot 10^{4}{ }^{\circ} \mathrm{C} / \mathrm{s}$ and the subsequent heat treatment of welded joints increases their strength to the level of strength of the base metal of stamped semi-finished products of 1570 alloy. It was established that during electron beam welding, the welding speed and, consequently, the rate of «hardening» do not affect the strength level of heat-treated joints. The optimal mode of heat treatment is artificial aging at a temperature of $350{ }^{\circ} \mathrm{C}$ and $1 \mathrm{~h}$ duration. It is possible to increase the strength of welded joints of 1570 alloy to the level of strength of rolled plates by $30 \%$ applying a cold plastic deformation or by $20 \%$ applying deformation with a subsequent artificial aging. 10 Ref., 3 Tables, 9 Figures.
\end{abstract}

Ke yw ords : electron beam welding, aluminium alloy, welded joints, welding speed, heat treatment, strength

Scandium is the most effective hardener and modifier of aluminium alloys among other rare-earth metals. The main obstacle to the widespread use of scandium in metallurgy has always been its high cost. However, the development of new technologies for scandium extraction and production of Al-Sc master alloys made it possible to create industrial aluminium alloys of Al-Mg system alloyed with scandium [1].

The high-strength aluminium 1570 alloy is based on the well-known AMg6 alloy. The main difference between 1570 and AMg6 alloy is that it is additionally alloyed with the scandium element in the amount of $0.15-0.35 \%$. The introduction of $0.5 \% \mathrm{Sc}$ in the $\mathrm{Al}-6.5 \% \mathrm{Mg}$ alloy provides an increase in $\sigma_{\mathrm{t}}$ by 1.5 times and $\sigma_{0.2}$ twice, reaching 430 and $260 \mathrm{MPa}$, respectively [2]. The main increase in strength is provided with the introduction of small additives of scan$\operatorname{dium}(0.2 \%)$. The level of strength properties of 1570 alloy largely depends on the type of semi-finished product and can range from 370 to $450 \mathrm{MPa}$ for $\sigma_{\mathrm{t}}$, and from 240 to $340 \mathrm{MPa}$ for $\sigma_{0.2}$. The higher the degree of deformation during pressure treatment and the lower the pressure treatment temperature, the higher the level of strength properties. Highly deformed cold-rolled sheets have the maximum strength, and massive hot-deformed semi-finished products manu- factured with a small degree of deformation have the minimum strength [3]. One of the reasons for the positive effect of scandium on the strength characteristics of $\mathrm{Al}-\mathrm{Mg}$ system alloys is the stability obtained as a result of pressure treatment of the nonrecrystallized structure, which is predetermined by the formation of secondary particles of $\mathrm{Al}_{3} \mathrm{Sc}$ phase precipitated during heating and by the deformation from supersaturated solid solution. The second reason for hardening is the direct strengthening action of $\mathrm{Al}_{3} \mathrm{Sc}$ phase particles [4]. Even small additions of scandium $(0.15 \%)$ cause a sharp increase in the temperatures of the beginning and end of recrystallization [5]. The strength of $\mathrm{Al}-6.5 \% \mathrm{Mg}-\mathrm{Sc}$ alloys remains almost the same before recrystallization, and after its beginning it changes slightly.

Alloys of $\mathrm{Al}-\mathrm{Mg}-\mathrm{Sc}$ systems belong to the group of heat unhardened, because they are not subjected to heat treatment in the form of «hardening» and subsequent aging. However, the technological parameters for manufacture of semi-finished products of 1570 alloy are selected so as to provide the maximum transition of scandium to supersaturated solid solution (i.e. hardening) and regulated decomposition of this solution during subsequent heating (i.e. aging) [6]. The predominant mode of artificial aging was determined

\footnotetext{
${ }^{*}$ By hardening the authors understand superfast crystallization.

V.V. Skryabinskyi — https://orcid.org/0000-0003-4470-3421, V.M. Nesterenkov — https://orcid.org/0000-0002-7973-1986,

M.O. Rusynyk — https://orcid.org/0000-0002-7591-7169, V.R. Strashko — https://orcid.org/0000-0001-6852-3551 
in [7], where the effect of aging temperature on hardness and electrical resistance of Al-Mg-Sc alloys was studied. It was found that artificial aging at the temperatures of $150-200{ }^{\circ} \mathrm{C}$ is accompanied by a slight increase in hardness. In the case of increasing aging temperature to $250-350{ }^{\circ} \mathrm{C}$, an effective hardening of alloys is observed. The maximum values of hardness are reached after artificial aging at $350{ }^{\circ} \mathrm{C}$ within 0.5-1.0 h. The decomposition of a solid solution abnormally supersaturated with scandium is characterized by high temperature, short incubation period and high stability of properties during heating to $300{ }^{\circ} \mathrm{C}$. The data on the heat treatment modes that strengthen welded joints produced by EBW are not available in the literature.

During welding the weld metal is not subjected to pressure treatment and the only factor influencing the fixation of scandium in a supersaturated solid solution and, consequently, the ability of the molten metal to strengthening during artificial aging, is the rate of «hardening», i.e. in our case, the rate of cooling the weld pool metal immediately before crystallization. On the experimental $\mathrm{Al}-\mathrm{Mg}-\mathrm{Sc}$ alloys, maintaining scandium at $0.4-1.0 \%$, it was found that at a hardening rate of $10^{2}{ }^{\circ} \mathrm{C} / \mathrm{s}$, scandium partially turns into a supersaturated solid solution and is partially solidified in the form of intermetallics. At a rate of «hardening» of $10^{5}{ }^{\circ} \mathrm{C} / \mathrm{s}$ much more scandium passes in the supersaturated solid solution, which contributes to $10^{2}$ times increase in the density of precipitations of the strengthening of $\mathrm{Al}_{3} \mathrm{Sc}$ phase, formed during aging [8, 9]. Using such a highly concentrated heat source for welding as an electron beam, it is possible to change the welding speed in a wide range, changing the cooling rate of the weld pool metal, i.e. the rate of «hardening». Thus, we will probably be able to change the amount of scandium fixed in the solid solution, which will affect the strength of welded joints after further artificial aging.

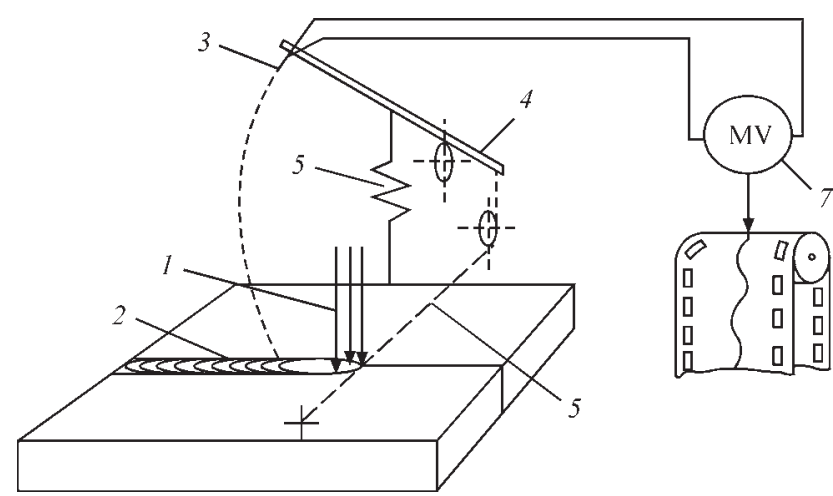

Figure 1. Scheme of measuring temperature of weld pool metal: 1 - electron beam; 2 - weld; 3 - thermocouple; 4 - balancing lever; 5 - holding wire; 6 - spring; 7 - self-recording device
The aim of this work is to determine the rate of «hardening» the weld metal at EBW of aluminium 1570 alloy, as well as the temperature of artificial aging and the degree of plastic deformation of welded joints, providing maximum increase in their strength.

It was of interest to determine the dependence of real cooling rate of the weld pool metal before crystallization (which for 1570 alloy will be the rate of the weld metal «hardening») on the welding speed. The experiments were performed in EBW of plates of aluminium AMg6 alloy (closest as to its chemical composition to 1570 alloy) of $15 \mathrm{~mm}$ thickness. The welding modes were selected in such a way as to provide a guaranteed penetration with the formation of a uniform weld reinforcement. A brazed joint of a chromel-alumel thermocouple was immersed in the tail part of the weld pool and its values were recorded with a self-recorder. The temperature of the weld pool was recorded directly, and the instantaneous cooling rate was determined as the tangent of the angle of inclination of the temperature function tangent to the diagram at the point of interest. In order to reduce the inertia of the measurements, the diameter of the wire for manufacture of thermocouples was chosen as the minimum possible $(0.1 \mathrm{~mm})$. The thermocouple readings were recorded with a N338 type recorder. The speed of the tape feed was $100 \mathrm{~mm} / \mathrm{s}$. The scheme of the experiment is shown in Figure 1.

The plates of AMg6 alloy were welded with an electron beam 1 to form a weld 2. Thermocouple 3 was fixed at the end of the balancing lever 4 , located in such a way that in the lower position of the balancing lever the brazed joint of the thermocouple was immersed in a liquid metal pool on the weld axis. The balancing lever was in equilibrium under the action of the spring 6 on the one side and the holding steel wire 5 on the other. Thermocouple 3 was connected to the self-recorder 7 . Before conducting the experiment, thermocouple 3 was lifted by rotating the balancing lever 4 at an angle of about $45^{\circ}$ with respect to the plane of the welded plates, stretching the spring 6 and fixing this position by securing the end of the holding wire 5 . In this position, the scheme of measuring the temperature of weld pool was ready for operation. During welding the holding wire was cut by the electron beam at the moment of crossing, and the balancing lever under the action of the spring lowered the brazed joint of the thermocouple in the tail of the weld pool. The lowering accuracy was adjusted by the position of holding wire relative to the brazed thermocouple, based on the actual dimensions of the weld pool, measured experimentally for different welding modes. Despite some primitiveness of the measurement scheme, it was possible not only to record the 


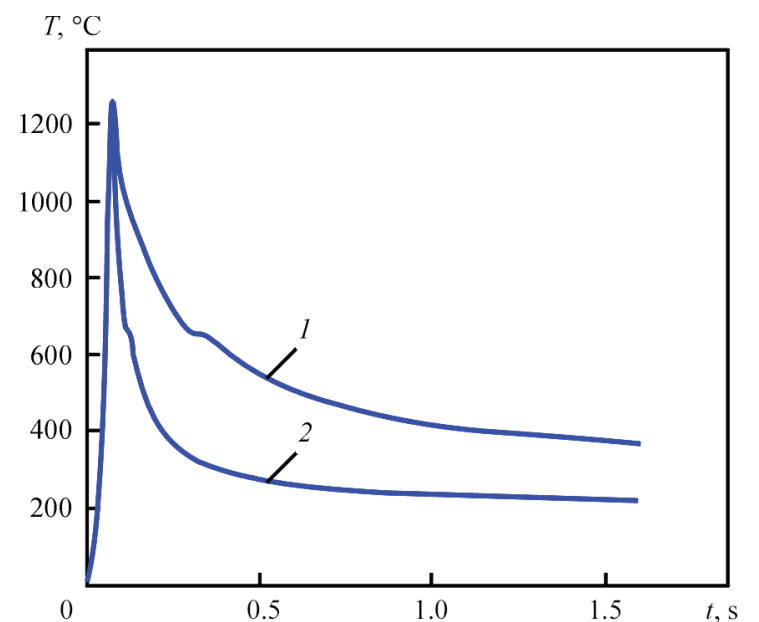

Figure 2. Examples of experimentally measured curves of cooling weld pool metal in EBW of AMg6 alloy at different speeds: $1-5.6 ; 2-16.8 \mathrm{~mm} / \mathrm{s}$

cooling curves of the weld metal, but also to record horizontal planes on them, which indicate the release of latent heat of crystallization. Metal cooling curves of the weld pool and weld for different EBW speeds are shown in Figure 2.

As is seen from Figure 2, at the beginning of the curve there is a sharp jump in temperature from 20 to $1200^{\circ} \mathrm{C}$. Then the temperature decreases exponentially. From the obtained curves, the cooling rates of the weld pool metal before crystallization were calculated (Figure 3). With an increase in the welding speed from 2.8 to $16.8 \mathrm{~mm} / \mathrm{s}$ (from 10 to $60 \mathrm{~m} / \mathrm{h}$ ) the cooling rate increases from $5 \cdot 10^{2}$ to $1 \cdot 10^{4}{ }^{\circ} \mathrm{C} / \mathrm{s}$. It should be taken into account that the error due to the inertia of the temperature measurement scheme could affect only the underestimation of the actual cooling rates. In this regard, we will consider these cooling rates to be minimal and in EBW of 1570 alloy will call them the rates of «hardening» the weld metal.

Investigations of the effect of the rate of «hardening» of the weld metal on the strength of welded joints were performed on stamped plates of 1570 alloy with a

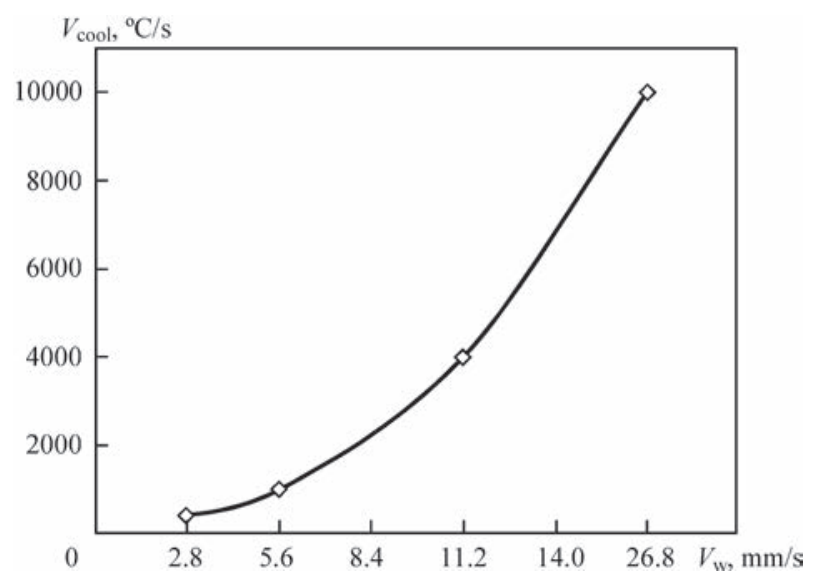

Figure 3. Dependence of cooling rate of weld pool metal before crystallization on welding speed in EBW of AMg6 alloy

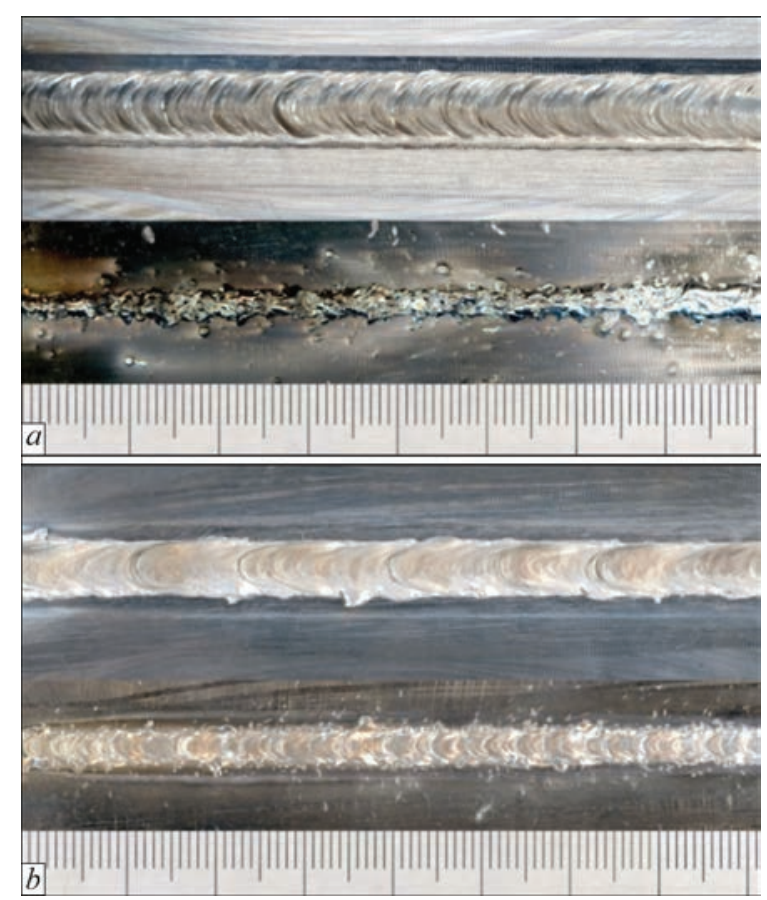

Figure 4. Facial side and root of the weld of specimens from stampings of 1570 alloy with a thickness of $30 \mathrm{~mm}$, welded at the speeds of $2.8(a)$ and $16.8 \mathrm{~mm} / \mathrm{s}(b)$

thickness of $30 \mathrm{~mm}$. The experiments were performed in the electron beam welding machine UL-209M with the power source ELA $60 / 60$ with a voltage of $60 \mathrm{kV}$. In EBW, the beam current and the focusing current were chosen from the condition of a guaranteed penetration and formation of the reverse weld bead. A circular scanning of a beam with a diameter of $1.5 \mathrm{~mm}$ and a frequency of $600 \mathrm{~Hz}$ was used. Two welding speeds were chosen: 2.8 and $16.8 \mathrm{~mm} / \mathrm{s}$, which correspond to the minimum and maximum speeds used in industry for EBW of high-strength aluminium alloys [10]. The appearance of welds is shown in Figure 4.

Cross-sections of welded joints are shown in Figure 5.

Welds have a width of about $3 \mathrm{~mm}$ with almost parallel boundaries of the penetration zone in the central and lower parts. From the side of the beam inlet, there is an increase in the width of the penetration zone to $4.5 \mathrm{~mm}$ for a welding speed of 16.8 and up to

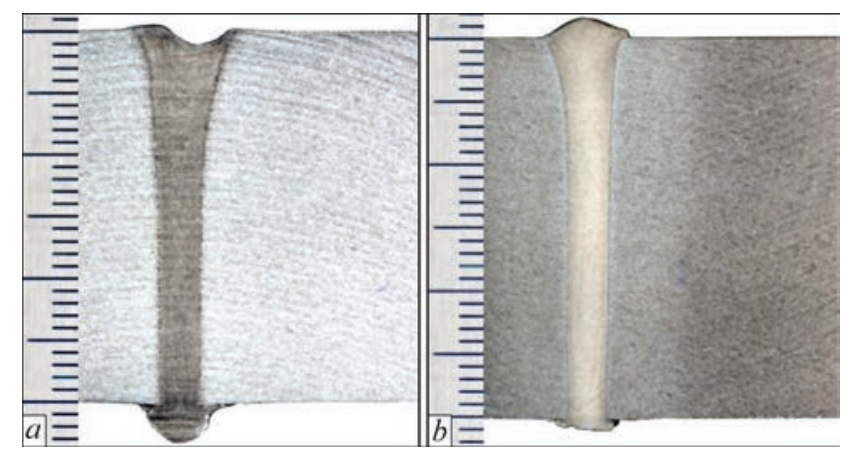

Figure 5. Cross-sections of joints of plates of 1570 alloy welded at a speed of $2.8(a)$ and $16.8 \mathrm{~mm} / \mathrm{s}(b)$ 
Table 1. Chemical composition of base metal and weld metal of stamped semi-finished product of 1570 alloy, wt.\%

\begin{tabular}{|c|c|c|c|c|c|c|c|c|c|}
\hline \multirow{2}{*}{$\begin{array}{c}\text { Location } \\
\text { of determination }\end{array}$} & \multicolumn{9}{|c|}{ Chemical composition, $\%$} \\
\hline & $\mathrm{Al}$ & $\mathrm{Mg}$ & $\mathrm{Mn}$ & Sc & $\mathrm{Zr}$ & $\mathrm{Si}$ & $\mathrm{Fe}$ & $\mathrm{Cu}$ & $\mathrm{Zn}$ \\
\hline Base metal & Base & 6.45 & 0.32 & 0.16 & 0.025 & 0.041 & 0.07 & 0.014 & 0.02 \\
\hline Weld & Same & 6.35 & 0.31 & 0.16 & 0.025 & 0.040 & 0.06 & 0.015 & 0.02 \\
\hline
\end{tabular}
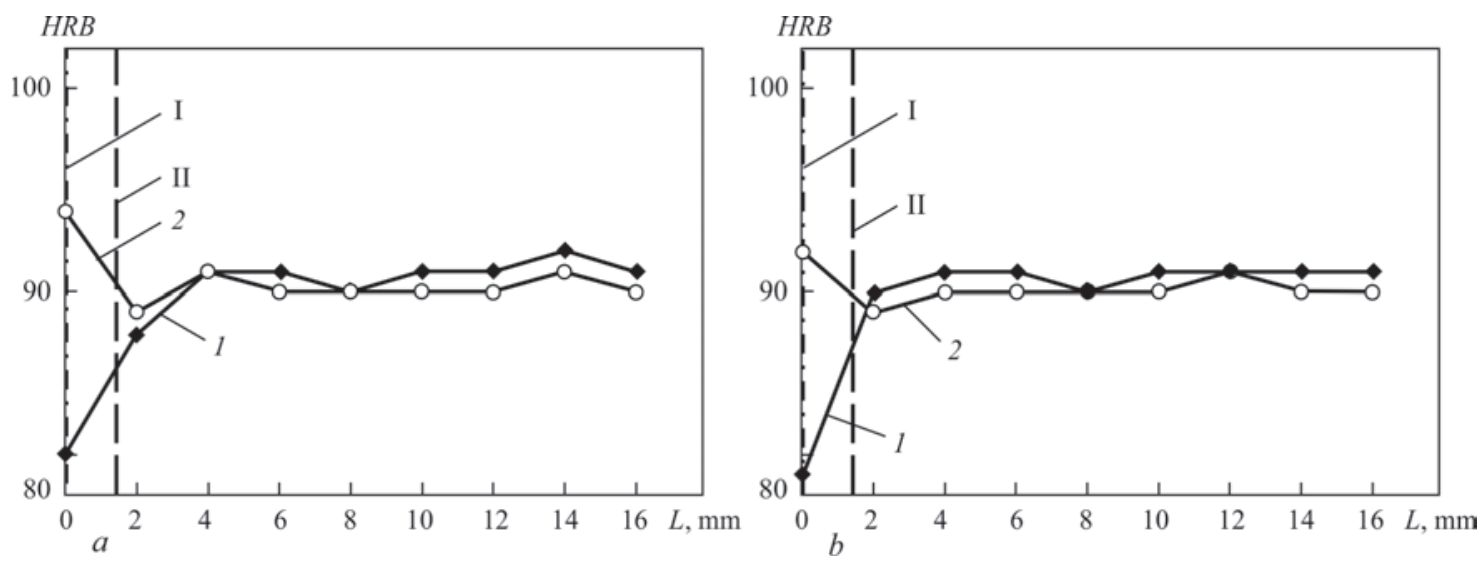

Figure 6. Distribution of hardness in the cross-section of joints welded at a speed of $2.8(a)$ and $16.8 \mathrm{~mm} / \mathrm{s}(\mathrm{b})$ : curves 1 — welded joints without heat treatment; 2 - the same after artificial ageing at $350{ }^{\circ} \mathrm{C}$; lines I — weld axis; II — fusion line

$6 \mathrm{~mm}$ for a speed of $2.8 \mathrm{~mm} / \mathrm{s}$. At a welding speed of $16.8 \mathrm{~mm} / \mathrm{s}$, the weld has a uniform reinforcement on the front facial side and weld root and on the side of the beam inlet, the weld was formed with a decrease of about $1 \mathrm{~mm}$ in welding with $2.8 \mathrm{~mm} / \mathrm{s}$ speed.

The chemical composition of the weld metal and the base metal of the stamped plates of 1570 alloy was determined using the equipment DFS-36 for spectral analysis. The results of the analysis are given in Table 1. As is seen from Table, the evaporation of alloying elements in EBW of 1570 alloy is insignificant. It is possible to note only a small decrease in the content of magnesium which losses make about $0.1 \%$.

The hardness measurements were used to assess the degree of decrease in strength and change in the properties of the weld metal and HAZ. The Rockwell device with a load on a steel ball of $600 \mathrm{~N}$ according

Table 2. Temporary resistance $\sigma_{t}$ of welded joints of stamped semi-finished product of 1570 alloy with a thickness of $30 \mathrm{~mm}$ without heat treatment and after artificial aging for different welding speeds

\begin{tabular}{|c|c|c|c|}
\hline $\begin{array}{c}\text { Welding speed, } \\
\mathrm{mm} / \mathrm{s}\end{array}$ & $\begin{array}{c}\text { Rate of «hard- } \\
\text { ening» of weld } \\
\text { metal, }{ }^{\circ} \mathrm{C} / \mathrm{s}\end{array}$ & $\begin{array}{c}\sigma_{\mathrm{t}} \text { of welded joint, } \\
\mathrm{MPa}\end{array}$ & $\begin{array}{c}\sigma_{\mathrm{t}} \text { of welded } \\
\text { joint after artifi- } \\
\text { cial aging } \\
\text { at } 350^{\circ} \mathrm{C}, \mathrm{MPa}\end{array}$ \\
\hline 2.8 & $>5 \cdot 10^{2}$ & $\frac{326-332}{328}$ & $\frac{383-386\left(^{*}-2\right.}{384}$ \\
\hline 16.8 & $>1 \cdot 10^{4}$ & $\frac{329-332}{331}$ & $\frac{385-3877^{*}-2}{386}$ \\
\hline $\begin{array}{l}\text { *In the numerator the minimum and maximum values and in the } \\
\text { denominator the mean value of three dimensions are shown; }(*)-\end{array}$ \\
fracture of $100 \%$ of specimens occurred on the base metal outside \\
the HAZ.
\end{tabular}
used. The measurement results are shown in Figure 6.

The hardness of the weld metal after welding is HRB 81-82. Artificial aging at a temperature of $350{ }^{\circ} \mathrm{C}$ increases the hardness of the weld metal to the HRB 92-94 and even makes it by 2-3 units higher than the hardness of the base metal. In the near-weld zone before and after heat treatment some decrease in hardness (by 1-3 units) is observed. The width of HAZ is about $3 \mathrm{~mm}$ for welding speed of $2.8 \mathrm{~mm} / \mathrm{s}$ and, accordingly, decreases with increasing speed to $16.8 \mathrm{~mm} / \mathrm{s}$.

The strength of welded joints before and after artificial aging was determined by the tensile test of standard round specimens with a working part diameter of $9.0 \mathrm{~mm}$. The test results are given in Table 2 .

From Table 2 it is seen that the strength of welded joints both before and after heat treatment depends little on the rate of «hardening» of the weld metal. The fracture of tensile specimens occurs in the area with the lowest strength. Prior to artificial aging, such an area is a weld. After aging, all specimens fractured along the base metal outside the HAZ, i.e. aging at $350{ }^{\circ} \mathrm{C}$ strengthens the weld metal to a level above the strength of the base metal. This is also evidenced by the measurements of the hardness of welded joints. This can be explained only by the fact that in EBW of 1570 alloy in the solid solution of the weld metal a larger amount of scandium is fixed than in the alloy itself during manufacture of stamped semi-finished products. Accordingly, during further heat treatment, the density of the precipitation of strengthening particles $\mathrm{Al}_{3} \mathrm{Sc}$ in the weld will be higher than in the base 


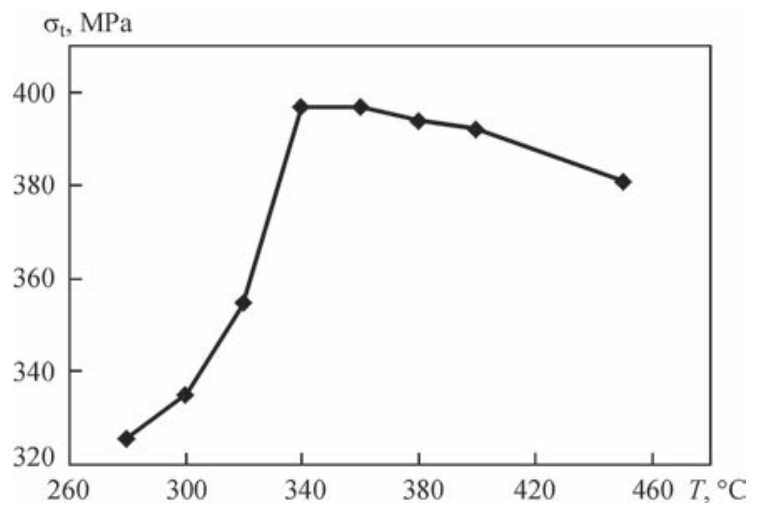

Figure 7. Dependence of temporary resistance of joints of plates of 1570 alloy of $26 \mathrm{~mm}$ thickness on temperature of artificial aging

metal. Thus, in the range of welding speeds from 2.8 to $16.8 \mathrm{~mm} / \mathrm{s}$, the strength of the weld metal will be higher than the strength of the base metal. Thus, in cases where the heat treatment of the joints is provided after welding, the speed of EBW of 1570 alloy can be adjusted in a wide range without fear of reducing their strength.

Investigations of the effect of artificial aging temperature on the strength of welded joints of 1570 alloy were performed on rolled plates and stamped semi-finished products. The plates of $26 \mathrm{~mm}$ thickness were welded at a speed of $14 \mathrm{~mm} / \mathrm{s}$, stamping of $60 \mathrm{~mm}$ thickness is $1 \mathrm{~mm} / \mathrm{s}$. The welded joints of the plates were artificially aged at the temperatures from 280 to $450{ }^{\circ} \mathrm{C}$ for $1 \mathrm{~h}$. The dependence of the strength of the joints of the plates of 1570 alloy on aging temperature is shown in Figure 7 . The given data show that in the temperature range of $280-340{ }^{\circ} \mathrm{C}$ an effective strengthening of welded joints occurs. At the temperatures of $340-360{ }^{\circ} \mathrm{C}$, the temporary resistance of the joints is maximum, and with a further increase in temperature, it begins to decrease. The decrease in strength at the aging temperature above $360{ }^{\circ} \mathrm{C}$ is probably predetermined by the beginning of recrystallization processes. All specimens subjected to aging at a temperature of $340^{\circ} \mathrm{C}$ and higher, fractured throughout the base metal outside the HAZ (see Figure 8). Thus, the optimal mode of heat treatment

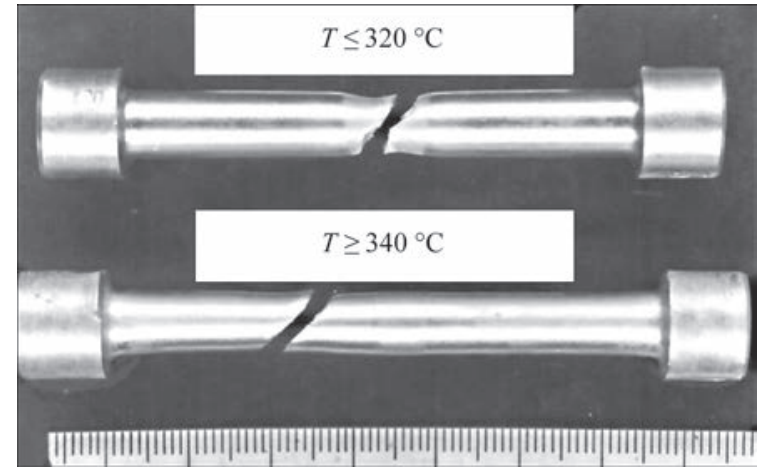

Figure 8. Nature of fractures of specimens after tensile tests of 1570 alloy artificially aged at different temperature

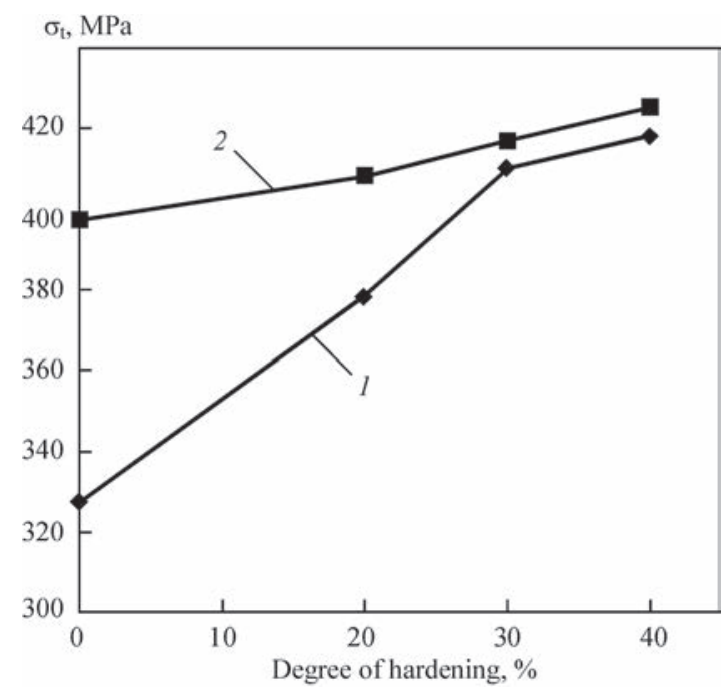

Figure 9. Temporary resistance of joints of plates of 1570 alloy with a thickness of $26 \mathrm{~mm}$ depending on degree of hardening: 1 - welding + hardening; 2 - welding + hardening + heat treatment

of welded joints of 1570 alloy produced by EBW is artificial aging at $350 \pm 10{ }^{\circ} \mathrm{C}$ for $1 \mathrm{~h}$.

Table 3 shows the results of tensile tests of specimens cut out from the base metal and welded joints of various semi-finished products of 1570 alloy without heat treatment and after artificial aging. The Table shows that the aging of welded joints at a temperature of $350{ }^{\circ} \mathrm{C}$ makes it possible to increase their strength by $50-70 \mathrm{MPa}$, and to reach the level of strength of

Table 3. Temporary resistance $\sigma_{\mathrm{t}}(\mathrm{MPa})$ of base metal and welded joints of various semi-finished products of 1570 alloy without heat treatment and after artificial aging

\begin{tabular}{|c|c|c|c|c|}
\hline Type of semi-finished product & Base metal & Welded joint & $\begin{array}{c}\text { Welded joint after } \\
\text { artificial aging at } 320{ }^{\circ} \mathrm{C}\end{array}$ & $\begin{array}{c}\text { Welded joint after } \\
\text { artificial aging at } 350{ }^{\circ} \mathrm{C}\end{array}$ \\
\hline Plate of $26 \mathrm{~mm}$ thickness & $\frac{402-415}{410}$ & $\frac{320-332\left(^{*}\right)}{325}$ & $\frac{347-385\left(^{*}\right)}{367}$ & $\underline{392-402\left(^{* *}\right)}$ \\
\hline Stamping of $60 \mathrm{~mm}$ thickness & $\frac{377-395}{385}$ & $\frac{318-336\left(^{*}\right)}{325}$ & $\frac{372-383\left(^{*}\right)}{379}$ & $\underline{380-390\left(^{* *}\right)}$ \\
\hline $\begin{array}{l}\text { In the numerator the minimum and maximum values and in the denominator the mean value of five dimensions are shown; }(*)-\text { fracture } \\
\text { of specimens occurred on the weld metal; }(* *)-\text { fracture of specimens occurred on the base metal outside the HAZ. }\end{array}$
\end{tabular}


the base metal of the stamped semi-finished product of 1570 alloy before welding.

In order to achieve a uniform strength of welded joints of rolled plates of 1570 alloy with the base metal, they were subjected to cold plastic deformation by rolling. Before rolling the reinforcement and the root of the weld were removed to the level of plates surface. The direction of rolling coincided with the direction of welding. The strength of welded joints depending on the degree of plastic deformation is shown in Figure 9.

As the degree of deformation increases from 0 to $40 \%$, the strength of the joints increases from 320 to $420 \mathrm{MPa}$. At a plastic deformation of $30 \%$, the welded joints become equal in strength to the base metal of the rolled plates. Some of the specimens after rolling were heat-treated in a mode that provides the maximum increase in strength of the joints of 1570 alloy (artificial aging of $350^{\circ} \mathrm{C}$ for $1 \mathrm{~h}$ ). Heat treatment increases the strength of all specimens, and to achieve equal strength of the joints of rolled plates with the base metal it is enough to conduct plastic deformation by $20 \%$.

\section{Conclusions}

1. Measurements of the rate of «hardening» of the weld metal in EBW of the $\mathrm{Al}+6 \% \mathrm{Mg}$ alloy and investigations of its effect on the ability of welded joints of 1570 alloy to strengthening during heat treatment were carried out. With increasing welding speed from 2.8 to $16.8 \mathrm{~mm} / \mathrm{s}$, the hardening rate increases from $5 \cdot 10^{2}$ to $1 \cdot 10^{4}{ }^{\circ} \mathrm{C} / \mathrm{s}$. In this range of hardening rates, the artificial aging of welded joints of 1570 alloy increases the strength of the weld metal above the strength of the base stamping metal. This effect can be explained by the fact that in EBW more scandium passes into the solid solution of the weld metal than during the manufacture of semi-finished products of 1570 alloy. During artificial aging of welded joints, a larger amount of strengthening particles of $\mathrm{Al}_{3} \mathrm{Sc}$ is precipitated from the solid solution in the weld metal than in the base metal. Thus, in cases where artificial aging of joints is used after welding, their strength does not depend on the speed of EBW.

2. Artificial aging of welded joints of 1570 alloy of $1 \mathrm{~h}$ duration provides the greatest increase in strength at an aging temperature of $350{ }^{\circ} \mathrm{C}$. In this case, the welded joints produced by EBW become equal in strength to the base metal of the stamped semi-finished products.

3. It is possible to produce welded joints of 1570 alloy equal in strength with the rolled plates using cold plastic deformation by $30 \%$ or deformation by $20 \%$ with a subsequent artificial aging.

1. Mukhachev, A.P., Kharitonova, E.A., Skipochka, D.G. (2016) Scandium and its alloys with aluminium. Voprosy Atomnoj Nauki i Tekhniki, 1, 45-50 [in Russian].

2. Drits, M.E., Toropova, L.S., Bykov, Yu.G. (1980) Influence of REM on mechanical properties of alloy $\mathrm{Al}-6.5 \% \mathrm{Mg}$. Metallovedenie i Termich. Obrab. Metallov, 10, 35-37 [in Russian].

3. Elagin, V.I., Zakharov, V.V., Rostova, T.D. et al. (1991) Structure and properties of wrought semi-finished products from aluminium alloys with scandium. Tekhnologiya Lyogkikh Splavov, 12, 21-28 [in Russian].

4. Drits, M.E., Pavlenko, S.G., Toropova, L.S. et. al. (1981) On mechanism of scandium effect on improvement of strength and thermal stability of alloys of Al-Mg system. DAN SSSR, 257(2), 353-356 [in Russian].

5. Elagin, V.I. (1970) About alloying of wrought aluminium alloys with transition metals. In: Physical metallurgy of alloys of light metals. Moscow, Nauka, 51-59 [in Russian].

6. Filatov, Yu.A. (2014) Alloys of Al-Mg-Sc system as a special group of wrought aluminium alloys. Tekhnologiya Lyogkikh Splavov, 2, 34-41 [in Russian].

7. Drits, M.E., Toropova, L.S., Anastasieva, G.K. et al. (1984) Influence of homogenizing heating on properties of alloys of Al-Sc and Al-Mg-Sc systems. Izv. AN SSSR, Metally, 3, 196-201 [in Russian].

8. Berezina, A.L., Segida, E.A., Monastyrskaya, T.A., Kotko, A.V. (2008) Influence of crystallization rate on abnormal oversaturation of Al-Mg-Sc alloys. Metallofizika i Novejshie Tekhnologii, 30(6), 849-857 [in Russian].

9. Fedorchuk, V.E., Kushnaryova, O.S., Alekseenko, T.A., Falchenko, Yu.V. (2014) Peculiarities of alloying of weld metal of high-strength aluminium alloy welded joints with scandium. The Paton Welding J., 5, 30-34.

10. Ternovoj, E.G., Bondarev, A.A. (2012) Electron beam welding of thick-wall shells of aluminium AMg6 and M40 alloys. Ibid., 4, 8-14.

Received 14.04.2020
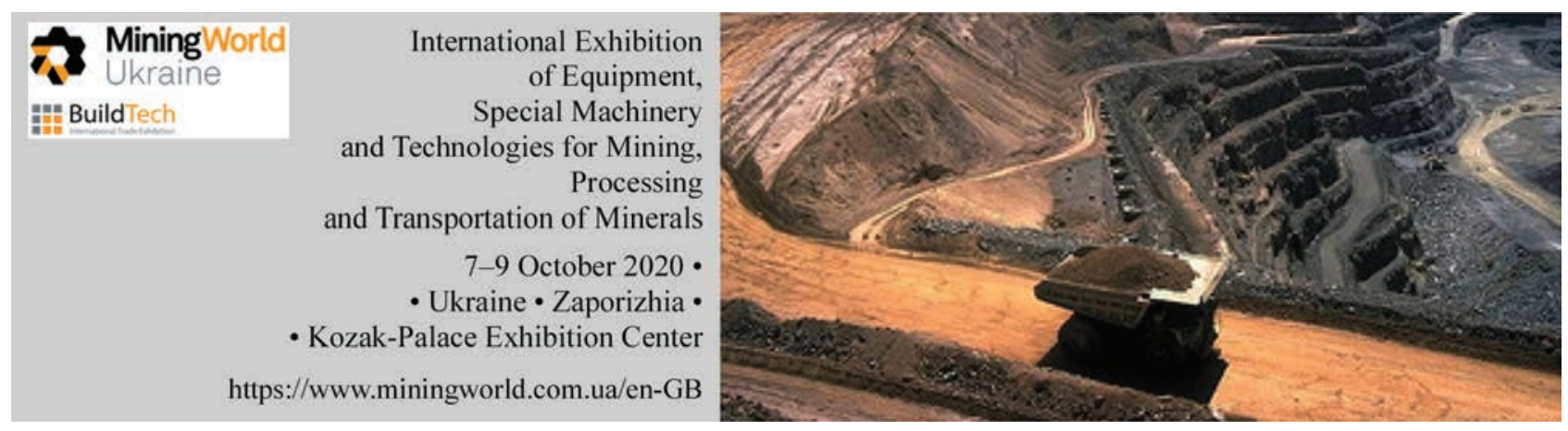


\title{
PROBLEMS AND PROSPECTS OF SURFACING OF COPPER AND COPPER PARTS BY WEAR-RESISTANT LAYERS (Review)
}

\author{
A.A. Babinets ${ }^{1}$, I.O. Ryabtsev ${ }^{1}$, I.P. Lentyugov ${ }^{1}$, I.I. Ryabtsev ${ }^{1}$, Yu.V. Demchenko ${ }^{1}$ and A.I. Panfilov ${ }^{2}$ \\ ${ }^{1}$ E.O. Paton Electric Welding Institute of the NAS of Ukraine \\ 11 Kazymyr Malevych Str., 03150, Kyiv, Ukraine. E-mail: office@paton.kiev.ua \\ ${ }^{2}$ Steel Work Company \\ 32 Sobornosti Str., 50065, Kryvyi Rih, Ukraine. E-mail: a.panfilov@steel-work.net
}

\begin{abstract}
The prospects for application of the methods of arc and plasma-powder surfacing, in order to increase the wear resistance of copper parts, are shown, proceeding from the results of literature analysis. Selection of promising materials was performed for deposition of copper-resistant layers on copper surfaces by these methods. Comparative evaluation of physico-mechanical properties of copper and the main alloying elements of promising surfacing materials was performed. 31 Ref., 1 Table, 6 Figures.
\end{abstract}

Ke y w ords: surfacing of copper, wear-resistant layer, increase of wear resistance, copper, dissimilar metals, weldability, fusion zone

Copper has such unique properties, as high electric and heat conductivity, ductility and corrosion resistance, which it preserves in a broad range of temperatures $\left(-253-500{ }^{\circ} \mathrm{C}\right)[1-7]$. Such properties allow widely using copper and its alloys in different industries, when manufacturing cable and electric contact products, heat exchangers, moulds, tuyeres, pipelines, chemical apparatus components, etc.

At the same time, owing to low heat- and wear resistance [8], copper has limited application in some metallurgical industries, in particular, under the conditions of contact with molten metal, high-temperature gas flows, aggressive gases and abrasive substance. Copper parts wear rapidly under such extreme service conditions. Moreover, such defects as burn-through, corrosion, cracks, etc., can form on their surfaces and welds [5-9].

In this connection, the question arises of improvement of fatigue life of copper parts, manufacturing which often involves the need to join copper and its alloys to steel and alloys of other alloying systems [3]. Proceeding from the fact that repair of units, replacement equipment and spare parts make up a considerable portion of product cost in industry [10], the question of improvement of wear resistance of copper parts, which are operating under difficult conditions of elevated temperatures and mechanical loads, different kinds of wear, corrosion and other unfavourable factors, is quite urgent now.

One of the possible solutions of this problem is creating protective deposited layers with high service properties on the copper parts. Up to now, however, mostly the questions of direct welding of copper and its alloys to steel, as well as steel surfacing by copper, bronze or brass, in order to save nonferrous metals, have been well studied [1-9]. The counterquestion on copper surfacing by wear-resistant alloys of different alloying systems, today remains practically unstudied. This is, primarily, related to great difficulties arising at deposition of alloys, having much higher melting temperature, lower heat conductivity and other physico-mechanical properties, which differ significantly from similar characteristics of copper.

Analysis of the methods to produce wear-resistant layers on copper surfaces. Questions of weldability of such dissimilar materials as steel and copper, while ensuring the required physico-chemical properties of both the wear-resistant layer, and the entire part as a whole, requires development of such technological processes, which take into account not only metallurgical compatibility, but also the difference in the physical properties of the materials being joined: heat conductivity, heat capacity, melting temperature, electric conductivity, coefficients of thermal expansion (CTE), etc. [1].

Analysis of publications [11-14, etc.] shows that thermal methods of deposition of coatings of different composition are the most often used, in order to solve this problem, and there as also scattered data on application of some solid-phase surfacing or welding methods. 


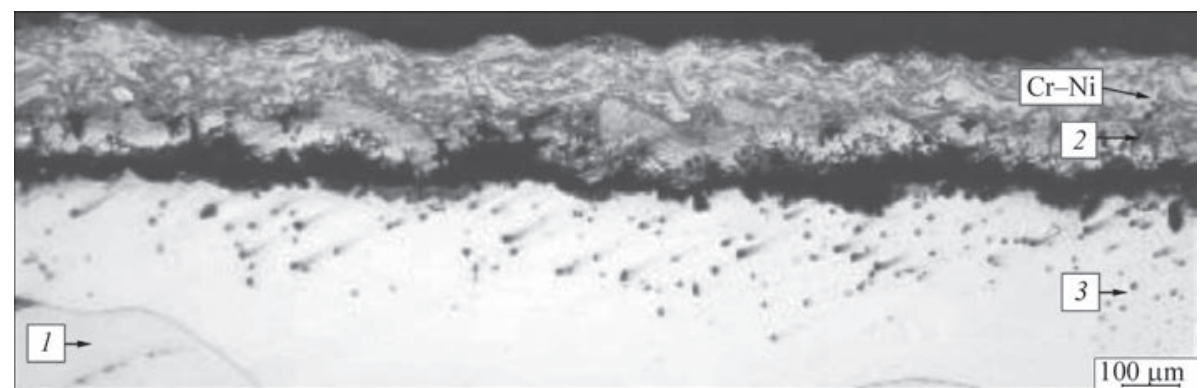

Figure 1. Microstructure of a copper sample with aluminium underlayer and $\mathrm{Cr}-\mathrm{Ni}$ spraying [11]: 1 — copper base; 2 — porous layer; 3 - $\alpha$-phase

So, the method of thermal deposition of coatings became rather widely applied in industry, due to its versatility, which allows applying diverse materials: metals (including refractory metals of $\mathrm{W}$ and Mo type), $\mathrm{Ni}$ and $\mathrm{Co}$ based metals, ceramics based on $\mathrm{Zr}$ oxides, etc. [15].

It was proposed to apply this process [11] also for improving the resistance of some copper parts, operating under the conditions of high-temperature gas-abrasive wear. For this purpose, layers of aluminium-containing coating $0.1-0.5 \mathrm{~mm}$ thick were applied on the copper surface. However, despite the fact that average resistance of parts strengthened by such a method, increased 1.5-2.0 times, an uncontrollable appearance of damage was noted, which was caused by sudden delamination of the coating in service, as a result of low strength of the produced joint and considerable difference between CTE of the coating and copper (Figure 1) [11].

In order to eliminate this drawback, the authors of [8] recommended applying additional heat treatment, during which aluminium diffuses into copper. This was supposed to increase the strength of adhesion of the coating to the base metal, and to enable producing a layer, having higher high temperature and wear resistance, compared to copper.

However, heat treatment does not always improve the strength of adhesion of the coating and copper base [11]. It is explained by the fact [5] that diffusion of coating elements into copper results in a significant lowering of their concentration in the diffusion layer and increase of the amount of brittle oxides in it that, contrarily, may promote delamination of part of this layer from the coating side.

In work [16] this phenomenon was considered in greater detail. One can see from Figure 2 that microscopic cracks are present between the coating and the base, which at long-term operation under wear come together to form fragments (Figure 2, b), delaminate and form plates of wear products. The authors of the same work note that delamination is a dominating wear mechanism of specimens produced by this method, and the method proper is labour-consuming and has a low productivity.

In work [17] it is noted that application of plasma method of deposition of protective coatings of different composition on a copper base allows increasing the wear resistance, compared to pure copper 1.5-3.0 times. It should be noted, however, that application of thin coatings $(0.5-0.7 \mathrm{~mm})$ under the conditions of gas-abrasive wear does not allow a significant improvement of the fatigue life of such parts.

It is common knowledge that surfacing methods became widely applied, both in manufacture of new and in repair of worn parts [10], as they allow a significant improvement of their fatigue life through deposition of layers of different composition, which differ from base metal by their physico-chemical properties $[18,19]$. In addition, surfacing allows achieving much higher strength of bonding of the base and deposited metals, than at deposition of thermal coatings.

However, surfacing of steel exactly with nonferrous metals, and not vice versa, has been quite well studied so far. For the first case, the simplest and most effective is application of the methods of consum-

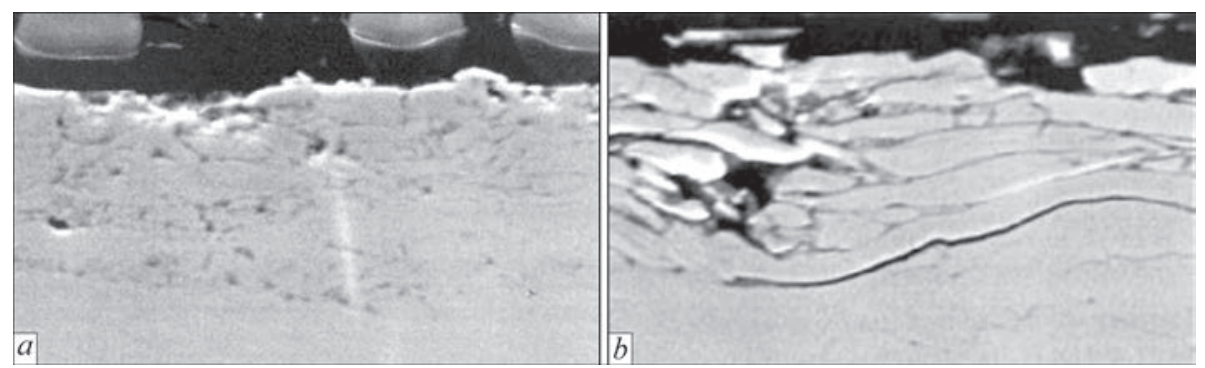

Figure 2. Microstructure of the subsurface layer of the coating, obtained after thermal spraying and strengthening heat treatment [16]: $a$ - availability of microcracks under the surface; $b$ - formation of plates and their delamination 
able-electrode surfacing, with application of special gases or fluxes as a protective environment $[9,20]$.

It should be noted that the main disadvantage of arc surfacing methods is a considerable penetration depth that may lead to excess mixing of nonferrous metal with steel, and appearance of cracks and pores in the deposited layer [20]. However, despite the fact that the great penetration depth is characteristic, for instance, submerged-arc welding, it, nonetheless, is quite often used in welding copper and steel parts, 5-40 mm thick [9, 14. 21].

Gas-shielded surfacing is characterized by greater versatility. Its main advantage is the impossibility of visual observation of the process of its prompt adjustment, if required [20, 22]. Special surfacing methods, such as pulsed-arc surfacing with split or strip electrode, etc., allow reducing the penetration depth. They, however, have certain limitations as to their adaptability to manufacture, for instance, at strip surfacing of products of a complex shape [20].

At the same time, proceeding from the data in technical literature and practical experience $[23,24]$, it is known that in surfacing with electrodes and wires, the penetration depth can be reduced due to optimization of electric parameters of arc surfacing and application of small diameter wires (up to $2.0 \mathrm{~mm}$ ).

It is also known that plasma surfacing is one of the surfacing methods, which ensure minimum penetration of the base metal that allows reducing the fraction of its participation in the deposited layer [4, 25, 26]. In addition, its offers the advantages of a wide range of adjustment of surfacing mode parameters, and possibility of applying a wide class of materials, as well as performance of product preheating without application of extraneous heat sources $[4,17,25]$.

In technical literature, however, the data on application of both the arc and plasma surfacing to strengthen the surfaces of parts from pure copper are quite scarce. For instance, in work [26], a methods of plasma surfacing of aluminium bronzes with cobalt and nickel alloys is described. Practically the only mention about the methods of pure copper surfacing with steel and alloys is found in works [17, 27], which describe the method of producing protective layers 1.5-2.0 mm thick by electron beam surfacing. When this method is used, good adhesion of the protective material based on refractory metal carbides to the copper surface has been achieved, while the fatigue life of parts with such strengthening increased up to two times.

At the same time, this method has certain disadvantages. In addition to rather complex and rather expensive equipment, during deposition part of the powder being deposited does not reach the weld pool [27].
In order to solve this problem, the authors of work [27] made cardinal changes in the technology of electron beam surfacing: at the first stage, flame spraying of the coating was performed, which was then melted by the electron beam. However, such additional operations made the deposition process even more complicated and increased the probability of appearance of different defects in the surfaced product.

We should separately mention such special methods of producing a steel-copper bimetal joint, as explosion welding, pressure welding with preheating, friction stir welding, high-temperature synthesis, etc. $[12,13,17,28]$. Despite the fact that these methods allow making a rather reliable joint, their application to produce wear-resistant layers is often essentially limited by the geometrical dimensions and shapes of the parts proper. In addition, they also have their disadvantages, for instance with the detonation method, air voids can form on the joint boundary that may lead to erosion failure of the coating or its spallation [13].

Selection of wear-resistant materials for deposition on copper surfaces. Proceeding from the data of literature analysis, we can single out several classes of materials, which are suitable for the above-mentioned service conditions $[10,25]$ :

- heat-resistant steels, complexly alloyed by chromium, molybdenum, nickel, etc.;

- high-carbon high-chromium iron-based steels (Sormite type);

- alloys on nickel or cobalt base.

Heat-resistant steels of $\mathrm{Fe}-\mathrm{C}-\mathrm{Cr}-\mathrm{Mo}-\mathrm{V}$ alloying system are widely used for strengthening metallurgical equipment components, operating under thermal cycles, and high dynamic loads, in combination with abrasive wear. Steels with a high tungsten content have the highest hardness and heat resistance at high temperatures. However, thermal stability and impact toughness of such steels is comparatively low [10]. Tungsten replacement by molybdenum (complete or partial) lowers the heat resistance of the steel, but essential increases its thermal stability. Steels of this

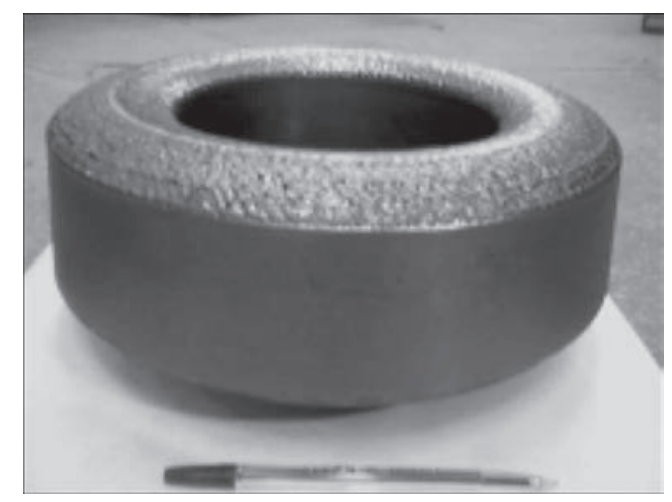

Figure 3. Appearance of the tuyere head of a blast furnace, surfaced by electron beam method [27] 
class are prone to cracking at surfacing, so surfacing is performed with preheating and sometimes concurrent heating.

High-carbon high-chromium steels with carbon and chrome content up to 5 and $30 \%$, respectively, are widely applied for surfacing parts operating under the conditions of intensive wear at high temperatures (up to $1000{ }^{\circ} \mathrm{C}$ ) [10]. Different methods can be used for surfacing by these materials. However, surfacing technology is associated with considerable difficulties, in connection with prevention of cracking. Preheating and concurrent heating of the part up to $600{ }^{\circ} \mathrm{C}$ are mostly used for this purpose, and after surfacing the part is placed into a furnace heated up to the temperature of $650-700{ }^{\circ} \mathrm{C}$ and slowly cooled together with it.

Nickel-based alloys have high high-temperature resistance, high thermal fatigue resistance, high resistance against different kinds of corrosion and low susceptibility to cracking at surfacing. Some of the most common grades of this type of alloys are Hastalloy and Inconel of alloying systems of $\mathrm{Ni}-\mathrm{Cr}-\mathrm{Mo}-\mathrm{Nb}$ type [10]. By the data of numerous studies [6, 7, 21, 27 , and oth.], application of materials, alloyed with nickel, allows producing metal with better indices of weldability, corrosion and wear resistance. In addition, by some data [21], additional alloying with nickel at cast iron surfacing by copper alloys promotes a more uniform distribution of base metal in the deposited metal without formation of individual iron inclusions in the upper layer of copper.

Cobalt-based alloys of $\mathrm{Co}-\mathrm{C}-\mathrm{Cr}-\mathrm{W}$ alloying system are characterized by high wear, high-temperature and corrosion resistance, etc. in many aggressive media [10]. Hardness of such alloys at temperatures above $650{ }^{\circ} \mathrm{C}$ in higher than that of nickel-based alloys. The main disadvantage of cobalt alloys is their high cost, as well as cracking susceptibility.

In terms of weldability, mutual solubility of the main alloying elements of steels and alloys, mentioned above, as well as copper, is important. Constitutional diagrams of the respective binary systems are given in Figure 4 [29].

1) Carbon. Constitutional diagram of $\mathrm{Cu}-\mathrm{C}$ state (Figure 4, a) shows that copper is in equilibrium with carbon in the solid and liquid state. Carbon solubility in liquid copper in wt.\% is as follows: 0.0001 at $1100{ }^{\circ} \mathrm{C} ; 0.00015$ at $1300{ }^{\circ} \mathrm{C}$ and 0.003 at $1700{ }^{\circ} \mathrm{C}$. There are data that near the boiling temperature copper dissolves up to $1 \mathrm{wt} . \%$ (5 at.\%) C, which precipitates from the solution in the form of graphite even at rapid quenching [29].

2) Iron. Copper forms a solution with iron with up to $3.0 \%$ iron solubility in molten copper up to the temperature of $1025^{\circ} \mathrm{C}$ (Figure $4, b$ ). Copper solubility in $\gamma$-Fe at temperatures of 1470,1370 and $1100^{\circ} \mathrm{C}$ is equal to $10.0 ; 12.0$ and 8.0 at. \%, respectively. In this system two peritectic and one euitectoid equilibria are in place, and at strong overcooling (overcooling degree of $100{ }^{\circ} \mathrm{C}$ and higher) an area of nonmixing in the liquid state appears. Critical mixing temperature is $20^{\circ} \mathrm{C}$ below the liquidus temperature at equiatomic bonding [29].

3) Nickel. Among structural metals, only in $\mathrm{Cu}-$ $\mathrm{Ni}$ system its component metals have unlimited mutual solubility, and are characterized by formation of a continuous row of solid solutions $(\mathrm{Cu}, \mathrm{Ni})$ with face-centered cubic structure during crystallization (Figure $4, c$ ). There are also some calculated data on the availability of the separation boundary of the solid solution and critical point of nonmixing, which correspond to Ni concentration of 69.7 at.\% and temperature of $342{ }^{\circ} \mathrm{C}$ and are related to magnetic transformation of $\mathrm{Ni}$ [29].

4) Cobalt. $\mathrm{Cu}-\mathrm{Co}$ system (Figure $4, d$ ) is a diagram of peritectic type. Eutectoid transformation is in place in the solid state. Maximum solubility of copper in $\alpha$-Co is achieved at the temperature of $1367^{\circ} \mathrm{C}$ and is equal to 19.7 at.\%. In alloys of $\mathrm{Co}-\mathrm{Cu}$ system strong overcooling (by $100{ }^{\circ} \mathrm{C}$ and more) results in appearance of an area of nonmixing in the liquid state, which is almost symmetrical relative to the joint axis. At equiatomic bonding, the critical mixing point is located $90^{\circ} \mathrm{C}$ below the liquidus curve [29].

5) Chromium. In keeping with $\mathrm{Cu}-\mathrm{Cr}$ constitutional diagram (Figure 4, e), this system demonstrates the presence of a eutectic equilibrium and existence of two solid solutions based on $\mathrm{Cu}$ and $\mathrm{Cr}$. However, the nature of phase-equilibria in the high-temperature region at concentrations of $0-55$ at. $\% \mathrm{Cu}$ is ambiguous. It is believed that monotectic equilibrium at the temperature of $1767 \pm 8{ }^{\circ} \mathrm{C}$ and concentration of 18.8 at. $\% \mathrm{Cu}$ is in place in the entire concentration range in alloys containing from 4 up to 45 at. $\% \mathrm{Cu}$. The area of separation of the two liquids extends from 18.8 to 45 at. $\% \mathrm{Cu}$ in a narrow temperature range, the upper limit of which is not higher than $1900^{\circ} \mathrm{C}$. Also confirmed is the existence of a two-phase region (liquid $+\mathrm{Cr}$ ) in the concentration range of 42-97 at. $\% \mathrm{Cr}$ at the temperature of $1550{ }^{\circ} \mathrm{C}$. Maximum solubility of chromium in copper at the temperature of $1076.6^{\circ} \mathrm{C}$ is equal to 0.89 at.\% [29].

6) Molybdenum. Constitutional diagram of $\mathrm{Cu}-\mathrm{Mo}$ was not plotted experimentally, due to the fact that $\mathrm{Cu}$ and Mo do not mix in the liquid and solid state, while mutual solubility of the components at the temperature of $900{ }^{\circ} \mathrm{C}$ is extremely small. Therefore, the constitutional diagram of this system, which is shown in Fig- 

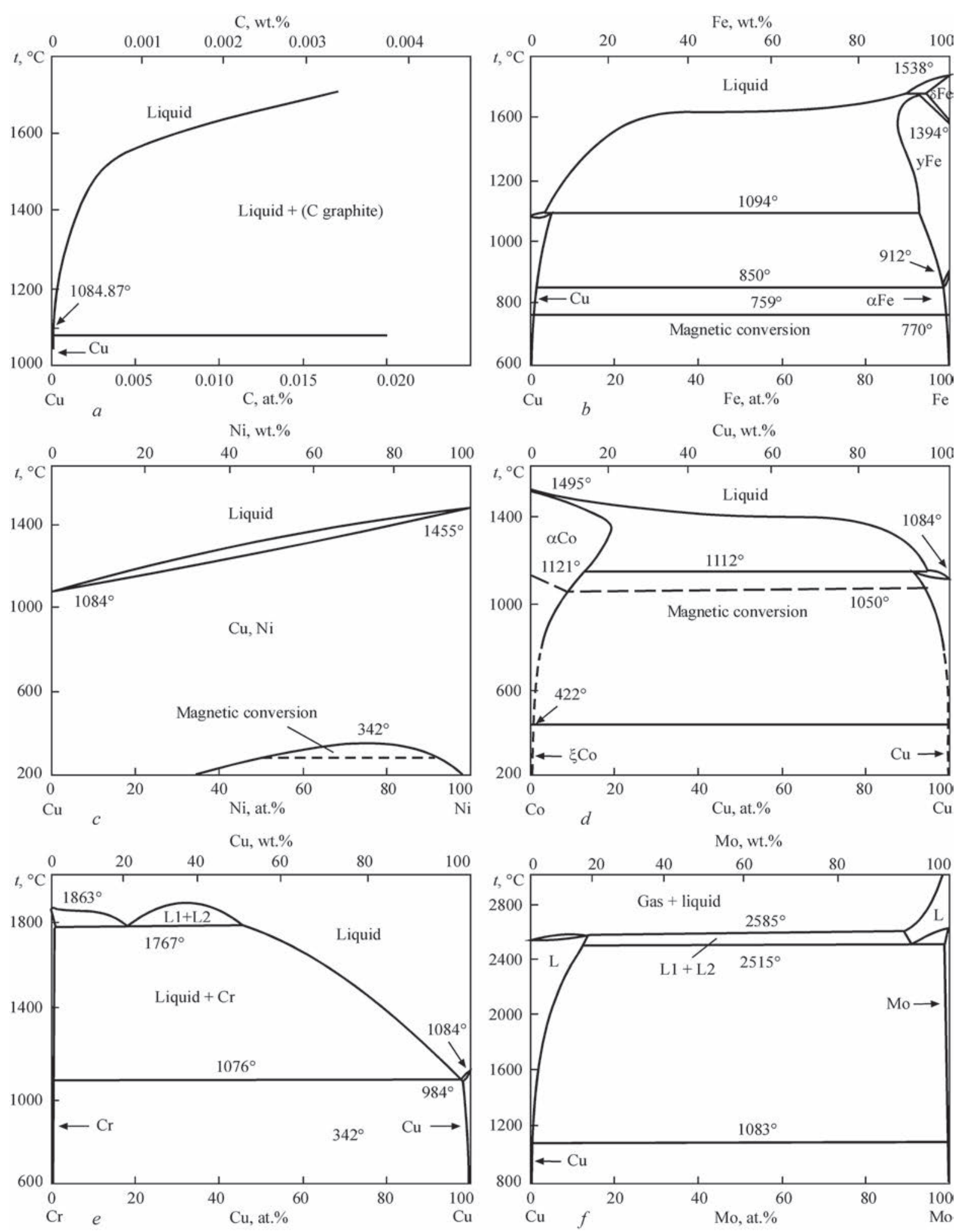

Figure 4. Constitutional diagrams of $\mathrm{Cu}-\mathrm{C}(a), \mathrm{Cu}-\mathrm{Fe}(b), \mathrm{Cu}-\mathrm{Ni}(c), \mathrm{Co}-\mathrm{Cu}(d), \mathrm{Cr}-\mathrm{Cu}(e)$ and $\mathrm{Cu}-\mathrm{Mo}(f)$ binary systems [29]

ure $4, f$, was derived exclusively by calculation methods, in keeping with which the monotectic and eutectic equilibria are in place in the system. Mo solubility in $\mathrm{Cu}$ is equal to 1.91 and 2.50 at.\% at temperatures 1900 and $2100{ }^{\circ} \mathrm{C}$, respectively, and $\mathrm{Cu}$ solubility in Mo is equal to 2.3 at. $\%$ at the temperature of $950{ }^{\circ} \mathrm{C}$ [29].

In view of the above-said, quite promising are the ideas on copper surfacing by wear-resistant alloys

based on iron, nickel or cobalt, complexly alloyed by other elements, which have high mutual solubility with copper. This should promote reduction of chemical inhomogeneity and lowering of the probability of precipitation of individual inclusions, both in the base and in the deposited metal.

Problems of weldability of alloys based on iron, nickel and cobalt in welding with copper. Consid- 
ering the possibility of deposition of wear-resistant alloys on the copper base, it should be noted that by some data [30], in copper welding to steel, application of increased content of iron powder leads to negative impact on the quality of the produced joint. This is caused by higher concentration of iron dendrites on the fusion boundary that, on the one hand, ensures an increase of weld hardness and its strength, but at the same time reduces weld ductility, leading to defect formation in it, thus lowering the service properties of the welded joint [21].

At the same time, copper joint with nickel can be relatively easily produced by the methods of fusion welding without filler or with a filler of copper, nickel, and copper-nickel alloys [1-3]. The fusion boundary of such a joint is clear-cut and has well-defined transition layers. However, in keeping with the data of work [3], this is not regarded as a disadvantage, as the strength of this joint is rather high and fracture runs beyond the fusion zone.

In order to assess the weldability of alloys based on iron, nickel and cobalt with copper, it is necessary, first of all, to compare their main properties (Table).

One can see from the Table, that the essential difference in some physical properties of these metals can impair their weldability. In addition, higher oxidation of copper and considerable absorption of gases by it have a negative effect on weldability [4].

By the data of $[4,9,22]$, the following main factors can be singled out, which affect the weldability of alloys based on iron, nickel and cobalt with copper:

- high heat conductivity of copper that leads to high cooling rates and need to apply the welding heat sources with very high heat input, or considerable temperatures of preheating and concurrent heating, and most often both the one and the other;

- much lower temperature of copper melting;

- short time of weld pool existence in the liquid state that limits the possibilities of its metallurgical processing and requires active deoxidizers;

- considerable CTE of copper that makes more complicated fastening and preservation of the posi- tion of the parts during welding, and that determines the need to take additional measures against the structure deformation;

- high fluidity of copper that limits the used positions of the parts being surfaced, and, for instance during deposition of circular beads in surfacing cylindrical parts;

- significant impact of impurities on copper properties and weldability that requires application of metal with strictly regulated content of oxygen, bismuth, lead, sulphur and antimony;

- high sensitivity of copper to hydrogen, that requires taking special measures to lower its content in the welding zone, in order to prevent porosity;

- light oxidation of copper in the molten state which leads to formation of low-melting eutectics that lowers the weld metal resistance to solidification cracking.

Under the impact of these factors, several main problems are singled out which are characteristic for welding copper and the above-mentioned alloys: formation of hot cracks, including those filled by nonferrous metal; formation of brittle interlayers, as well as significant interpenetration on copper-alloy boundary $[1-3,20]$. The data given below disclose the outlined problems in greater detail. However, they mainly concern welded joints of copper-steel type or cases of copper deposition on steel, as the questions of fusion welding of copper with alloys on nickel and cobalt base are hardly covered in technical literature.

By the data of work [2], in welding copper to steel, at increase of copper content in the weld metal above $3 \%$, the hot cracking susceptibility rises abruptly. In this case, at solidification of weld metal, copper, owing to limited solubility in steel, precipitates on the grain boundaries, and cracks form under the impact of tensile stresses and Rebinder effect.

Initial penetration of copper along the steel grain boundaries that proceeds under the impact of the capillary effect, diffusion and dissolution of steel in copper, is further facilitated by that the surface energy on $\mathrm{Fe}-\mathrm{Cu}$ boundary is approximately two times smaller Comparison of crystallographic and physical properties of pure copper, iron, nickel and cobalt [31]

\begin{tabular}{|c|c|c|c|c|}
\hline Characteristic & $\mathrm{Cu}$ & $\mathrm{Fe}$ & $\mathrm{Ni}$ & Co \\
\hline Atomic mass & 63.54 & 55.85 & 58.69 & 58.93 \\
\hline Crystalline lattice type & f.c.c. & $\begin{array}{l}\gamma-\text { f.c.c. } \\
\alpha-\text { b.b.b. }\end{array}$ & f.c.c. & f.c.c. \\
\hline Melting temperature, ${ }^{\circ} \mathrm{C}$ & 1083 & 1535 & 1453 & 1494 \\
\hline Boiling temperature, ${ }^{\circ} \mathrm{C}$ & 2310 & 2450 & 2732 & 2960 \\
\hline Coefficient of thermal expansion by $1^{\circ} \mathrm{C}, 10^{-6}$ & 17.06 & 12.15 & 13.6 & 12.5 \\
\hline Heat conductivity, $\mathrm{W} /(\mathrm{m} \cdot \mathrm{K})$ & 413 & 94 & 107 & 122 \\
\hline Specific heat capacity, $\mathrm{J} /(\mathrm{kg} \cdot \mathrm{K})$ & 385 & 449 & 500 & 244 \\
\hline Specific electric resistance, $\mathrm{Ohm} \cdot \mathrm{m}, \cdot 10^{-8}$ & 1.68 & 10.0 & 6.99 & 5.68 \\
\hline Density, $\mathrm{kg} / \mathrm{m}^{3}$ & 8930 & 7850 & 8900 & 8900 \\
\hline
\end{tabular}




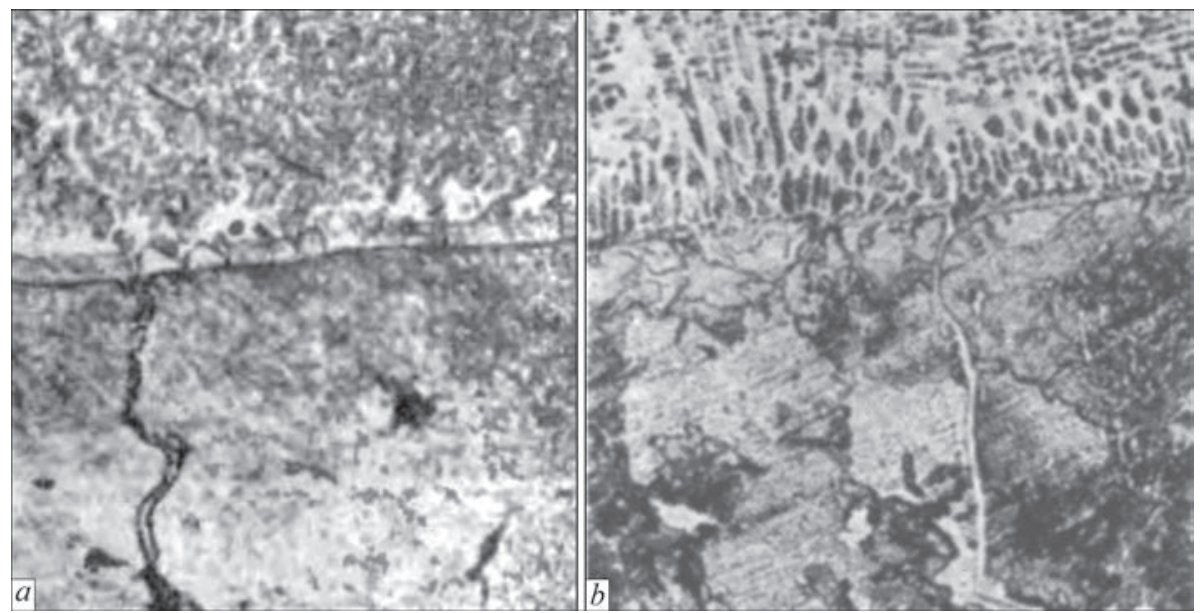

Figure 5. Fusion zone in argon-arc spraying of Br. A5 bronze on St3 steel (a) and Br. ANZh6-3-1 bronze on steel 20 (b), $\times 300$ [2]

than that on Fe-Fe boundary. Therefore, the strength on grain boundary, which is in contact with liquid copper, turns out to be lower, and tensile stresses, developing in the metal, are sufficient for final rupture of the weakened boundary and instantaneous filling of the newly formed crack by copper (Figure 5). Nonferrous metal penetration into steel to the depth of more than $2.5 \mathrm{~mm}$ in some cases lowers the static, and particularly, fatigue life of steel [2]. Alongside cracks in the usual sense, defects of the type of «healed» cracks completely filled with copper or copper alloy, are characteristic for steel surfacing with copper.

In order to eliminate these defects, in work [3], it is proposed to add a certain amount of aluminium to the weld pool. In this case, the produced welded joints of copper with low-carbon steel had higher values of mechanical properties in the presence of aluminium in the weld, compared with the respective characteristics without aluminium. Moreover, aluminium addition to the weld pool was favourable for the structure of the weld metal and near-weld zone.
Weldability of copper with steel impairs formation of brittle interlayers in the near-weld zone on the fusion boundary (Figure 6). Their formation and development are associated with diffusion of some elements from steel into copper. In order to prevent formation of interlayers of this type, it is recommended to perform preliminary deposition of layers from alloys, which reduce the possibility of formation brittle interlayers and iron transition into copper and vice versa [2].

Studying the physico-mechanical properties of welded joints of copper-low-carbon steel, exposed to variable temperatures in service, showed [14] that at up to $2 \%$ mass fraction of iron, the weld metal strength is equal to that of base metal (copper) in the entire testing temperature range. Iron content in copper above $7 \%$ leads to an abrupt lowering of the joint ductile properties that may lead to hot cracking. Complex evaluation of mechanical properties, long-term strength, thermal cycle fatigue and fracture mode showed that when welded joints of copper-low-carbon steel are exposed to increased and variable tem-
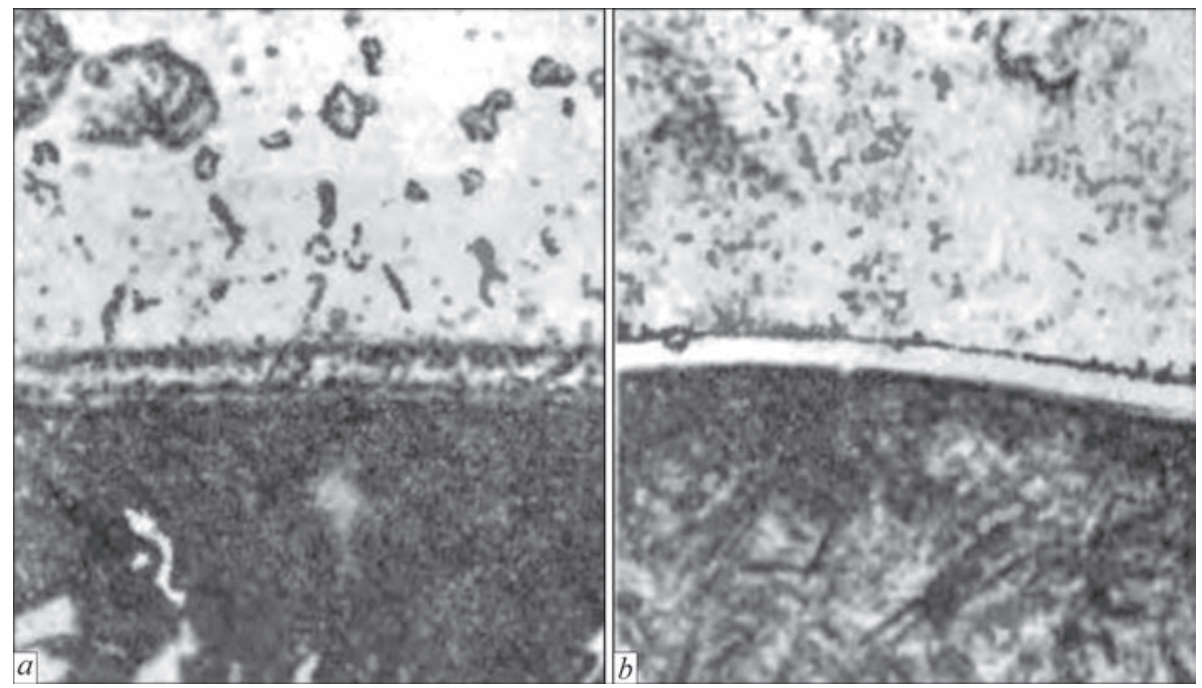

Figure 6. Brittle interlayers in the fusion zone at plasma surfacing of steel 20 with Br.AMts9-2 bronze $(a)$ and of $38 \mathrm{KhNMA}$ steel with Br. KMTs3-1 bronze (b), ×300 [2] 
peratures in service, 3-6\% iron content in the weld metal is optimum [14].

As to the depth of copper-steel interpenetration, according to the data of [2], the admissible penetration depth, which does not affect the mechanical properties of steel, is limited by $0.3-0.5 \mathrm{~mm}$. By other data [3], however, copper alloy penetration into highstrength steel to the depth of up to $1.2 \mathrm{~mm}$ practically does not affect the static and cyclic strength under tension, static and impact bending of bimetal samples.

Problems of surfacing copper with alloys based on iron, nickel and cobalt and methods of solving them. Considering the possibility of deposition of wear-resistant layers on a copper base, the above-mentioned problems, arising when producing the steel (alloy)-copper welded joint, are complemented by problems caused by the technological features of running of such a process.

Firstly, as was noted earlier, this problem remains practically unstudied today - known are just a few cases of mentioning the methods of electron beam surfacing of copper with different grades of steel in technical literature. These results, however, do not always look valid or economically justified.

Secondly, all the known wear-resistant steels and alloys have much higher melting temperature, than copper $\left(\approx 1500{ }^{\circ} \mathrm{C}\right.$ against $\left.\approx 1100{ }^{\circ} \mathrm{C}\right)$. At first glance, this should lead to increased penetration of copper. However, due to the high heat conductivity of copper (more than 4 times higher than that of steel - see the Table), the drops of molten deposited metal can quickly loose heat that will lead to an abrupt lowering of fluidity and wettability, and, hence, to poor formation of the deposited metal on the copper surface, or even to absence of formation and fusion. It is well known [9] that in butt welding of steel sheets, copper backing is quite often used in production, in order to ensure complete penetration and good formation of the reverse surface of the weld. After welding is over, this backing is rather easily removed and does not have any traces of adhesion to the weld.

In addition, due to its higher heat conductivity, copper will heat very quickly during surfacing, that increases the probability of overheating and subsequent through penetration of the copper base.

Thirdly, the above differences in the physical properties of steel and copper will lead to high temperature gradients and high cooling rates, as well as a short time of staying of the weld pool in the liquid state. This may lead to appearance of individual copper inclusions at weld pool solidification that further on lower the deposited metal performance.

In view of the absence of any recommendations in the technical literature on the features of running of the process of pure copper surfacing with nickel and cobalt alloys (as with iron based alloys), we can only proceed from the data on physico-chemical properties of these metals, considering the fact that both nickel and cobalt, similar to iron, differ greatly from copper by their melting temperature and heat conductivity. Therefore, at copper surfacing by the above alloys, the above-mentioned regularities will be true for them to a certain extent, as they were determined for the cases of copper welding to steel and surfacing of copper and its alloys with steel.

Solving all the above-mentioned problems requires a thorough and substantiated selection of the surfacing technique and technology, surfacing materials, as well as staying within a rather narrow temperature range of preheating and concurrent heating of the copper parts. In view of the foregoing and practical experience, such surfacing methods as gas-shielded arc surfacing with wires of the respective alloying, as well as plasma-powder one by alloys based on iron, nickel and cobalt, look promising.

Here, application of technological measures reducing the penetration and fraction of base metal in the deposited metal, as well as adjustment of energy input of surfacing, can have a positive effect on the quality of fusion of the wear-resistant layer and the copper base. At arc surfacing, the most widely spread in industry, this can be achieved through application of small-diameter electrode wires (1.2-2.0 mm dia); moderate electric modes, in which a stable transfer of electrode metal and minimum base metal penetration are ensured, as well as application of pulse, magnetic-pulse and other technologies. In our opinion such a comprehensive approach, on the one hand, should promote sound fusion of the wear-resistant layer with copper, and on the other hand, it should not allow overheating of the copper base that may lead to a change of the geometrical dimensions of the part.

Thus, despite considerable difficulties, arising at wear-resistant arc or other methods of copper surfacing, these processes are quite promising, in terms of ensuring a considerable extension of fatigue life of copper parts, operating under the conditions of abrasive and gas-abrasive wear, as well as wear at high-temperature friction of metal against metal.

1. Mvola, B., Kah, P. \& Martikainen, J. (2014) Welding of dissimilar nonferrous metals by GMAW processes. Int. J. of Mechan. and Materials Eng., 21(9). DOI:10.1186/s40712014-0021-8.

2. Gurevich, S.M. (1990) Nonferrous metal welding guide. Kiev, Naukova Dumka, [in Russian].

3. Bailey, N. (1986) Welding dissimilar metals. Cambridge, Woodhead Publ. Ltd.

4. Neulybin, S.D., Belinin, D.S., Kuchev, P.S., Gilev, I.A. (2013) Research plasma surfacing of copper by working of plasma 
torch on direct and reverse polarity current. Master's J., 2, 22-27.

5. Radyuk, A.G., Titlyanov, A.E., Strizhakova, T.I. et al. (2008) The influence of aluminum on the nickel and chromium diffusion into copper during the deposition and thermal treatment of gas-thermal coatings. Russian J. of Nonferrous Metals, 49, 261-263. DOI:10.3103/S1067821208040093 [in Russian].

6. Neulybin, S.D., Belinin, D.S., Terentyev, S.A. (2017) Comparative analysis of wear and corrosion attack resistance of bimetal steel-copper products manufactured by plasma-jet hard-facing with direct and reversed polarity current. Procedia Eng., 206, 1401-1406. DOI: 10.1016/j.proeng.2017.10.652.

7. Robert, W. Messler (2019) A practical guide to welding solutions: overcoming technical and material-specific issues. Wiley-VCH Verlag $\mathrm{GmbH} \&$ Co. KGaA. DOI:10.1002/9783527818815.

8. Akimov, V.A. (2011) Research and improvement of the technology for manufacturing air lances of blast furnaces by applying aluminum-containing gas-flame coatings with subsequent heat treatment. Moscow, Institut Stali i Splavov [in Russian].

9. Paton, B.E. (1974) Technology of the fusion electric welding of metals and alloys. Moscow, Mashinostroenie [in Russian].

10. Rjabcev, I.A., Senchenkov, I.K., Turyk, Je.V. (2015) Surfacing. Materials, technologies, mathematical modeling. Gliwice, Wydawnictwo Politechniki Slaskiej.

11. Gerasimova, A., Devyatyarova, V., Kondratenko, V. (2017) Creation of the wear-resistant layer on narrow walls MNLZ crystallizers with use gas-thermal covering. Bulletin of Sci. and Practice, 1, 32-38.

12. Demidenko, L.Yu., Onatskaya, N.A., Polovinka, V.D. (2014) Effect of temperature of thermomechanical treatment on quality of dissimilar metal joints. The Paton Welding J., 12, 11-14. DOI:10.15407/tpwj2014.12.03.

13. Poleshchuk, M.A., Atroshenko, M.G., Shevtsov, A.V., Puzrin, A.L. (2016) Deposition of protective coatings on copper plates of CCM molds by the method of autovacuum brazing. Ibid., 10, 37-40. DOI:10.15407/tpwj2016.10.07.

14. Koleda, V.N. (2012) Improvement of the technology for submerged-arc welding of copper to steel. Ibid., 3, 39-43.

15. Wan X., Liu X.W, Zhang M.Y. (2007) Experimental research on $\mathrm{ZrO}_{2}$ coating for single tuyere of small blast furnace. Refractories, China, 41, 220-222, 229.

16. Shmorgun, V.G., Slautin, O.V., Evstropov, D.A. et al. (2015) Methods for producing wear-resistant coatings based on titanium cuprides. Izv. VGTU, 12, 22-28, [in Russian].

17. Portnov, L., Nikitin, L., Bugaev, S., Shchipitsyn, V. (2014) Improving the durability of blast-furnace tuyeres. Metallurgist, 58, 488-491. DOI:10.1007/s11015-014-9938-7.
18. Senchenkov, I.K., Chervinko, O.P., Ryabtsev, I.A., Babinets, A.A. (2014) Determination of the service life of hardfaced components under thermal and cyclic loading. Welding Int., 28(1), 80-84. DOI:10.1080/09507116.2013.796661.

19. Babinets, A.A., Ryabtsev, A.A. (2016) Fatigue life of multilayer hard-faced specimens. Ibid., 30(4), 305-309. DOI:10. 1080/01431161.2015.1058004.

20. Ilyushenko, V.M., Anoshin, V.A., Majdanchuk, T.B., Lukianchenko, E.P. (2014) Effectiveness of application of new consumables in welding and surfacing of copper and its alloys (Review). Paton Welding J., 6-7, 80-83. DOI:10.15407/ tpwj2014.06.16.

21. Psaras, G.G., Ezhel, A.I. 1985) For welder of nonferrous metals: Refer. Book. Donetsk, Donbass, [in Russian].

22. Nevidomsky, V.A., Krasilnikov, S.G., Panin, A.D. et al. (2003) Experience in welding of copper-steel moulds at NKMZ Company. Paton Welding J., 8, 46-48.

23. Babinets, A.A., Ryabtsev, I.A., Panfilov, A.I., Zhdanov, V.A. (2016) Influence of methods of arc surfacing with flux-cored wire on penetration of base metal and formation of deposited metal. Ibid., 11, 17-22. DOI:10.15407/tpwj2016.11.03.

24. Babinets, A.A., Ryabtsev, I.A. (2017) Flux-cored wire for wear-resistant surfacing of thin-sheet structures. Ibid., 1, 54-57. DOI:10.15407/tpwj2017.01.10.

25. Pereplyotchikov, E.F. (2004) Plasma-powder cladding of wear- and corrosion-resistant alloys in valve manufacturing. Ibid., 10, 31-37.

26. Pereplyotchikov, E.F. (2015) Plasma-powder surfacing of nickel and cobalt alloys on copper and its alloys. Ibid., 5-6, 10-13. DOI:10.15407/tpwj2015.06.02.

27. Beljuk, S.I., Samarcev, V.P., Pay, A.G., Gal'chenko, N.K. (2006) Electron beam surfacing in the steel industry. In: Proc. of $2^{\text {nd }}$ Int. Sem. on Plasma Emission Electronics. Respublika Burjatija, Ulan-Udje, 101-107, [in Russian].

28. Grigorenko, G.M., Adeeva, L.I., Tunik, A.Yu. et al. (2015) Application of friction stir welding method for repair and restoration of worn-out copper plates of mccb moulds. The Paton Welding J., 5-6, 55-58. DOI:10.15407/tpwj2015.06.13.

29. Massalski, T.B. (2007) Binary alloy phase diagrams. Materials Park, Ohio, ASM Int.

30. Chigarev, V.V., Gavrish, P.A., Vasil'eva, L.V. (2011) Increase of the productivity of welding of cooper with steel. Eastern-European J. of Enterprise Technologies, 4-5, 4-7.

31. Lide, D.R., Haynes, W. (2018) CRC Handbook of chemistry and physics: A ready-reference book of chemical and physical data. Boca Raton, Taylor and Francis. 


\title{
IMPROVEMENT OF CRACK RESISTANCE OF BANDED SUPPORT ROLLS AT HIGH-SPEED SURFACING WITH LOW ENERGY INPUT
}

\begin{abstract}
S.V. Shchetynin, V.I. Shchetynina and S.P. Desyatskii
Priazovskyi State Technical University

7 Universitetskaya Str., 87555 Mariupol, Ukraine. E-mail: shchetynin.sergey2012@gmail.com

The objective of the work is improvement of deposited metal crack resistance and development of the process of highspeed surfacing of banded support rolls with a low energy input. In order to achieve the set objective, we developed the process of improving the crack resistance due to high-speed surfacing of banded support rolls with a low energy input. In keeping with the equation of heat propagation at high-speed surfacing with a low energy input, increase of deposition rate is accompanied by lowering of the heat input, narrowing of melting isotherm width and HAZ. Calculation and experimental methods were used to establish that at increase of deposition rate, lower heat input results in decrease of deformations and welding stresses, and reduction of the HAZ, where cold cracks form, that prevents delamination of the deposited metal. Melting and solidification rates rise, time of the pool staying in the liquid state is reduced that prevents liquid metal flowing out of the weld pool and improves deposited metal formation. Established regularities were the base for development of the process of high-speed surfacing with low energy input, at which the heat input and welding stresses decrease, HAZ is reduced and deposited metal delamination is prevented, melting and solidification rates increase, time of the pool staying in the liquid state becomes shorter, and crack resistance of banded support rolls becomes higher. Developed process of high-speed surfacing of banded support rolls with a low energy input provides a lowering of the heat input and welding stresses, HAZ reduction, increase of melting and solidification rates and crack resistance, and absence of deposited metal delamination or band failures. 11 Ref., 6 Figures.
\end{abstract}

Ke y w ord s: high-speed surfacing with low energy input, melting isotherms, heat input, welding stresses, HAZ, crack resistance, banded support rolls

In manufacture of banded support rolls by fitting the band on the axle with tension, stresses develop in the band that is why it is necessary to ensure minimum residual welding stresses in surfacing, which, adding up with the inherent stresses, cannot lead to band fracture. The band is made from high-carbon $90 \mathrm{KhF}$ steel prone to hot and cold cracking. Therefore, increase of crack resistance of banded support rolls is an important science and technology problem.

Cold and hot crack resistance is largely determined by the speed and energy input of the surfacing process. It is generally known that at reduction of energy input, the probability of cold cracking becomes higher, due to increase of the cooling rate $[1,2]$. M.M. Prokhorov [1], however, notes that considerable reduction of the energy input and increase of the heating rate may lead to lowering of cold cracking probability.

In order to increase the crack resistance, of great importance are the works on studying the stress-strain state of welded structures [3-5], which are of considerable theoretical and practical interest.

Banded support rolls of 3000 mill with body diameter of $2.1 \mathrm{~m}$, body length of $3 \mathrm{~m}$, and weight of $120 \mathrm{t}$, are made by pulling a heated band over the axle. Here, the band diameter becomes greater and after cooling it is reduced, that ensures band fitting on the axle with tension. Here, inherent residual stresses develop in the band.

Support rolls, which prevent sagging and fracture of cast iron working rolls, are operated under the conditions of high specific pressures that leads to wear and reduction of their diameter. Therefore, after operation, arc surfacing is performed for strengthening and reconditioning.

Due to inherent residual stresses and deposition of a band from $90 \mathrm{KhF}$ steel, prone to cracking, it is necessary to ensure minimum residual welding stresses at surfacing, which, while adding up with the inherent residual stresses, may lead to band fracture.

As was established, at arc surfacing of banded support rolls at high energy input of $2.2 \mathrm{MJ} / \mathrm{m}$, after heat treatment and slower cooling, the band broke before it was mounted in the rolling mill. Fracture mode was brittle, the band cracked, and a piece of the band flew like a shell with high kinetic energy. The energy, applied to the band, at deposition with a high energy input, was transformed into kinetic energy. 
An effective method to increase the crack resistance is high-speed surfacing at low energy input, the impact of which on crack resistance of the deposited metal is insufficiently studied [6-8].

The objective of the studies is improvement of the deposited metal crack resistance and development of the process of high-speed surfacing of banded support rolls with low energy input that prevents band breaking.

High-speed surfacing with a low heat input corresponds to the scheme of bead deposition on a massive body by a powerful quickly moving arc, for which the temperature field is described by the developed by M.M. Rykalin [9] equation of the process of heat propagation:

$$
T(X, Y, Z)=\frac{q_{\mathrm{a}}}{2 \pi \lambda(-X)} \stackrel{\circ}{a}^{-\frac{V Y^{2}}{4 a(-X)}},
$$

where $q_{\mathrm{a}}$ is the effective thermal power of the $\operatorname{arc}\left(q_{\mathrm{a}}=\right.$ $\left.=0.24 I U \eta_{\mathrm{a}}, 5356.8 \mathrm{cal} / \mathrm{s}\right) ; \lambda$ is the heat conductivity coefficient, $0.1 \mathrm{cal} / \mathrm{cm} \cdot \mathrm{s} \cdot{ }^{\circ} \mathrm{C}$; $a$ is the thermal diffusivity $\left(0.1 \mathrm{~cm}^{2} / \mathrm{s}\right) ; V$ is the deposition rate $(2.08 ; 1.39$; $0.695 \mathrm{~cm} / \mathrm{s}) ; X$ is the abscissa along the surfacing direction, $\mathrm{cm} ; Y$ is the ordinate normal to the surfacing direction, cm; $I$ is the current $(800 \mathrm{~A}) ; U$ is the arc voltage $(31 \mathrm{~V}) ; \eta_{a}$ is the effective efficiency (0.9 in submerged-arc welding).

For body surface $Z=0$, the equation of heat propagation at high-speed surfacing at a low heat input has the following form:

$$
\frac{2 \pi \lambda T(-X)}{q_{\mathrm{a}}}=a^{-\frac{V Y^{2}}{4 a(-X)}},
$$

then:

$$
\begin{gathered}
-\frac{V Y^{2}}{4 a(-X)}=\ln \frac{2 \pi \lambda T(-X)}{q_{a}} \\
Y^{2}=-\frac{4 a(-X)}{V} \ln \frac{2 \pi \lambda T(-X)}{q_{a}} \\
Y=\sqrt{-\frac{4 a(-X)}{V}\left(\ln \frac{2 \pi \lambda T}{q_{a}}+\ln (-X)\right) .}
\end{gathered}
$$

Calculation of isotherms at wire electrode surfacing is performed on a personal computer by a specially developed program, for base metal surface $(Z=$ $=0)$, the thermal condition of which determines weld formation.

The adequacy of the equation of the process of heat propagation at high-speed surfacing with a low heat input was confirmed by good convergence of the calculated and experimental data of melting isotherms

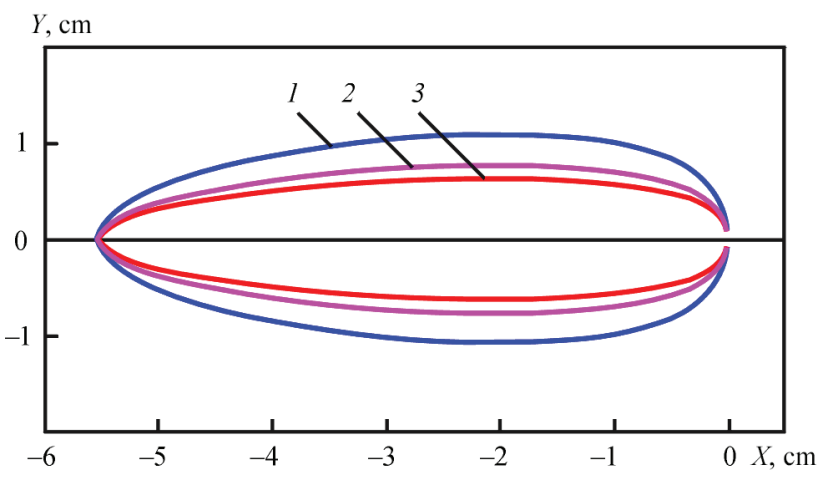

Figure 1. Dependence of melting isotherm on deposition rate: $1-25 ; 2-50 ; 3-75 \mathrm{~m} / \mathrm{h}$

and weld width, obtained at high-speed surfacing with PD-Np 25Kh5FMS wire of $3.6 \mathrm{~mm}$ diameter, with flux AN-26P of plates from St. 3 steel of $30 \times 300 \times 400 \mathrm{~mm}$ size. Arc surfacing was conducted in the following mode: current of 750-800 A, arc voltage of 30-32 V, speed of $0.7 ; 1.4 ; 2.1 \mathrm{~cm} / \mathrm{s}$. Here, the heat input was equal to $3.3 ; 1.65 ; 1.1 \mathrm{MJ} / \mathrm{m}$. VDU 1604 rectifier was used as the heat source.

As was established, at increase of the deposition rate, the width of melting isotherms becomes smaller (Figure 1), that is in good agreement with the experimental data on weld width, as a result of lowering of the heat and energy input.

At arc surfacing, vacancies develop in the deposited metal under the impact of thermal excitation [1], as the energy of vacancy appearance is smaller than that of formation of interstitial atoms. In the zone of vacancy occurrence, the static equilibrium of the forces of interatomic interaction is disturbed, that leads to shifting of adjacent atoms from their equilibrium positions, microdistortion of the crystalline lattice, microstresses, increase of dislocation density and residual welding stresses.

Cracks form, when welding stresses become greater than the interatomic bonds [6]. Therefore, in order to avoid band breaking at surfacing the banded support rolls, it is necessary to ensure minimum residual welding stresses, which are determined by heat input and deformations.

In order to study the impact of deposition rate on longitudinal deformation, surfacing of plates $(8 \times 120 \times 900) \cdot 10^{-3} \mathrm{~m}$ and $(30 \times 120 \times 900) \cdot 10^{-3} \mathrm{~m}$ was performed by a composite electrode at different speeds.

In keeping with literature data [8], the dependence of residual welding stresses on deposition rate is as follows:

$$
\sigma \geq \mu E \frac{q_{\mathrm{a}}}{V F}, \mathrm{~Pa}
$$




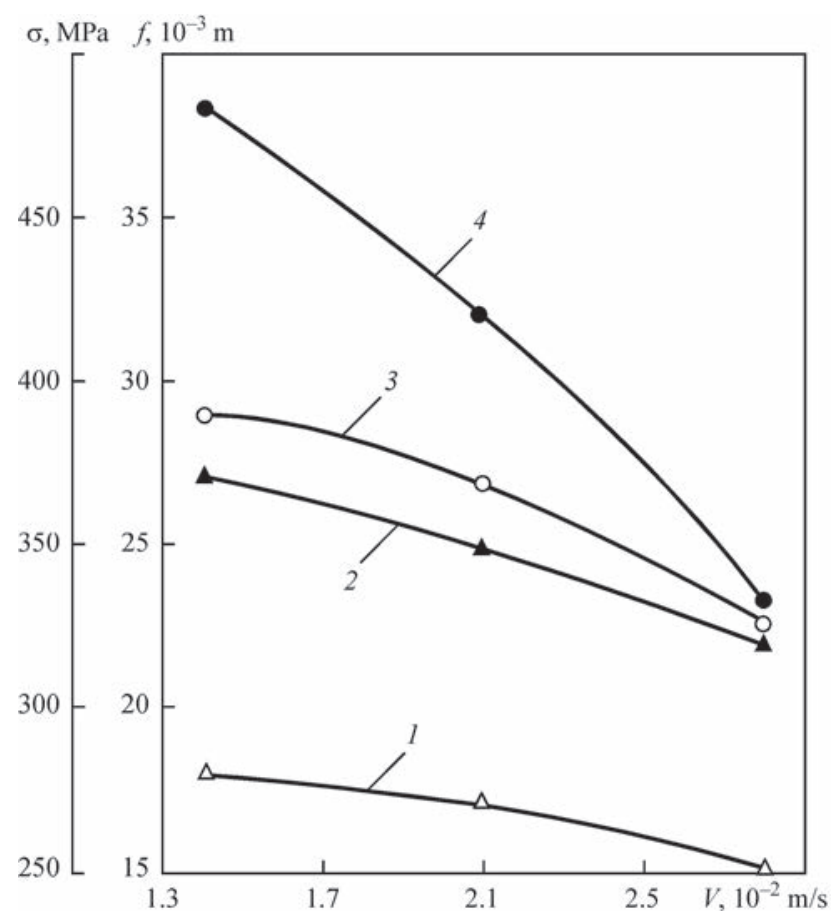

Figure 2. Regularity of the impact of deposition rate $V$ on deformations $f(1,2)$ and welding stresses $\sigma(3,4)$ in plates of $(30 \times 120 \times 900) \cdot 10^{-3} \mathrm{~m}(1,3),(8 \times 120 \times 900) \cdot 10^{-3} \mathrm{~m}(2,4)$ size

where $\mu$ is the Poisson's ratio (for carbon steel $\mu=$ $=0.33$ ); $E$ is the modulus of elasticity (for carbon steel $\left.E=(2.0-2.1) \cdot 10^{5} \mathrm{MPa}\right) ; q_{\mathrm{a}}$ is the effective thermal power $(\mathrm{J} / \mathrm{s}) ; V$ is the deposition rate, $\mathrm{m} / \mathrm{s} ; q_{\mathrm{a}} / V$ is the energy input, $\mathrm{MJ} / \mathrm{m} ; \mathrm{F}$ is the plate cross-section, $\mathrm{m}^{2}$.

Longitudinal plastic deformation of the plates depends on residual welding stresses [8]:
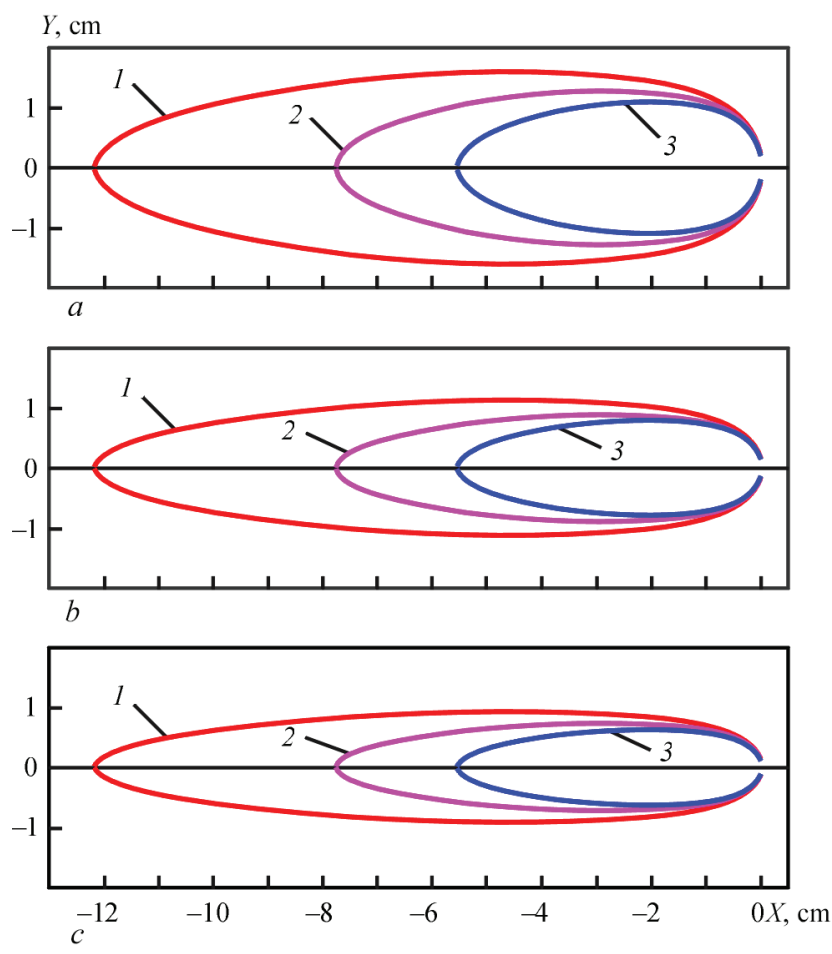

Figure 3. Temperature field at deposition at the rate of 25 (a), 50 (b), $75 \mathrm{~m} / \mathrm{h}(c): 1-T=700 ; 2-1100 ; 3-1539{ }^{\circ} \mathrm{C}$

$$
f=0.613 l \sqrt{\frac{\sigma-\sigma_{\mathrm{cr}}}{E}, \mathrm{~m}},
$$

where $l$ is the plate length, $\mathrm{m} ; \sigma_{\mathrm{cr}}$ is the critical value of welding stresses, Pa.

Critical value of residual welding stresses, which leads to plastic deformation is [8]:

$$
\sigma_{\mathrm{cr}}=\frac{\pi^{2} E}{12}\left(\frac{\delta}{l}\right)^{2}, \mathrm{~Pa},
$$

where $\delta$ is the plate thickness, $\mathrm{m}$.

At stresses above the critical value, plastic deformation of the plate occurs.

It follows from the given expressions, that the residual welding stresses are directly proportional to plate deformation [8]:

$$
\sigma=\frac{f^{2} E}{0.613^{2} l^{2}}+\frac{\pi^{2} E}{12}\left(\frac{\delta}{l}\right)^{2}, \text { MPa. }
$$

As was established, at increase of the deposition rate and lowering of the energy input, decrease of the heat input results in reduction of base metal deformation and residual welding stresses (Figure 2) that considerably increases the crack resistance.

Cold cracking resistance of the deposited metal is largely determined by the residual welding stresses, which add up at deposition that leads to cracking. Deposition of wear-resistant layer is performed in five or greater number of passes, therefore welding stresses increase abruptly, and deposited layer thickness on the radius is limited by the value of $0.025 \mathrm{~m}$, exceeding which leads to considerable increase of residual welding stresses and deposited metal delamination in the zone of fusion with the base metal. This is confirmed at surfacing of working rolls of 1700 mill, when at deposition of $0.04 \mathrm{~m}$ on the radius, the deposited metal separated from the base metal. Therefore, investigations were conducted at five-layer surfacing. Weld metal properties were found by measuring the $\mathrm{HAZ}$, which was determined by melting isotherms at $1539^{\circ} \mathrm{C}$ and at the temperature of $1100{ }^{\circ} \mathrm{C}$.

As was established (Figures 3, 4), with increase of the deposition rate and lowering of energy input, the heat input and HAZ are decreased that ensures lowering the susceptibility to cold cracking and deposited metal separation.

In the weld pool crater, the arc melts the base metal with the speed of welding on the axis, which rises from 25 to 50 and $75 \mathrm{~m} / \mathrm{h}$ with increase of welding speed (Figure 5). As the base metal in the crater melts, in the area of the side edges the speed drops from the welding speed to zero in the area of crater transition to 


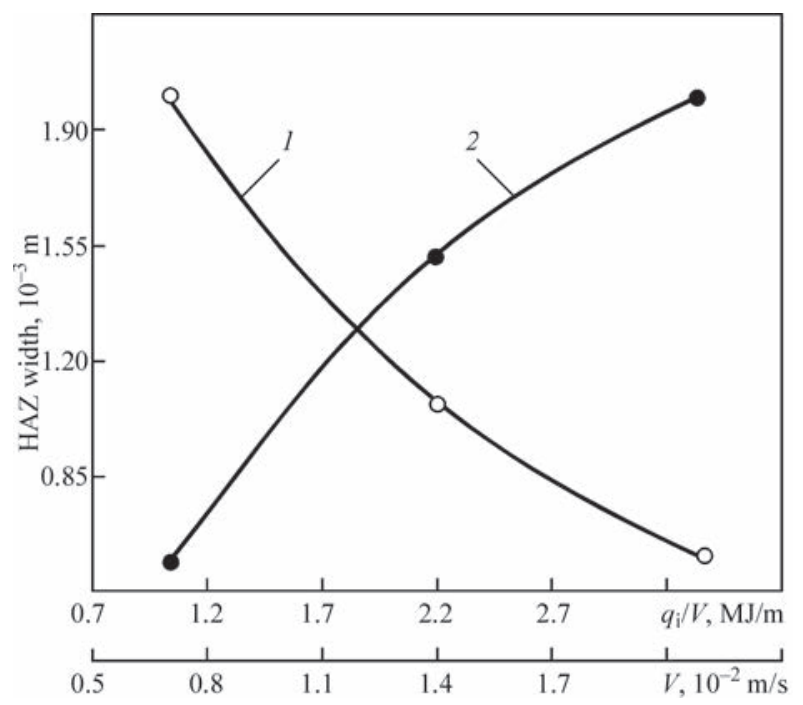

Figure 4. Dependence of HAZ width of deposition rate $V(1)$ and energy input $q_{\mathrm{a}}$ (2)

the tail part of the weld pool, where the solidification rate of liquid metal of the weld pool rises from zero in the area of the side edges, to the welding speed on the axis of the pool tail part.

Three times increase of the heating rate, from 200 up to $600{ }^{\circ} \mathrm{C}$, has a greater impact on refinement of the austenite grain, than does the increase of the cooling rate by 25 times, from 10 up to $250{ }^{\circ} \mathrm{C}$ [10], that should be taken into account, when studying the brittle fracture and cold cracking susceptibility.

The regularity of the change of base metal melting rate in the weld pool crater and of the solidification rate in the pool tail part coincides with the melting isotherm, in keeping with the equation of heat propagation at high-speed surfacing with low energy input.

Crack resistance largely depends on the rate of heating and melting, cooling and solidification, and time of the pool staying in the liquid state.

At high-speed surfacing with low energy input for a powerful quickly moving heat source, the time of the pool staying in the liquid state is determined by the equation for the melting isotherm and weld pool length [9]:

$$
T_{\mathrm{m}}=\frac{q_{\mathrm{a}}}{2 \pi \lambda V t_{1}},{ }^{\circ} \mathrm{C},
$$

from which it follows that the time of the pool staying in the liquid state depends on the surfacing speed and energy input:

$$
t_{1}=\frac{q_{\mathrm{a}}}{2 \pi \lambda V T_{\mathrm{w}}},{ }^{\circ} \mathrm{C} .
$$

With increase of the deposition rate, the time of the pool staying in the liquid state is reduced (Figure 6), that results in prevention of liquid metal flowing out

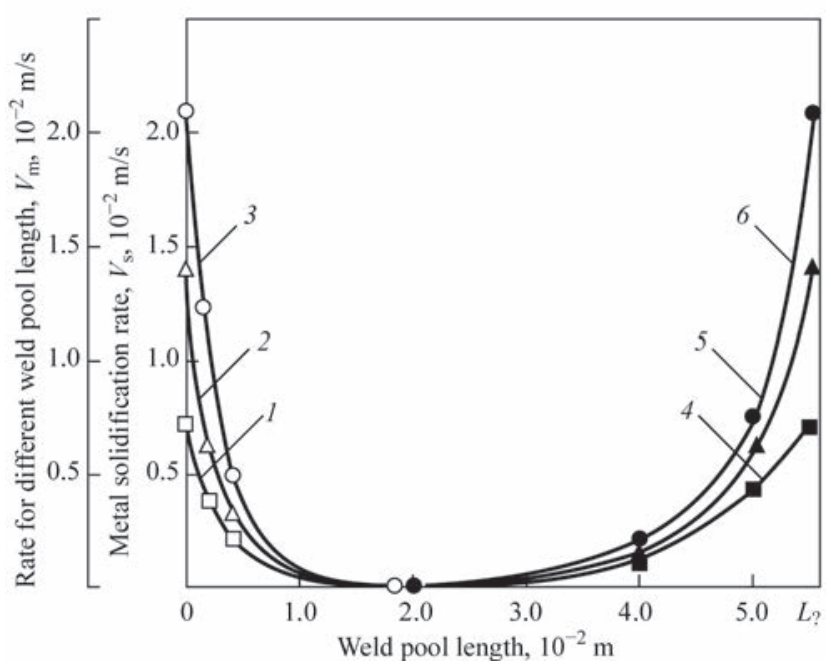

Figure 5. Base metal melting rate $v_{\mathrm{m}}(1-3)$ and solidification of weld pool liquid metal $v_{\mathrm{s}}(4-6)$ at deposition rate of $25 \mathrm{~m} / \mathrm{h}(1,4)$, $50(2,5)$ and $75(3,6)$

of the weld pool and ensuring sound formation of the deposited metal.

In order to increase the crack resistance of banded support rolls, a method of high-speed surfacing of high-carbon steels [11] with a low energy input of $1.1 \mathrm{MJ} / \mathrm{m}$ was developed, using the following mode: current of 750-800 A, arc voltage of 30-32 V, and deposition rate of $75 \mathrm{~m} / \mathrm{g}$.

The process effectiveness was confirmed at highspeed surfacing of banded support rolls of 3000 mill with low energy input, at surfacing which with low energy input the band did not break. High-speed surfacing of the rolls was performed with preheating up to $300-350{ }^{\circ} \mathrm{C}$, by deposition of a buffer layer by Zv08G2S low-carbon wire of $4 \mathrm{~mm}$ diameter, with AN-60 flux, and deposition of a wear-resistant layer by PD-Np-25Kh5FMS flux-cored wire of $3.6 \mathrm{~mm}$

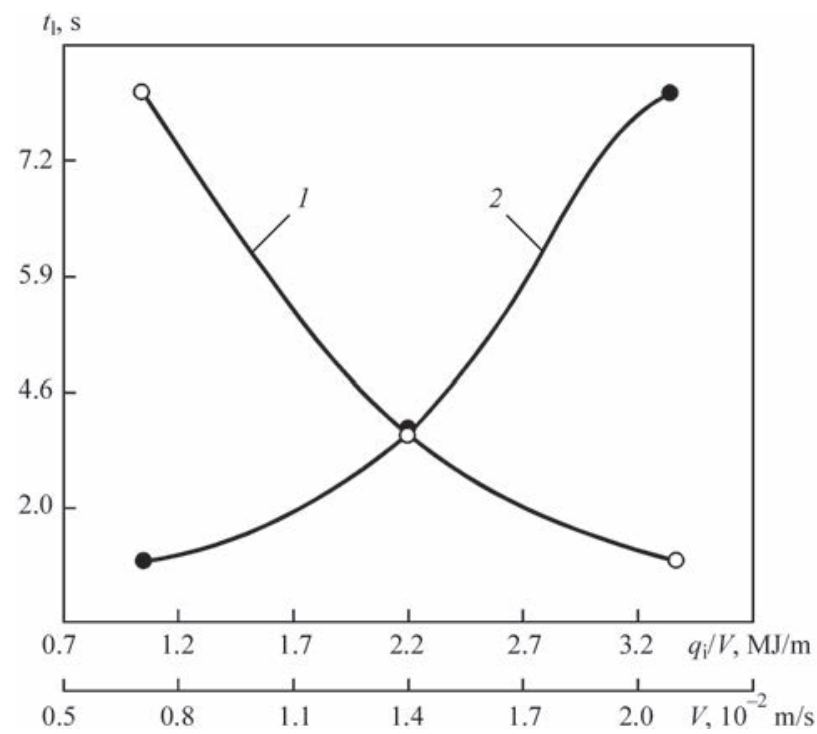

Figure 6. Dependence of the time of the pool staying in the liquid state $t_{1}$ on melting rate $V(1)$ and energy input $q_{\mathrm{a}}(2)$ 
diameter with flux AN-26P and energy input of $1.1 \mathrm{MJ} / \mathrm{m}$, heat treatment and retarded cooling.

Preheating temperature, with increase of the carbon content, rises from $150-200{ }^{\circ} \mathrm{C}$ for steel 45 , to $300-350{ }^{\circ} \mathrm{C}$, for steel $90 \mathrm{KhF}$.

After arc surfacing, in order to lower the welding stresses, roll heat treatment is performed in the following modes: roll temperature before heat treatment $300{ }^{\circ} \mathrm{C}$; heating up to the temperature of $400-450{ }^{\circ} \mathrm{C}$ at the rate of $5-10{ }^{\circ} \mathrm{C} / \mathrm{g}$; soaking at this temperature for 8-10 h; cooling to the temperature of $300^{\circ} \mathrm{C}$ at the rate not higher than $10-15^{\circ} \mathrm{C} / \mathrm{g}$.

After the temperature of $300{ }^{\circ} \mathrm{C}$ has been reached, the roll is placed into a thermostat for retarded cooling.

The developed process of high-speed surfacing of banded rolls at a low energy input ensures minimum heat input and residual welding stresses, reduction of the HAZ, cold cracking susceptibility and probability of deposited metal delamination; increase of melting and solidification rate, improvement of crack resistance and no band breaking.

\section{Conclusions}

1. Adequacy of the equation of heat propagation at high-speed surfacing with a low heat input is confirmed by good convergence of the calculated data of melting isotherms and experimental data on the weld width.

2. Proceeding from the calculated-experimental data, it was found that at high-speed surfacing with a low energy input, the heat input and residual welding stresses, HAZ, cold cracking susceptibility and probability of deposited metal delamination, and time of the pool staying in the liquid state are reduced, while melting and solidification rate is increased, that improves the crack resistance of banded support rolls.

3. The process of high-speed surfacing with a low energy input of banded support rolls was developed, which ensures lowering of the heat input and residual welding stresses, reduction of the HAZ, increase of the melting and solidification rate, and cracking resistance, absence of deposited metal delamination or band breaking.

1. Prokhorov, N.N. (1976) Physical processes in metal during welding. Moscow, Metallurgiya [in Russian].

2. Shorshorov, M.Kh., Belov, V.V. (1972) Phase transformations and changes of properties of steel in welding. Moscow, Nauka [in Russian].

3. Makhnenko, V.I. (1976) Calculation methods of investigation of kinetics of welding stresses and strains. Kiev, Naukova Dumka [in Russian].

4. Makhnenko, V.I., Poznyakov, V.D., Velikoivanenko, E.A. et al. (2009) Risk of cold cracking in welding of structural highstrength steels. The Paton Welding J., 12, 2-6.

5. Yushchenko, K.A., Velikoivanenko, E.A., Chervyakov, N.O. et al. (2016) Effect of anisotropy of properties of nickel alloy on stresses and plastic deformations in weld zone. Ibid., 10, 2-7.

6. Finkel, V.M. (1970) Physics of fracture. Moscow, Metallurgiya [in Russian].

7. Nikolaev, G.A., Kutkin, S.A., Vinokurov, V.A. (1982) Strength of welded joints and deformations of structures. Moscow, Vysshaya Shkola [in Russian].

8. Vinokurov, V.A., Grigoryants, A.G. (1984) Theory of welding stresses and strains. Moscow, Mashinostroenie [in Russian].

9. Rykalin, N.N. (1951) Calculation of thermal processes in welding. Moscow, Mashgiz [in Russian].

10. Volobuev, Yu.V., Fedorov, V.G., Kuligin, G.B. (1983) Evaluation of influence of parameters of welding thermal cycle on austenitic grain size in heat-affected zone of steels of 12KhN4MA type. Svarochn. Proizvodstvo, 12, 6-8 [in Russian].

11. Shchetynin, S.V., Shchetynina, V.I. (2019) Method of electric arc surfacing of low-carbon steels. Ukraine Pat. 119594, Int. Cl. B23 K 9/04 [in Ukrainian].

Received 24.10.2019
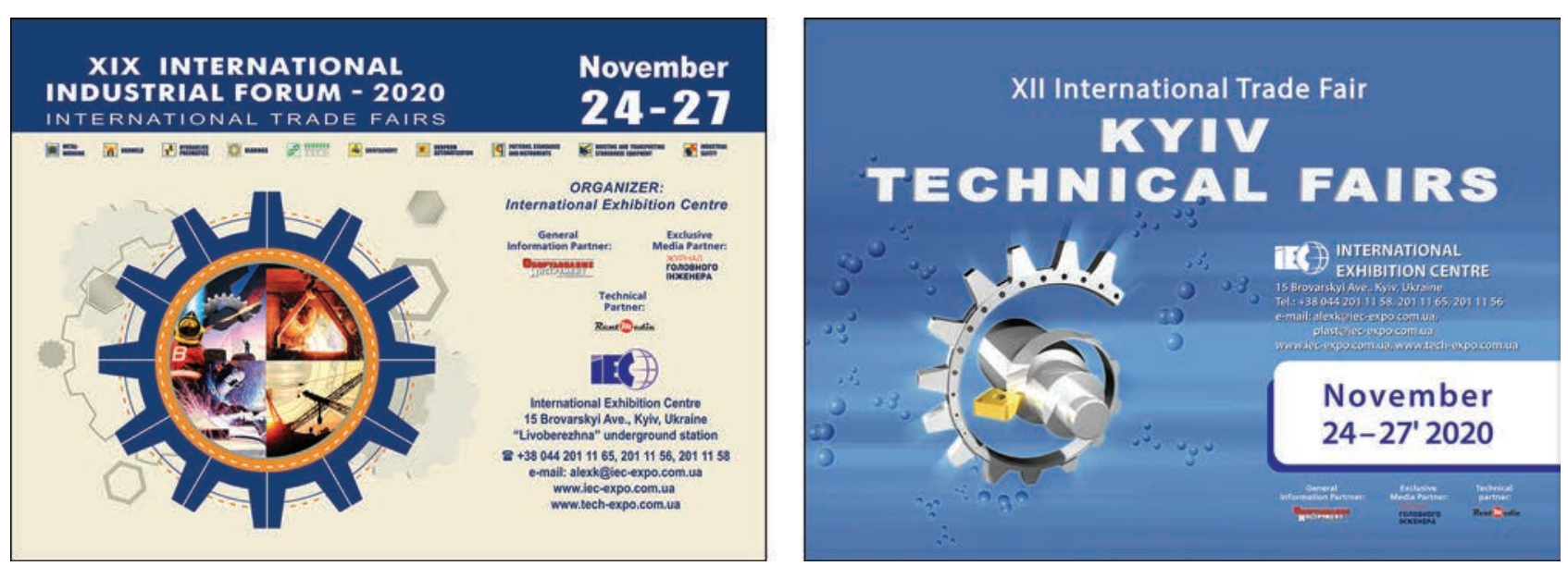


\title{
MICROSTRUCTURE OF TITANIUM ALLOYS PRODUCED BY THE METHOD OF LAYER-BY-LAYER ELECTRON BEAM SURFACING USING THE WIRE OF GRADE Ti6Al4V
}

\author{
V.M. Nesterenkov, M.O. Rusynyk, O.M. Berdnikova, V.A. Matviichuk and V.R. Strashko \\ E.O. Paton Electric Welding Institute of the NAS of Ukraine \\ 11 Kazymyr Malevych Str., 03150, Kyiv, Ukraine. E-mail: office@paton.kiev.ua
}

\begin{abstract}
The specimens of products of titanium alloy of various shapes using the wire of grade Ti6Al4V were produced by electron beam surfacing. In the deposited layers no defects were detected. In the course of the work, the investigations of microstructure, phase composition and mechanical properties of the specimens were carried out. For the deposited metal, the structure consisting mainly of lamellar-acicular a'-phase is typical. The structure contains a small amount of $\beta$-phase, which lies in the form of thin interlayers layers between the acicular precipitations of $\alpha^{\prime}$-phase. It is not detected using the optical microscope, however can be detected applying electron microscopy and X-ray examinations. The microstructure of the deposited metal is mostly equilibrium and granular, gradient in sizes and microhardness. The microhardness of the boundary zones differs from the microhardness of the grain matrix, which may be associated with the difference in the content of alloying elements. Towards the top of the built specimen, the hardness decreases slightly. 9 Ref., 1 Table, 9 Figures.
\end{abstract}

Ke y w ords: additive technologies, electron beam gun, electron beam surfacing, titanium alloy, metallography, microstructure, microhardness

Today, additive technologies is one of the promising areas that are rapidly developing in industrial production. The market of additive technologies consists of production of the equipment and its maintenance, development of the software, models of the future parts and creation of products according to drawings of the customer.

The additive equipment includes many software and hardware machines that perform various tasks and functions. Among them, manufacture of products according to the digital model applying the method of layer-by-layer deposition of consumables remains common [1].

Laser additive technologies have become the most widespread. However, to create large, material-intensive products like housings, an increased efficiency of layer-by-layer surfacing is required. In this case, it is most advantageous to use the energy of the electron beam, which is focused and supplied directly into the zone of alloy by the electron-optical system of the electron beam gun (EBG).

The use of electron beam additive technologies in aircraft and turbine construction, where light, chemically active materials based on aluminum and titanium are used, is especially relevant. The process takes place in vacuum, which allows surfacing a part without additional shielding gases, at the same time maintaining the purity of the original material.

In this work, the studied material was titanium Ti6Al4V alloy, produced by electron beam surfacing.
Titanium alloys are one of the main structural materials currently applied in various industries. Among titanium alloys Ti6Al4V is widespread. It is widely used in aerospace and medical fields. Namely in these industries the task of rapid and simple creation of a wide range of nomenclature products $[2,3]$ from Ti6Al4V alloy is set.

The aim of the work was to study microstructures and microhardness of specimens from Ti6A14V alloy made by layer-by-layer growing using electron beam additive technology by filler wire.

To achieve this aim, the following tasks were set in the work:

- holding the specimens welded in vacuum by the wire of grade Ti6Al4V;

- study of microstructure of the deposited specimens;

- measurement of microhardness of specimens.

Electron beam surfacing using wire. The surfacing technology consists in layer-by-layer deposition of metal in the form of a wire, which is melted by electron beam gun to produce a workpiece, the geometry of which is as close to the final product as possible. The advantage of the technology is a high speed of product manufacturing, which is up to $12 \mathrm{~kg} / \mathrm{h}$. The technology allows manufacturing large-sized metal products, including those of refractory and heat-resistant alloys with a high density and homogeneity [4]. 


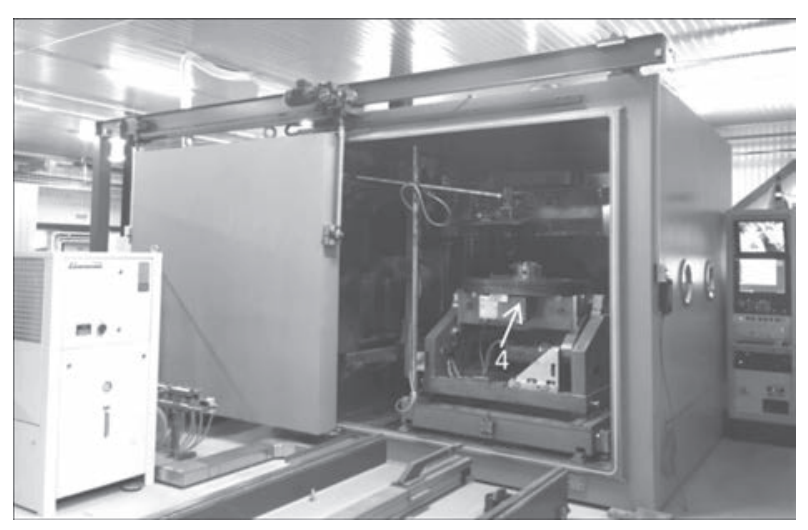

Figure 1. Electron-beam installation with mechanism for moving and feeding wire for surfacing

A high repeatability of the results of electron beam surfacing technology in combination with the flexibility of the process control allows forming parts with the required structure and specified properties. During the surfacing process, the electron beam creates a pool of the molten metal on the surface of a part. The part being deposited moves relative to the fixed electron gun and the filler wire feed mechanism, or the electron gun with the wire feed device moves relative to the fixed base $[5,6]$.

To manufacture product specimens, a wire with the diameter of $2 \mathrm{~mm}$ of grade Ti6Al4V was used. Surfacing was carried out in the electron beam installation equipped with the mechanism for moving and feeding wire (Figures 1, 2).

For investigations linear and cylindrical specimens were deposited.

The process of electron beam surfacing takes place in vacuum chamber (Figure 1). The wire is fed from the coil by electric motor with reducer through the guide channel 1 and the nozzle 2 to the surfacing zone (Figure 2). In the process of surfacing, the variable parameters are wire feed rate and beam current. The surfacing is layer-by-layer, after each pass the manipulator is risen to a set value in the coordinate $Z-Z$. The cylindrical specimen was produced by rotating the surface to be deposited 3 by means of the vertical rotator 4 (Figure 2, a) relative to the fixed EBG 5. The linear specimen was
Chemical composition of the wire Ti6Al4V, wt.\%

\begin{tabular}{|c|c|c|c|c|c|c|}
\hline $\mathrm{V}$ & $\mathrm{Al}$ & $\mathrm{Fe}$ & $\mathrm{N}$ & $\mathrm{O}$ & $\mathrm{H}$ & $\mathrm{C}$ \\
\hline $3.5-4.5$ & $5.5-6.75$ & 0.4 & 0.05 & 0.2 & $\leq 0.015$ & 0.08 \\
\hline
\end{tabular}

produced by moving EBG 5 with the wire feed manipulator relative to a rigidly fixed plate 6 .

Thus, the following specimens were produced: cylindrical - with a diameter of $70 \mathrm{~mm}, 30 \mathrm{~mm}$ height and a wall thickness of 9-10 $\mathrm{mm}$. And a linear one of $100 \mathrm{~mm}$ length, $40 \mathrm{~mm}$ height with a wall thickness of $7.8 \mathrm{~mm}$.

The chemical composition of the wire of Ti6Al4V alloy is given in the Table.

Metallographic examinations. To reveal microstructure, the polished sections of deposited specimens were etched in a special reagent for etching titanium and its alloys of the following composition:

- hydrofluoric acid - 1 part;

- nitric acid - 1 part;

- water - 1 part.

Metallographic examinations were carried out in the microscope «Neophot-32» at different magnifications. The digital images of microstructures were obtained with the help of the «Olympus» camera. The Vickers hardness of the examined metal was measured in the microhardness tester M-400 of the Company LECO at the loads of $1.0 \mathrm{~kg}(H V 10)$ throughout the entire height of the sections with a step of $500 \mu \mathrm{m}$ and $0.1 \mathrm{~kg}(H V 1)$ for detailed examinations of the structure.

Cylindrical specimen. The specimen consists of 14 layers of deposited metal (Figure 2). Metallographic examinations of the deposited metal show that the structure mainly consists of recrystallized grains of different sizes with different degrees of etching. In the areas of the deposited metal no microdefects were detected.

In the lower part of the specimen (Figure 3, layers 1-4) the grain structure is mainly uniform, but as to the grain size the structure is gradient: $D_{\mathrm{g}}(\mathrm{min})=$ $=500-700 \mu \mathrm{m} ; D_{\mathrm{g}}(\max )=1800-2000 \mu \mathrm{m}$. Figure 4, $a$ shows the change of the minimum and maximum grain sizes $\left(D_{\mathrm{g}}\right)$ and the length of the crystallites $\left(L_{\mathrm{cr}}\right)$ throughout the height of the specimen in the deposited layers.
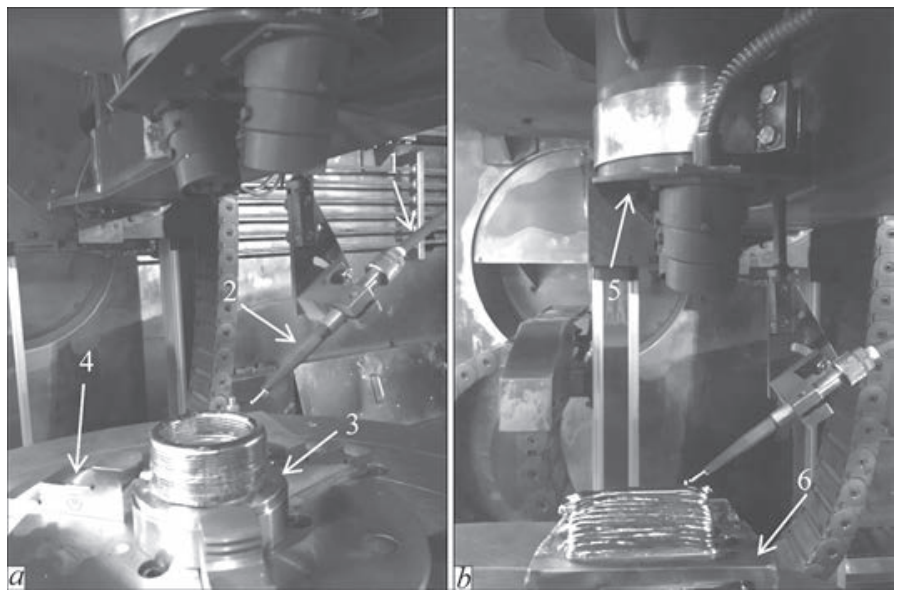

Figure 2. Specimens deposited by electron beam: $a$ - cylindrical; $b$ - linear 


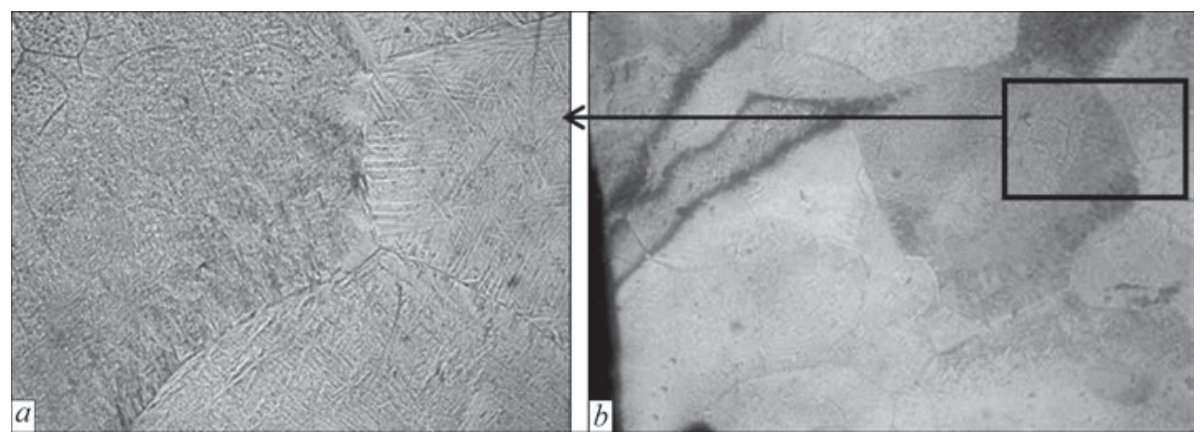

Figure 3. Microstructure of metal in the lower zone of the specimen: $a, b-$ fragments of microstructure: $a-\times 100 ; b-\times 25$

The hardness distribution is nonuniform. The values of hardness (HV10) and its change throughout the entire height of the cylindrical specimen are graphically shown in Figure 4, $b$.

During the transition to the next layers, the formation of large crystallites throughout the entire height of the specimen and a slight decrease in hardness with its relatively uniform distribution and characteristic values of HV10-2750-2820 MPa are observed (Figure 4, $b)$. It is established that in the recrystallized areas of the deposited metal the hardness is in the range from $H V 10-2600$ to HV10-3130 MPa (Figure 5). In a more detailed examination of the structure (at a magnification of $\times 100$ ) the following was established. For the deposited metal, the structure is characteristic, consisting mainly of a lamellar-acicular $\alpha^{\prime}$-phase (Figures 5, 6).
In the boundary zones of $\alpha^{\prime}$-phase, the etchability of which is weaker than the grain matrix, the hardness amounts to HV1-2870-3660 MPa. The microhardness of the boundary zones differs from the microhardness of the grain matrix, which may be associated with the difference in the composition of the alloying elements [4].

According to [7], the structure obviously contains a small amount of $\beta$-phase, which lies in the form of thin interlayers between the acicular precipitations of $\alpha^{\prime}$-phase and is not detected by optical microscope, but is determined by electron microscopy and X-ray examinations.

In deposition of the surfacing layers, as a result of heat treatment, throughout the height of the specimen, the structure represents large crystallites with a homogeneous lamellar-acicular structure of $\alpha^{\prime}$ - phase at the microhardness HV1-2830-3220 MPa. The sizes and
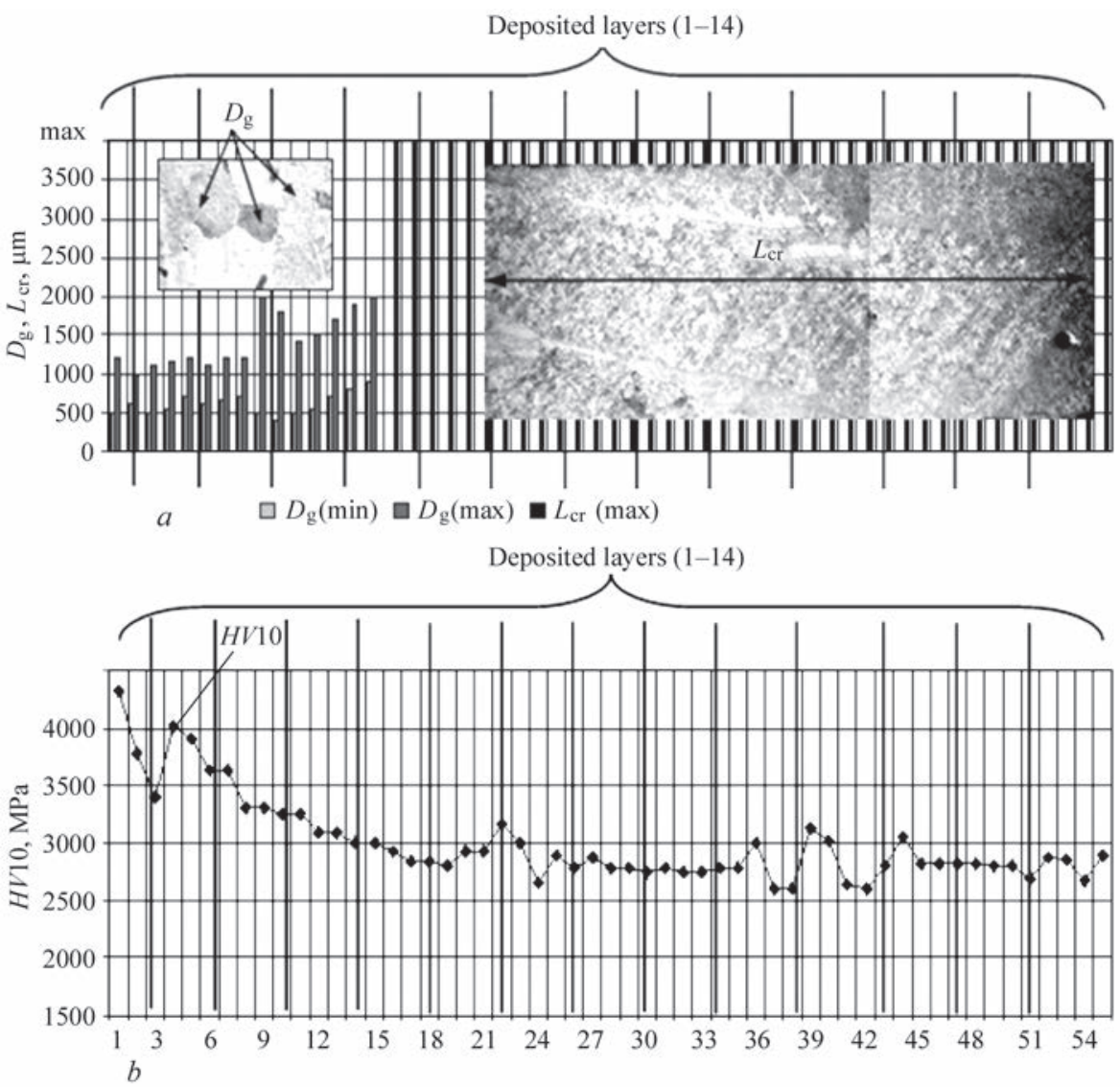

Figure 4. Change of structural parameters in the deposited layers: $a$ - grain size $\left(D_{\mathrm{g}}\right) ; b$ - microhardness $(H V 10)$ 


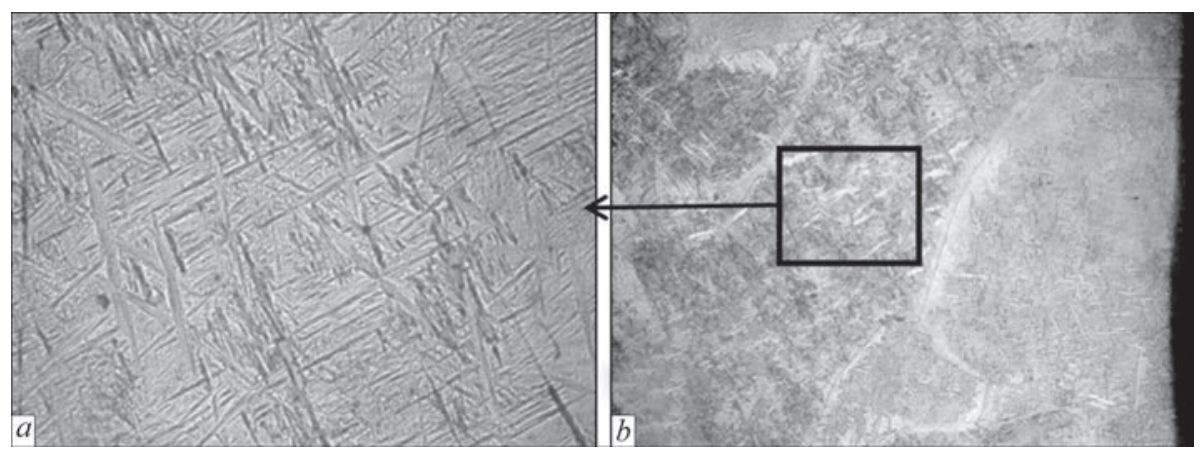

Figure 5. Microstructure of metal in the middle part of the specimen: $a, b-$ fragments of microstructure: $a-\times 100 ; b-\times 25$

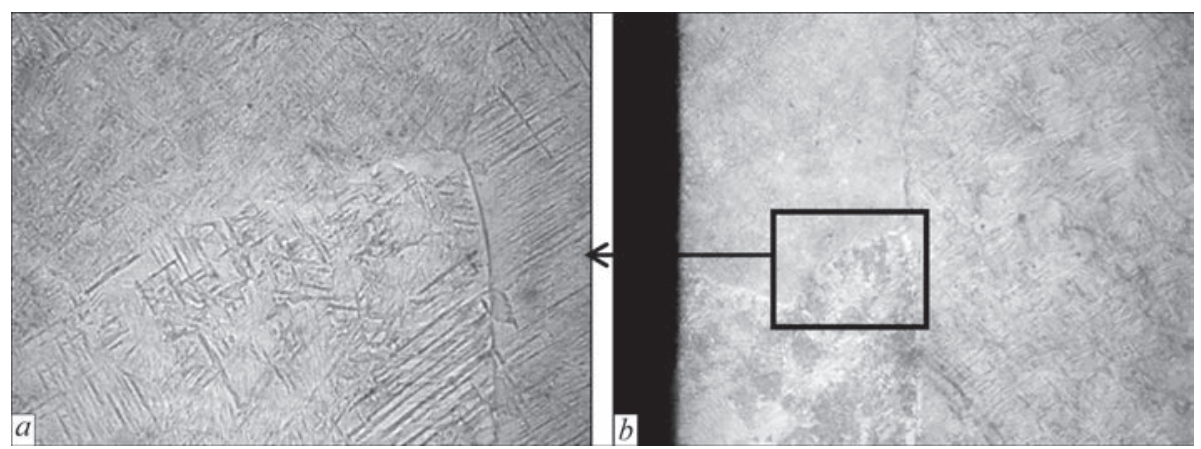

Figure 6. Microstructure of metal in the upper zone of the specimen: $a, b-$ fragments of microstructure: $a-\times 100 ; b-\times 25$

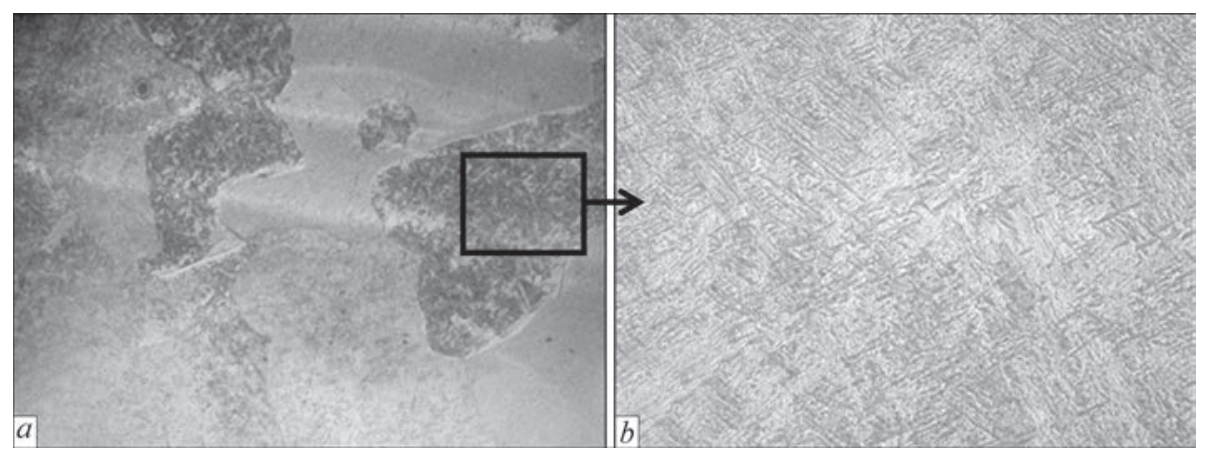

Figure 7. Microstructure of metal in the lower zone of the linear specimen: $a, b-$ fragments of microstructure: $a-\times 25 ; b-\times 200$ a shape of needles and plates depend on the purity and cooling rate of the metal [8]. The middle layer of the deposited metal is characterized by a thickening of the acicular component of $\alpha^{\prime}$-phase (Figure 5). It is known that with decreasing cooling rate the acicular precipitations of $\alpha^{\prime}$-phase are thickened [7].

Linear specimen. Surfacing consists of 12 layers (Figure 2, b). No structural defects were detected.

Metallographic examinations of the deposited metal showed that as well as in the cylindrical specimen, the structure consists of recrystallized grains of different sizes with different degrees of etchability.

In the lower part of the specimen (Figure 7, layers $1-8)$ the grain structure has a mixed character: relatively equilibrium grains and grains of irregular shape.

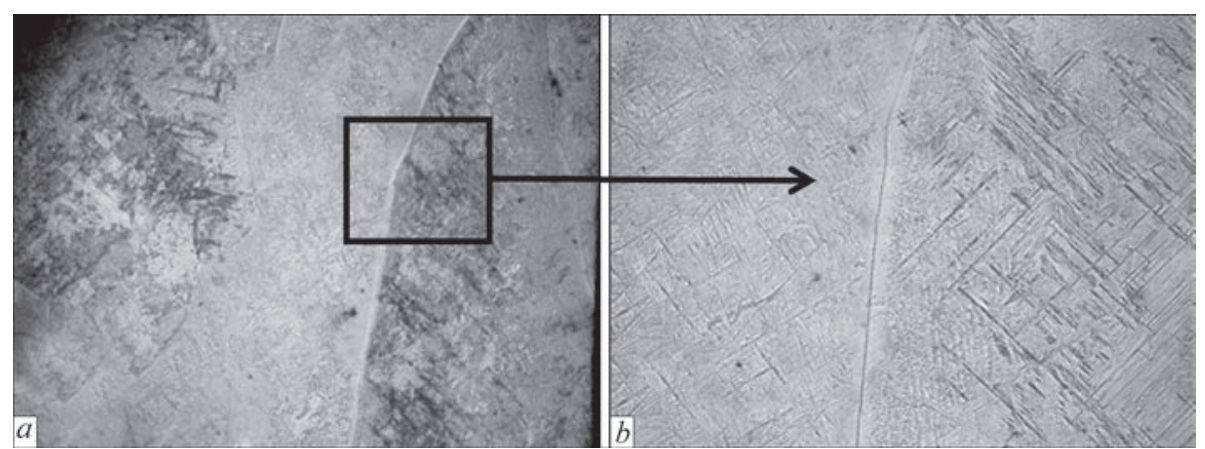

Figure 8. Microstructure of metal of the linear specimen in the upper zone: $\mathrm{a}, \mathrm{b}-$ fragments of microstructure: $a-\times 25 ; b-\times 100$ 

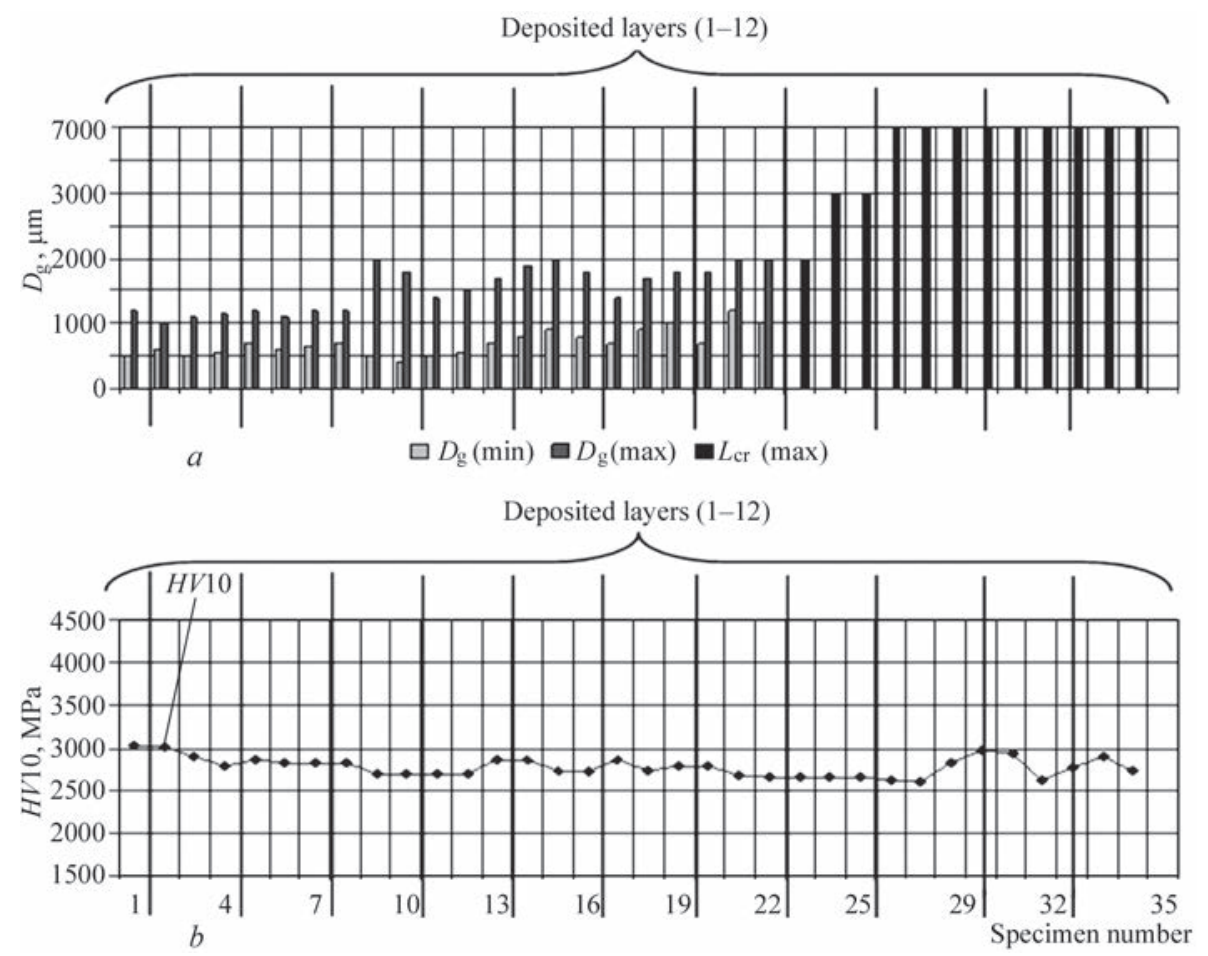

Figure 9. Change of structural parameters in the deposited layers: $a$ - grain size $\left(D_{\mathrm{g}}\right) ; b$ - microhardness $(H V 10)$

The grain size $\left(D_{\mathrm{g}}\right)$ in this zone is about $D_{\mathrm{g}}=$ $=500-1600 \times 700-4000 \mu \mathrm{m}$. The distribution of microhardness is relatively uniform. During the transition to the next layers (9-12), the formation of large crystallites of the size up to $h \times L_{\text {cr }}=2000 \times 7000 \mu \mathrm{m}$ is observed (Figures 8, 9,a).

The values of hardness (HV10) and its change throughout the entire height of the linear specimen are shown in (Figure 9, b). In the lower layer HV10$3030 \mathrm{MPa}$. At the transition to the next layers the hardness slightly decreases to HV10-2790-3010 MPa. It was established that the hardness throughout the entire height of the deposited metal is in the range from HV10-2630 to HV10-2930 MPa.

During a detailed examination of the deposited metal (magnification $\times 100$ ) it was found that the structure consists of a lamellar-acicular $\alpha^{\prime}$-phase (Figures 7, 8). The microhardness in the inner volumes of the grain structure is HV1-2210-2970 MPa. In the boundary zones of grains there are no areas with a low etchability. Their structure is the same as the grain matrix. This indicates the absence of chemical heterogeneity in the local areas of the structural components [7].

\section{Conclusions}

1. The applied technology of multilayer surfacing allows producing structure of cast metal without defects in the deposited layers.

2. Investigations of the structure of multilayer surfacing showed that in the lower layers mostly equilibrium grain structure is formed, gradient in sizes and microhardness ( $H V 1)$.
3. Massive crystallites are formed throughout the entire height of the investigated specimens (except for the lower layers). The inner lamellar-acicular structure of $\alpha^{\prime}$-phase grains is homogeneous and larger than in the lower layers.

1. Iliin, A.A., Kolachev, B.A., Polkin, I.S. (2009) Titanium alloys. Composition, structure, properties: Manual. Moscow, VILS-MATI [in Russian].

2. Al-Bermani, S.S., Blackmore, M.L., Zhang, W, Todd, I. (2010) The origin of microstructural diversity, texture, and mechanical properties in electron beam melted Ti-6Al-4V. Metallurg. and Mater. Transact. A, 41(13), 3422-3434. doi:10.1007/s11661-010-0397-x

3. Popov, A.A., Illarionov, A.G., Rossina, N.G., Grib, S.V. (2013) Physical metallurgy and heat treatment of titanium alloys. Structure and properties: Manual. Ekaterinburg, UrFU [in Russian].

4. Zhukov, V.V., Grigorenko, G.M., Shapovalov, V.A. (2016) Additive manufacturing of metal products (Review). The Paton Welding J., 5-6, 137-142.

5. Matviichuk, V.A., Nesterenkov, V.M., Rusynik, M.O. (2018) Application of additive electron-beam technologies for manufacture of metal products. Electrotechnica \& Electronica $E+E, \mathbf{3 - 4}, 69-73$.

6. Nesterenkov, V.M., Matviichuk, V.A., Rusynik, M.O. (2017) Principles of production of commercial items by rapid prototyping using electron beam technologies. In: Proc. of $8^{\text {th }}$ Int. Conf. on Beam Technologies in Welding and Materials Processing LTWMP (Odessa, 11-5 September, 2017), 73-77.

7. Grabin, V.F. (1975) Principles of physical metallurgy and heat treatment of welded joints of titanium alloys. Kiev, Naukova Dumka, 263 [in Russian].

8. Zamkov, V.N. (1986) Metallurgy and technology of welding of titanium and its alloys. Kiev, Naukova Dumka [in Russian]. 


\title{
AUTOMATIC ARC WELDING IN MANUFACTURE AND RENOVATION REPAIR OF PIPE ELEMENTS OF SPIRALS OF HIGH-PRESSURE HEATERS OF NPP POWER UNITS
}

\author{
L.M. Lobanov ${ }^{1}$, N.M. Makhlin², V.Ye. Popov ${ }^{2}$, D.S. Oliyanenko ${ }^{2}$ and O.V. Kovalyuk ${ }^{3}$ \\ ${ }^{1}$ E.O. Paton Electric Welding Institute of the NAS of Ukraine \\ 11 Kazymyr Malevych Str., 03150, Kyiv, Ukraine. E-mail: office@paton.kiev.ua \\ ${ }^{2} \mathrm{SE}$ «Scientific and Engineering Center of Welding and Control in the Field of Nuclear Energy of Ukraine \\ of E.O.Paton Electric Welding Institute of the NAS of Ukraine \\ 11 Kazymyr Malevych Str., 03150, Kyiv, Ukraine. E-mail: electro@paton.kiev.ua \\ ${ }^{3} \mathrm{SE}$ «Atomenergomash» of the SE NNEGC «Energoatom» \\ 52 Promyslova Str., 71503, PO Box 306, \\ Energodar, Zaporizhzhia Region, Ukraine. E-mail: office@aem.zp.ua
}

\begin{abstract}
The paper considers the possibility for applying automatic orbital welding using nonconsumable electrode in helium or plasma welding using the methods of autopressing or successive penetration to produce welded joints of pipe elements of spirals in high-pressure heaters. The results of testing this technology and the optimal modes of producing position welded joints of pipe elements in spirals of high-pressure heaters of NPP power units are presented. A description of technical proposals on creation of domestic welding equipment for implementation of the proposed technology was presented. It is shown that the use of the developed technology applying domestic equipment can significantly increase the labour efficiency when producing welded joints of pipe elements in spirals of high-pressure heaters and significantly improve their quality. 13 Ref., 3 Figures.
\end{abstract}

Keywords: high-pressure heaters, spirals of high-pressure heaters, automatic orbital welding, nonconsumable electrode, autopressing or successive penetration, constricted arc, helium arc or plasma welding, position butt joints of pipelines, plasmatron

Pipelines (including high-pressure ones) of NPP power units with WWER light-water reactors, as well as with reactors with boiling water are operated, as a rule, in the conditions of simultaneous exposure to high temperatures, elevated pressure, significant masses of water and/or water steam, as well as penetrated radiation. High-pressure pipelines can also include pipe structures of spirals of high-pressure heaters (HPH), which are important, fundamentally necessary and critical elements of the second circuit of NPP power units. The feed water, entering HPH spirals under pressure, is heated to the required temperature, after which this water enters the heat exchanger - steam generator (SG), where it is converted into steam, supplied to the turbine, which drives electric generators of the NPP power unit [1-3]. The characteristic features of HPH spirals are the presence of welded joints of pipe elements of spirals, as well as the parameters of the medium - feed water, supplied to the spiral at a rated pressure of $12.0 \mathrm{MPa}\left(120 \mathrm{kgf} / \mathrm{cm}^{2}\right)$, where this water is heated to a temperature of $235{ }^{\circ} \mathrm{C}$, as a result of which in the course of HPH operation the welded joints of their spirals undergo corrosion-erosion wear. Therefore, designing, manufacture and re- pair of HPH spirals have their own specifics [3, 4], which determines the technical requirements to the material, design and welded joints of HPH. There are single- and double-plane designs of HPH spirals, but single-plane spirals are the most widespread.

As to its design, the HPH spiral consists of three pipe elements joined by two welded butt joints. The billets for these elements are lengthy sections of a pipe with a rated diameter of $32 \mathrm{~mm}$ and a rated wall thickness of $4.0 \mathrm{~mm}$ of carbon steel 20. The length of one of the straight sections («central»), which are used as billets for pipe elements of HPH spiral, is $7000 \mathrm{~mm}$, the other two straight sections are 5980 and $5403 \mathrm{~mm}$, respectively, while the «central» section has an area with a S-shaped bend, which, according to the design documentation (DD), is produced before welding, which leads to different spatial positions of longitudinal axes of different areas of this section. All the abovementioned sections on the side of their ends have a V-shaped opening 1-24-1 (C-24-1), which is formed by means of a preliminary machining treatment. After producing welded joints of pipe elements, carrying out their heat treatment and non-destructive testing, from the pipe structure, produced in such a way by means of 
a special device, the spiral structure proper is formed. To the direct inlet and outlet areas of this structure, shanks are welded-on and heat treatment and non-destructive testing of its welded joints are carried out.

Until now, during manufacture and renovation repair of HPH spirals even in the factory conditions in order to produce welded joints of these spirals in domestic practice only manual multipass argon arc welding (TIG) with filler wire feed is used, the main problems of which are insufficient efficiency of these technological processes, impossibility in maintaining stability of quality of welded joints due to its dependence on the «human» factor, need in training and attractment of experienced high-skilled welders. Therefore, providing the growth of welding efficiency and stability of quality of welded joints of HPH spirals during their manufacture and renovation repair at domestic enterprises through the use of automatic or mechanized welding represents an urgent scientific and technical task.

To solve this problem, the possibilities of using various methods of arc welding, including automatic orbital welding using nonconsumable electrode in argon (GTAW), manual and automatic orbital welding using nonconsumable electrode in argon with activating fluxes (ATIG and GTAW-A respectively) and mechanized (automatic) welding using consumable electrode in mixture of shielding gases were previously investigated and analyzed [4]. During these investigations, it was taken into account that according to the Rules and Norms in the nuclear power engineering (PN AE) and other standard documents in Ukraine, welded joints of pipe elements of HPH spirals in the state of straight sections of pipes with a rated diameter of $32 \mathrm{~mm}$ and a rated wall thickness of $4.0 \mathrm{~m}$ and the opening of the edges being 1-24-1 (C-24-1) of steel 20 should be produced with a complete $(100 \%)$ penetration with a maximum reinforcement $(2.0 \pm 1.0) \mathrm{mm}$ and the convexity of the root weld of not more than $1.5 \mathrm{~mm}$ or its concavity, which does not exceed $0.6 \mathrm{~mm}$. The displacement of edges of pipe elements of $\mathrm{HPH}$ spirals should not exceed $0.4 \mathrm{~mm}$, and according to PN AE G-7-010-89, welded joints of these pipe elements can be classified as the category III (subcategory IIIc). In accordance with the results of the previous investigations, it was experimentally established that it is fundamentally impossible to achieve the required stable quality of welded joints of HPH spirals and their $100 \%$ penetration by using GTAW process applying the methods of autopressing or successive penetration, developed already in the 1970s and 1980s in the Research and Design Institute of Assembly Technologies (NIKIMT) [5, 6]. Most likely, this is explained by the fact that, firstly, steels of pearlite class (to which steel 20 belongs) as compared to the steels of austenite class are characterized by a much lower coefficient of linear expansion and a significantly higher thermal conductivity, which makes it impossible to provide sufficient compressive forces for the necessary thermoplastic deformations. Secondly, the rated wall thickness of HPH spiral pipeline is $4.0 \mathrm{~mm}$, and the ratio of the wall thickness $S$ to the rated outer diameter of the pipeline $\mathrm{D}_{\mathrm{p}}$ is only 0.125 , i.e. close to the lower limit of applicability of GTAW applying the methods of autopressing or successive penetration $[5,6]$. It was also found that the most effective way to produce welded joints of HPH spirals, as well as other high-pressure pipelines of NPP units, is mechanized multipass arc welding using consumable electrode in shielding gas mixture (it was found that to produce high-quality pipe joints of HPH spirals two welding passes are enough) [4]. However, it should be noted that the proposed technology can be implemented only in the case of using a stationary torch, rotary butts of welded products and innovative technological equipment.

According to the requirements of the effective DD on HPH, welded joints of pipe elements of their spirals are subjected to $100 \%$ non-destructive and selectively destructive testing. Among the non-destructive methods of testing the use of visual-instrumental control (VIC) and radiographic testing (RT) are envisaged [7]. In compliance with the corresponding requirements of the effective production and technical documentation (PTD) and DD on these products, during a selective destructive testing of welded joints of pipe elements of HPH spirals, the check of chemical composition of weld metal and determination of mechanical properties of welded joints as well as metallographic examinations are carried out.

Based on this, in the course of experimental and technological investigations, namely these non-destructive and destructive testing methods were used, and to perform testing by VIC and RT methods, metallographic examinations, mechanical tests and determination of chemical composition of weld metal and heat-affected-zone, the personnel of the department of the chief welder and the metal inspection service SE «Atomenergomash», SE «NNEGC Energoatom» were attracted, as well as the certified standard means available at them.

The analysis of the previously proposed technical solutions and practice have convincingly proved that the implementation of mechanized arc welding of rotary welded joints of HPH spirals using consumable electrode in shielding gas mixture is a rather complex task, which in the vast majority of cases is difficult to perform as far as it requires a complicated and expensive complex of technological equipment for its implementation, where one of the most important basic components is an innovative horizontal rotator [8].

Therefore, at PWI together with the Scientific and Engineering Center of welding and control in the field of nuclear energy additional investigations were conducted to determine the possibility of using constricted arc welding methods for automatic orbital welding 
of position butts by the methods of autopressing or successive penetration.

The method of helium arc welding is a variety of welding using nonconsumable electrode and it has much in common with argon arc welding using nonconsumable (tungsten) electrode (TIG). The main disadvantage of argon arc TIG and hence GTAW is a free-burning arc, which (especially at low currents) is characterized by a low stability in time and space and a low current density in the anode spot. As the current grows, the diameter of the column of a free burning arc increases, and the concentration of a thermal power on a welded product decreases, which causes an increase in the width of the weld and heat-affected zone (HAZ). In addition, moving away from the tungsten electrode, the temperature of the column of a free burning arc decreases sharply, due to which its ability to penetrate noticeably decreases [9-12]. Therefore, in the case of TIG, and hence GTAW, in order to achieve stability of weld quality, it is necessary to clearly maintain in advance the predetermined values of length of welding arc, which requires the necessary presence of devices and mechanisms or mechanical arc length stabilization systems (ALS) or electronic devices and mechanisms that provide automatic arc voltage regulation (AAVR) in the design of welding heads for GTAW.

The mentioned drawbacks of a free-burning argon arc are excluded during an intense constriction (contraction) of welding arc, which can be achieved in different ways. The most common among them is the use of helium as a shielding gas or a special torch - a plasmatron with a separate supply of plasma-forming and shielding gases and the mandatory presence of a low-power auxiliary («pilot») arc that burns between the electrode and the plasmatron nozzle $[11,12]$. The process of welding by constricted arc with the use of plasmatron was called "plasma welding». The column of the constricted plasma arc, which has a temperature of $20000 \mathrm{~K}$ and higher, is rigidly stabilized along the axis of the nonconsumable electrode. A high concentration of heat flow of this column on a welded product allows producing welded joints with a deep penetration and a relatively small width of the weld and the HAZ with increasing welding speed, resulting in an increased quality of welded joints. Increasing the guaranteed penetration depth by several times as compared to a free-burning arc allows joining metals of up to $30 \mathrm{~mm}$ thickness in a one pass (at the corresponding values of the main arc current and consumption of plasma-forming and shielding gases), and is much higher than that of a free-burning arc, the spatial stability of a constricted arc - to simplify the equipment for automatic welding, because in the case of a constricted arc the need in such devices and mechanisms as ALS or AAVR that support the set values of arc length or voltage constant during the welding process is eliminated $[11,12]$. The separate supply of plasma-forming and shielding gases makes it possible to use various mixtures of gases during welding (including those with enriched chemically active gases, which is excluded in the case of a free-burning arc). The use of a low-power auxiliary («pilot») arc provides the stability of welding process in an extremely wide range of welding currents, including their rather small values - up to $0.1 \mathrm{~A}$, which allows welding metals of such small thicknesses that are unattainable with TIG, - up to $0.01 \mathrm{~mm}$ thick.

In the vast majority of cases, helium arc and plasma welding is performed by an arc of direct polarity («minus» on the electrode) in continuous or pulsed modes or in a mode of welding current modulation, which burns between the tungsten electrode of the torch for TIG or GTAW or the plasmatron and a welded product (in plasma welding - jets of plasma-forming gas usually argon). Depending on the physicochemical properties of welded metal, to prevent the interaction of the molten pool of a liquid metal and the near-weld zone with the atmosphere in the case of plasma welding on the periphery of the arc a shielding gas: argon, helium, $\mathrm{CO}_{2}$, mixtures of argon with hydrogen, argon with helium, argon with nitrogen and other mixtures is supplied $[11,12]$. As the current source of the main (welding) arc, an adjustable rectifier of inverter or thyristor type with steeply descending (preferably with «vertical») external volt-ampere characteristics (VACh) and control of the pulse-width modulation method (PWM) is used. As a current source of a low-power auxiliary («pilot») arc, usually a low-power rectifier, which is not regulated or regulated stepwise (also with steeply falling VAChs) is used, which is made in the form of a diode rectifier or converter or of the type AC-DC or DC-DC - power (250-500) V·A.

The sequence of stages of the cycle of automatic orbital helium arc or plasma welding, which is shown in Figure 1, is the following.

When the welding head of the automatic machine for orbital helium arc or plasma welding is mounted on a welded product and fixed on it, the cycle of these welding methods begins after the START signal with the time interval «gas before welding» («pregas») is supplied, during which the supply of shielding gas to the torch for helium-arc welding or supply of plasma-forming and shielding gases to the plasmatron and their free laminar flow from them are provided.

At the end of the specified time interval by means of a special device (exciter) a noncontact ignition of the main arc (in the case of helium arc welding), or auxiliary («pilot») arc (in the case of plasma welding) occurs, which burns between the nonconsumable (tungsten) electrode (with the arising of these arcs, i.e. at the establishment of a stable arc discharge, the exciter automatically switches off), which causes either the excitation of the main arc (in the case of helium arc welding) or blowing of a plasma flame from the 


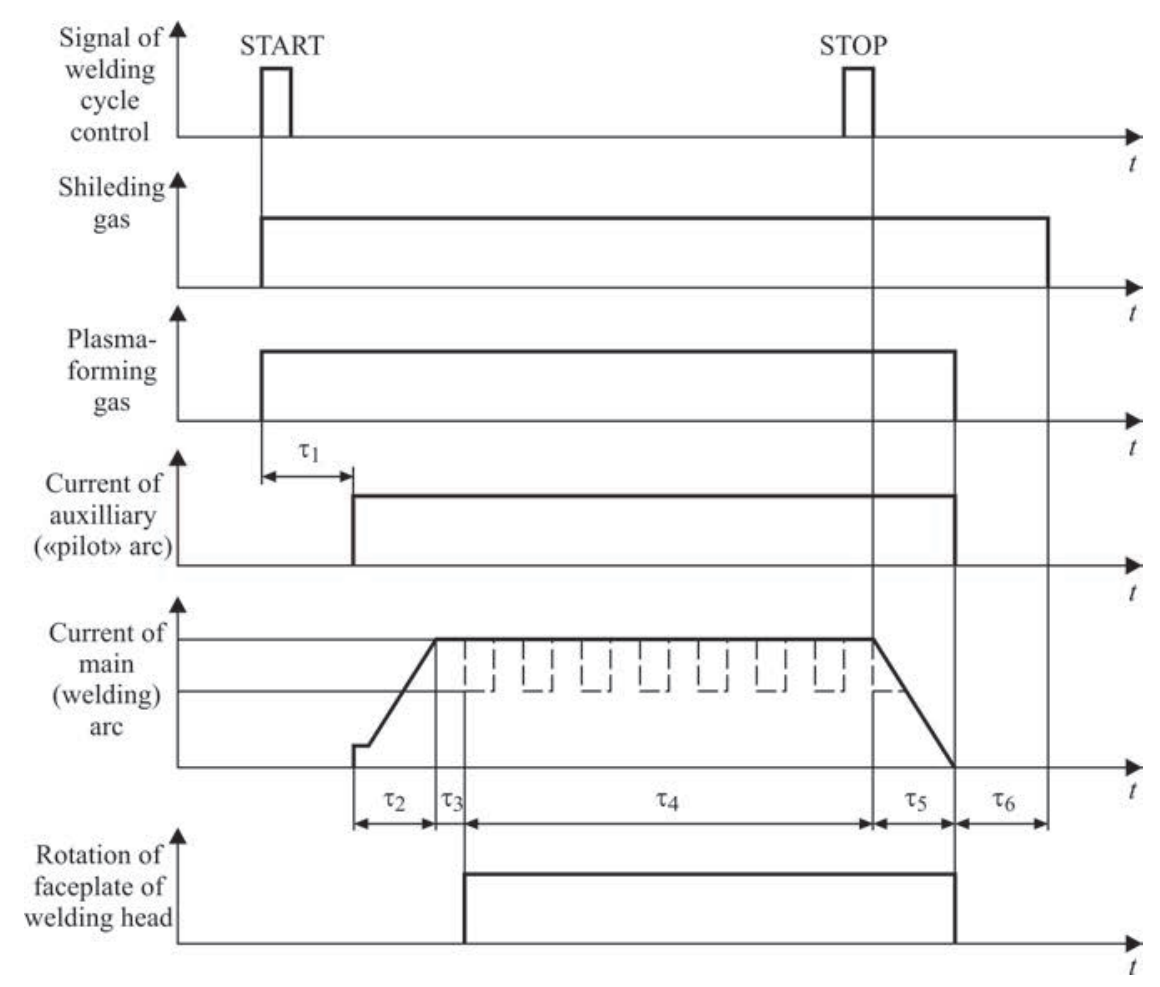

Figure 1. Cyclogram of the process of automatic orbital helium arc or plasma welding of position butts of pipe elements of HPH spirals of NPP power units: $t_{1}$ - time interval «gas before welding» («pregas»); $t_{2}$ - time interval «smooth increment» of the main (welding) arc current; $t_{3}$ - time interval «heating-up»; $t_{4}$ — time interval during which welding proper takes place; $t_{5}$ — time interval «smooth extinction»; $t_{6}$ - time interval «gas after welding» («postgas»)

plasmatron. At the same time, in the installation for plasma welding, the open-circuit voltage in the current source of the main (welding) arc is switched on, which is excited at the lowest value in the range of welding current control when the surface of a welded product is touched with a flame from the plasmatron.

During the time interval «smooth increment» the welding current gradually increases from the smallest value of the control range to its preliminary set (programmed) operating value, which eliminates the electrodynamic impact on the nonconsumable electrode of the torch for helium arc welding or plasmatron («shock» of the electrode).

At the moment of ending the time interval «smooth increment» the time interval «heating-up» begins, during which the formation of a molten pool of liquid metal on a welded product is provided, and the duration of this time interval is much shorter as compared to a free-burning arc. At the moment of ending the time interval «heating-up» on the electric drive of the rotator of the welding head, a signal of permission is automatically supplied and the faceplate of this head with the torch or plasmatron fixed on it begins rotating around the position butt of a high-pressure pipeline with a preliminary set (programmed) and stabilized speed (welding speed), while the welding current either remains unchanged or changes in accordance with a predetermined (programmed) pulsed mode, and in the latter case at the moment of ending the time interval «heating-up» a pause of welding current begins.
From the moment of ending the welding proper the STOP signal is supplied automatically (or manually) and during the time interval «smooth extinguishing» a smooth drop of welding current from operating to practically zero value begins. Thus, if the pulsed mode or the mode with modulation of welding current is provided, then, starting from the moment of reaching the equality of welding current values in a pulse and a pause, welding current will drop synchronously. At the same time both rewelding of a crater, as well as «overlapping» of an initial area of welding are provided, and at the moment of ending the time interval «smooth extinguishing» during plasma welding, the current of an auxiliary («pilot») arc is also automatically switched off, and also rotation of the faceplates of the welding head and the supply of a plasma-forming gas to the plasmatron are stopped. In addition, the time interval «gas after welding» («postgas») begins, during which the welding zone is blown with a shielding gas. At the moment of ending this time interval, the welding cycle is completely finished.

The functional-block diagram of the installation for automatic orbital plasma welding, designed at the Scientific and Engineering Center of welding and control in the field of nuclear energy, is shown in Figure 2. The installation is based on the domestic automatic machines ADTs 625 U3.1 and ADTs 628 UKhL4 for GTAW previously designed at PWI together with the Scientific and Engineering Center of welding and control in the field of nuclear energy. The 
functional-block diagram of the hardware-software complex for automatic orbital helium arc welding is given in [13] and does not differ from the diagram of the complex for automatic orbital argon-arc welding.

When in PWI together with the Scientific and Engineering Center of welding and control in the field of nuclear energy additional invesitgations were carried out to determine the possibility of using welding position joints of pipe elements of HPH spirals of NPP power units by a constricted arc, the specimens-simulators of pipe elements of HPH spirals of steel 20 with a rated outer diameter of $32.0 \mathrm{~mm}$ and a wall thickness of $4.0 \mathrm{~mm}$ were used, the ends of which were treated in accordance with the requirements to welded joints of type 1-21-1 (C-21-1) and 1-21-2 (C-39), which are regulated by PN AE G-009-89, PN AE G-010-89 and OST 24.125.02-89.

To conduct investigations on the specimens-simulators of HPH pipe elements of $(32 \times 4) \mathrm{mm}$, a model of an experimental installation was created, which included a modified model of the automatic machine ADTs 625 U3.1 for GTAW, the unit of autonomous cooling of the experimental model of the automatic machine ADTs $628 \mathrm{UKhL} 4$ for GTAW, experimental model of the installation UMPDS-0605 UKhL4 for arc and microplasma welding using nonconsumable electrode and two current sensors - the main and auxiliary («pilot») arc, based on the Hall effect. The power part of the power source (power sources of the main (welding) arc), welding head ADTs 625.03.00.000 (where in the case of plasma welding instead of the standard torch for welding using nonconsumable electrode in inert gases the plasmatron Yu7M3. 045.011-01 with a liquid (water) cooling was installed, control system of the experimental model of the automatic machine ADTs 625 U3.1 for GTAW and the experimental model of the autonomous cooling unit BVA-02 was installed. The basic parameters of the automatic machine ADTs 625 U3.1 for GTAW are given in [13].

The ends of the specimens-simulators of pipe elements of HPH spirals of steel 20, prepared for experimental welding in accordance with the requirements of standard documents, were subjected to automatic orbital helium arc and plasma welding using the methods of autopressing or successive penetration. Previously, applying the TIG method two or three tacks were produced for each weld, for which an experimental model of a specialized power source ITs 617 U3.1 for GTAW or TIG was used. For experimental welding of position butt joints of specimens-simulators of high-pressure pipe elements of $(32 \times 4) \mathrm{mm}$ of HPH spirals, the modernized experimental models of the installation UMPDS-0605 UKhL4 and the power source ITs 617 U3.1, as well as the automatic machines ADTs 625 U3.1 and ADTs 626 U3.1 for GTAW, the control sys- tems of these devices and the experimental model of the plasmatron U7M3.045.011-01 were used.

According to the results of several series of experimental welding it was established that:

- butt welded joints of specimens-simulators of high-pressure pipe elements of HPH spirals of NPP power units with WWER type reactors, produced using automatic orbital helium arc or plasma welding, provide the required penetration depth (Figure 3) and have almost no unacceptable defects, spattering and splashes of a welded product, which allows not only a significant (at least 6-8 times) increase in efficiency (as compared to the existing technology), but also a great simplification and reduction in the cost of both preparation for welding as well as for technological equipment to produce the abovementioned welded joints (as compared to the technological equipment for mechanized arc welding using consumable electrode in a mixture of shielding gases). Moreover, a constricted arc welding completely meets the requirements of $\mathrm{PN} \mathrm{AE}$ G-009-89, PN AE G-010-89 and OST 24.125.02-89;

- the use of automatic orbital helium arc or plasma welding to produce welded joints of pipe elements of HPH spirals of NPP power units with WWER-type reactors is an energy-saving process, because the implementation of the abovementioned welding methods requires welding current (main arc current), which is 1.3-2.0 times lower than during welding using free-burning argon arc;

- to produce high-quality welded joints of $\mathrm{HPH}$ spiral pipe elements of NPP power units by means of automatic orbital helium arc or plasma welding using the methods of autopressing or successive penetration, the optimal range of welding modes should have the following values of parameters: in case of welding position butt joints of pipe elements of HPH spirals $(32 \times 4)$, the current of the main arc (welding current) should be in the range from 65 to $80 \mathrm{~A}$, the current of the auxiliary («pilot») arc during plasma welding should be in the range from 3 to $7 \mathrm{~A}$, arc voltage should be in the range from 14 to $16 \mathrm{~V}$ during helium arc welding and from 9 to $11 \mathrm{~V}$ during plasma welding, the length of the main arc should be in the range from 0.5 to $1.1 \mathrm{~mm}$ during helium arc welding and from 3 to $6 \mathrm{~mm}$ during plasma welding, the speed of rotation of the faceplate of the welding head should be from 7 to $10 \mathrm{rpm}$, the number of full-ring passes should be 1-2. The installation (complex) for automatic orbital helium arc welding of joints of HPH spiral pressure elements of NPP power units should at least include the main arc current source (mainly of inverter type) with steeply falling (preferably «vertical») VAChs, a torch mounted on the faceplate of the welding head, modified welding heads ADTs 625.03.00.000 (with the own rotator and controller), welding cycle control unit (WCCU) to control the 


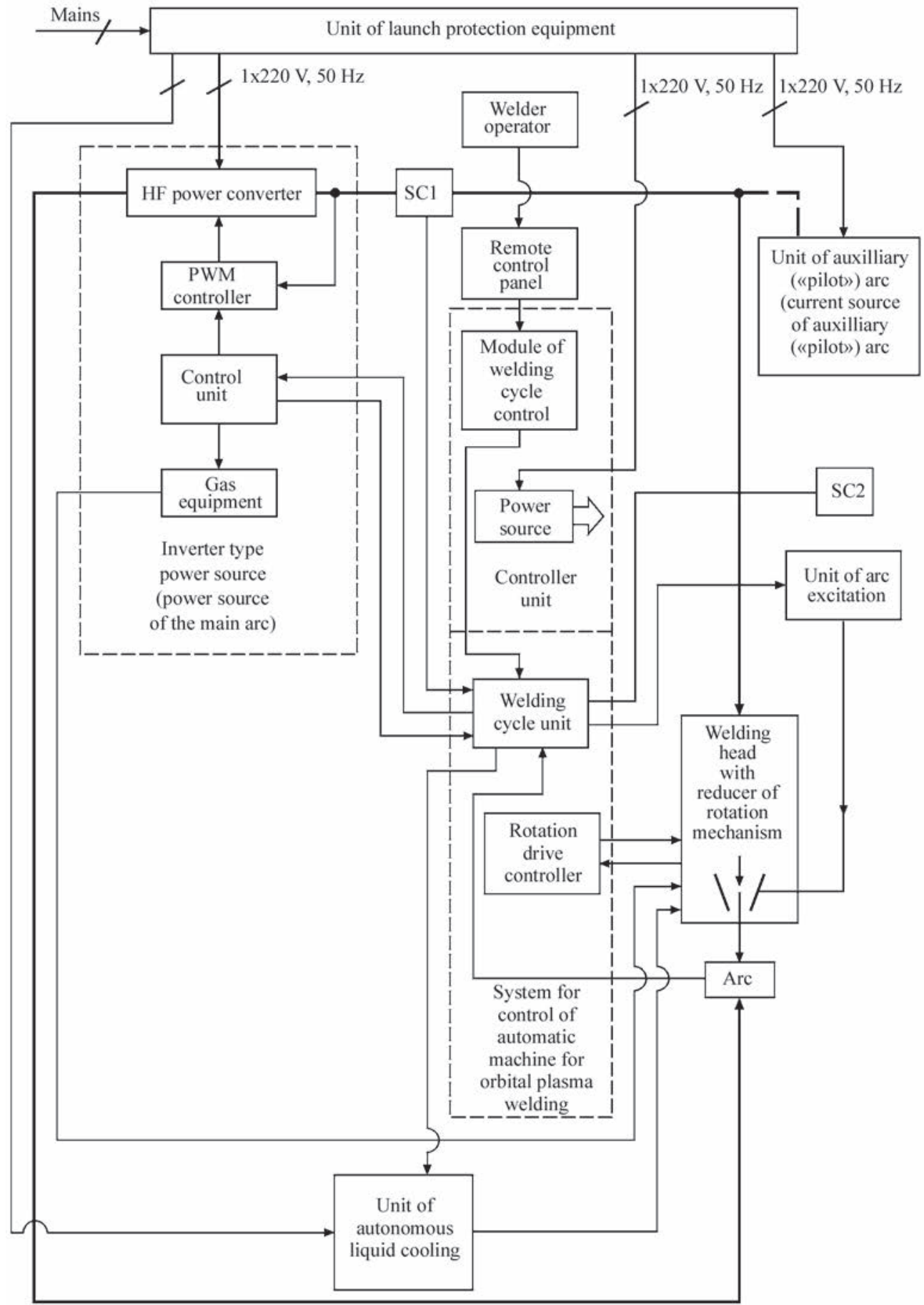

Figure 2. Functional-block diagram of the installation for automatic orbital plasma welding of position butt joints of high-pressure pipelines of NPP power units designed at the Scientific and Engineering Center of welding and control in the field of nuclear energy

welding process, the cyclogram of which is shown in Figure 1, interface unit (controller unit) for communication with all other components of automatic machines for orbital welding and the unit of launch protection equipment (ULPE), which provides the possibility of realizing «EMERGENCY STOP» after the command of the operator or automatically with almost instantaneous and complete deenergization of all without exception components of the hardware-software complex for automatic orbital welding and introduction of their additional protection against a long-term overload on current consumption and against a steady short circuit, and in the case of automatic orbital plasma welding, there is a built-in or separate unit of auxiliary («pilot») arc with steeply falling VAChs and its excitation unit, plasmatron designed for the highest value of the main arc current, autonomous cooling unit of the plasmatron, WCCU, interface unit (controller unit) and ULPE;

- in the process of automatic orbital welding of joints of pipe elements of HPH spirals of NPP power units, stability with accuracy of not worse than $\pm 5 \%$ of such parameters as the main arc current (welding current) at its length of up to $1.5 \mathrm{~mm}$ in the case of 


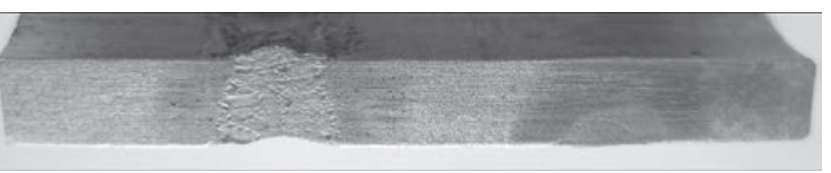

Figure 3. Macrostructure of welded joint of specimen-simulator of pipe elements of HPH spiral (position joints), produced using automatic orbital helium arc welding by the method of autopressing, where on the left a weld is shown formed in a one pass by automatic orbital helium arc welding, and on hte right the weld is shown formed by automatic orbital argon arc welding applying the same method

helium arc and from 3 to $8 \mathrm{~mm}$ in the case of plasma welding, as well as the speed of rotation of the faceplate of the welding head (welding speed) should be provided; the duration of the stages of which the welding cycle is composed, should be provided with an accuracy of not worse than $\pm 10 \%$, and the need in the use of preliminary tacks is excluded;

- the duration of the welding cycle during helium arc or plasma welding is (maximum) from 4 to $5 \mathrm{~min}$ against (30-32) min according to the existing technology of manual argon arc welding with the filler wire feed.

\section{Conclusions}

1. Automatic orbital helium arc or plasma welding of position joints of pipe elements of HPH spirals $(32 \times 4)$ are promising and the most cost-effective methods of welding during the manufacture and renovation repair of these welded structures.

2. The use of automatic orbital helium arc or plasma welding of position butt joints of HPH pipe elements of NPP power units allows not only a significant (at least 6-8 times) increase in welding efficiency (as compared to the existing technology) and a significant improvement in the quality of welded joints of the mentioned pipe elements, which significantly simplifies and reduces the cost for both preparation for welding as well as for technological equipment to produce the abovementioned welded joints (as compared to the technological equipment for mechanized arc welding using consumable electrode in a mixture of shielding gases).

3. The equipment for automatic orbital helium arc welding has a simpler structure as compared to the equipment for automatic orbital plasma welding, therefore, automatic orbital helium arc welding is more preferred.

4. Technical proposals on designing the installations (complexes) for automatic orbital helium arc and plasma welding of position butt joints of pipe elements of HPH spirals of NPP power units were developed.

5. The scope of the basic optimized parameters of the modes of automatic orbital helium arc or plasma welding of the joints of pipe elements of HPH spirals was determined.
6. It is established that the values of the parameters of the modes of automatic orbital helium arc or plasma welding (such as the main arc current (welding current) at its length of up to $2.5 \mathrm{~mm}$ in the case of helium arc welding and from 3 to $8 \mathrm{~mm}$ in the case of plasma welding, as well as welding speed - the speed of rotation of the welding head faceplate), which correspond to the scopes of the basic optimized parameters of the modes of automatic orbital helium arc or plasma welding of joints of pipe elements of $\mathrm{HPH}$ spirals with a rated outer diameter of $32 \mathrm{~mm}$ and a rated wall thickness of $4.0 \mathrm{~mm}$ using nonconsumable (tungsten) electrode with an accuracy of not less than $\pm 5 \%$, and the duration of the stages of which the welding cycle is composed, should be provided with an accuracy of not worse than $\pm 10 \%$.

1. Efimov, O.V., Pylypenko, M.M., Potanina, T.V. et al. (2017) Reactors and steam generatots of NPP power units: schemes, processes, materials, structures, models. Ed. by O.V. Efimov. Kharkiv, LLC «V spravi» [in Ukrainian].

2. Buongiomo, J. (2010) PWR description. Massachusetts Institute of Technology.

3. NP-045-03 (2003): Rules for device and safe operation steam and hot water pipelines for objects of atomic energy (Approved by Resolution Gosatomnadzor of Russia, No.3 and Gosgortekhnadzor of Russia, No.100, June 19, 2003). Moscow, Gosatomnadzor of Russia [in Russian].

4. Makhlin, N.M., Vodolazsky, V.E., Popov, V.E. et al. (2018) Selection of welding technology in manufacture and restoration repair of spirals of high-pressure heaters of NPP power units. The Paton Welding J., 4, 37-43.

5. Bukarov, V.A. (2002) Technology of automatic shielded-arc welding. In: Welding in nuclear industry and power engineering. Transact. of NIKIMT. Moscow, AT, Vol. 1, 149-210 [in Russian].

6. Ishchenko, Yu.S. (2018) Physico-technological principles of weld formation in arc welding process. Ibid., Vol. 2, 204-240 [in Russian].

7. Troitsky, V.A. (2006) Brief manual on quality control of welded joints. Kiev, Feniks [in Russian].

8. Lobanov, L.M., Vodolazsky, V.E., Makhlin, N.M. et al. (2017) Horizontal manipulator for arc welding of pipe structure parts. Positive decision on the application a2017 11752 from 01.12.2017 [in Russian].

9. Krivtsun, I.V., Demchenko, V.F., Krikent, I.V. et al. (2019) Effect of current and arc length on characteristics of arc discharge in nonconsumable electrode welding. The Paton Welding J., 5, 2-12.

10. Boyi, Wu, Krivtsun, I.V. (2019) Processes of nonconsumable electrode welding with welding current modulation (Review). Pt 1. Peculiarities of burning of nonstationary arcs with refractory cathode. Ibid., 11, 23-32.

11. Goloshubov, V.I. (2005) Welding power sources: Manual. Kyiv, Aristei [in Ukrainian].

12. Paton, B.E., Grigorenko, G.M., Shejko, I.V. (2013) Plasma technologies and equipment in metallurgy and foundry. Kiev, Naukova Dumka [in Russian].

13. Makhlin, N.M., Korotynskyi, O.E., Svyrydenko, A.O. (2013) Hardware and software complexes for automatic welding of permanent joints of pipelines of nuclear power plants. Nauka ta Innovatsii, 9(6), 31-45 [in Ukrainian]. 


\title{
DEVELOPMENT OF INDUCTORS FOR BULK AND SURFACE HEAT TREATMENT OF WELDED BUTT JOINTS OF RAILWAY RAILS
}

\author{
O.S. Prokofiev, R.S. Gubatyuk, O.S. Pismennyi, S.V. Rymar and Ye.O. Panteleymonov \\ E.O. Paton Electric Welding Institute of the NAS of Ukraine \\ 11 Kazymyr Malevych Str., 03150, Kyiv, Ukraine. E-mail: office@paton.kiev.ua
}

\begin{abstract}
The paper presents the concept of bulk and surface heat treatment of the welded butt joint of a railway rail by two or more inductors with the purpose of achieving favourable phase transformations of metal and normalizing its structure in the weld zone. Performed computations and experiments resulted in development of split inductors without magnetic circuits, which allow performance of bulk and surface induction heat treatment. Conducted experiments on heating a welded butt joint of a rail by the developed split inductors without the magnet cores demonstrated heating uniformity characteristics acceptable for bulk heat treatment of rails, limit temperatures and rates of heating of the main rail working areas both on the surface and in-depth of a narrow heating zone. 19 Ref. 2 Tables, 8 Figures.
\end{abstract}

Ke yw ords: inductor, induction heating, bulk heat treatment, surface heat treatment, welded butt joint of railway rails, normalizing of weld zone metal

In connection with development of high-speed railway transportation in Ukraine, the task of producing high-quality continuous welded rails of greater length and increased strength from hypereutectoid steels remains urgent. In Ukraine and in a number of countries in the world, rails are joined by flash-butt welding, both in the stationary rail-welding enterprises, and under the road conditions, by the technology and with application of equipment developed by PWI. Weld heat treatment is more and more often used in the world practice, in order to improve the metal structure in the weld and near-weld zone, and increase the reliability of the welds [1].

In metallurgical enterprises the rails are heat treated during manufacture. Engineering solutions for performance of induction heat treatment (HT) of the entire rail surface [2], or its head surface [2, 3] are known. Some inductor designs allow performance of HT in keeping with the technical requirements, which were in force during their development, but need upgrading now, in connection with the change of the composition of rail steel, which is close to alloyed steels, their manufacturing method, and change of the cross-section geometry towards the reinforcement. For these purposes, PWI developed an inductor design, which ensures more effective heating of the rail head surface [4].

At the same time, requirements to the rail welded butt joint become higher. Welded butt joints of rails of R65 type from low-alloyed steel $(\mathrm{Cr}-\mathrm{Si}-\mathrm{V})$ of $\mathrm{K} 76 \mathrm{~F}$ grade, manufactured in Ukraine, at increase of the train speed and of the load in the wheel-rail system also require HT [3], in order to avoid formation of unfavourable structures and produce normalized structure of the metal, with the structure becoming closer to the base metal both by its kind and mechanical values, as well as reduction of unfavourable residual stresses.

HT performance is also due to the need to correct the technological inheritance of the quality values (properties) of the metal in the weld zone, which starts from metallurgical processing and runs through the entire process of rail manufacture. The technological inheritance of metal quality includes fluctuations of the distribution of chemical elements, mechanical values and local stress-strain state, which are of a random nature and have an essential impact on the structure life cycle [5], if they occur in the weld zone.

In order to conduct HT of welded butt joints of the railway rails, the most effective is application of induction heating [1], performance of which is regulated by technical normative guidelines [6] and use of equipment, with which it is performed. The working tools of the induction units are inductors, which can be with and without magnetic circuits.

The work on development of the technology of performance of induction HT of the welded butt joints of railway rails and designing the respective equipment, is performed by many countries of the world [1]. In RF SPC «Magnit M» Ltd. developed complexes for

O.S. Prokofiev — https://orsid.org/0000-0003-4643-6611, R.S. Gubatyuk — https://orsid.org/0000-0002-0851-743x,

S.V. Rymar — https://orcid.org/0000-0003-0490-4608 
HT of rails [7, 8], which include multiturn inductors without magnet cores. Such complexes operate under the shop and track conditions with working current frequency of $6.0-8.0$ and $2.4-8.0 \mathrm{kHz}$. For construction of the railways, split single-turn high-frequency inductors with parallel conductors without magnetic circuits were developed in PRC $[9,10]$.

PWI performed work on development of the technology and portable equipment to ensure uniform heating of the rail weld with reduced heating zone $[11,12]$ for $2.4 \mathrm{kHz}$ working frequency of current. The equipment is designed for correspondence of normative requirements [6] to the European standard EN 14587 21-2005. Used as a work tool, is a split inductor with magnetic flux concentrators in the form of magnetic circuits $[13,14]$, which ensures in a sufficiently short time (180 s) the required bulk uniform heating to the specified temperature of all the rail areas.

The objective of the work is description of development at PWI of a test sample of a complex-shaped split inductor without magnetic circuits with a narrow zone of bulk heating of the welded butt joint of R65 rail, at $2.4 \mathrm{kHz}$ working frequency of current.

The base of development of a test sample of complex-shaped split inductor without magnetic circuits, was the concept of performance of bulk and surface HT of the butt welded joint of a railway rail by two or more inductors.

The development was mainly focused on performance of bulk HT of a welded butt joint as the main operation.

The test sample of a complex-shaped split inductor without magnetic circuits and its main characteristics and geometrical parameters were determined by preliminary calculations of a model of an induction system of «inductor-workpiece», taking into account the above requirements to HT of welded butt joints. Preliminary results on development of inductors for HT of both the welded butt joint of the rails and of the rails proper were also taken into account.

Because of the complex cross-sectional shape of railway rails, different volume of the metal in its elements, namely its head, web and foot, and well as the difference in the geometry of different types of rails, it is rather difficult to perform uniform induction bulk heating of the main working elements of the rail. And it is exactly fulfillment of this condition which ensures high-quality HT of the welded butt joint. However, even in this case, short zones of lower hardness form on both sides from the inductor edges along the rail longitudinal axis. This is due to the steel exposure to the impact of the temperature field in the region of $700-350{ }^{\circ} \mathrm{C}$, for sufficiently long time for formation of incomplete recrystallization zone. At rail operation, surface deformations can develop in these areas from rolling wheels.

In order to avoid this phenomenon, the concept was proposed of performance of bulk and surface HT of the welded butt joint of the railway rail by two and more inductors, in order to obtain favourable phase transformations of metal and normalizing its structure in the weld zone. For this purpose, it is proposed to perform in incomplete recrystallization zones additional surface HT by a pair of inductors for producing surface hardening of the metal in these zones. Surface HT can be performed simultaneously with bulk HT, or after performance of bulk HT by the main inductor. The electric and geometrical parameters of the additional pair of inductors and thermal heating cycle can differ from the parameters and cycle of the main inductor.

It is desirable to perform surface HT at higher frequency of current (more than $2.4 \mathrm{KHz}$ ), in order to reduce penetration of induced currents and thermal flows in-depth of the rail metal. Here, the metal is not exposed to intensive thermal impact inside the rail. The thermal fields which propagate from an additional pair of inductors over the rail surface promote refinement of the metal grains, producing uniform structures in the specified rail areas of a lower hardness, and also promote increase of its hardness and shortening of the extent of the above-mentioned zones of metal softening on the rail surface. Surface HT can be performed around the entire perimeter of the rail cross-section or over the head surface.

As the volume of the metal of welded butt joint of the rail, subjected to surface HT, is smaller than the volume of metal, subjected to bulk HT, smaller power is required for its performance, and even smaller - at surface HT of just the rail head, respectively.

In development and manufacturing of the structure of a split inductor without magnetic circuits for bulk HT of welded butt joints of railway rails, the following factors should be taken into account:

- possibility to perform HT under stationary conditions in rail-welding enterprises, on the track, in particular, in a confined space and on the already assembled railway track at its repair;

- complexity of inductor design, which is due to bringing together — bringing apart its branches relative to the rail;

- possible presence of electric contact at closing of the inductor branches with provision of its reliable connection and unhindered passage of high-frequency current through it, particularly, at long-term use, that determines reliable operation of the entire split inductor.

When developing the designs of split inductors without magnetic circuits to perform bulk HT of weld- 


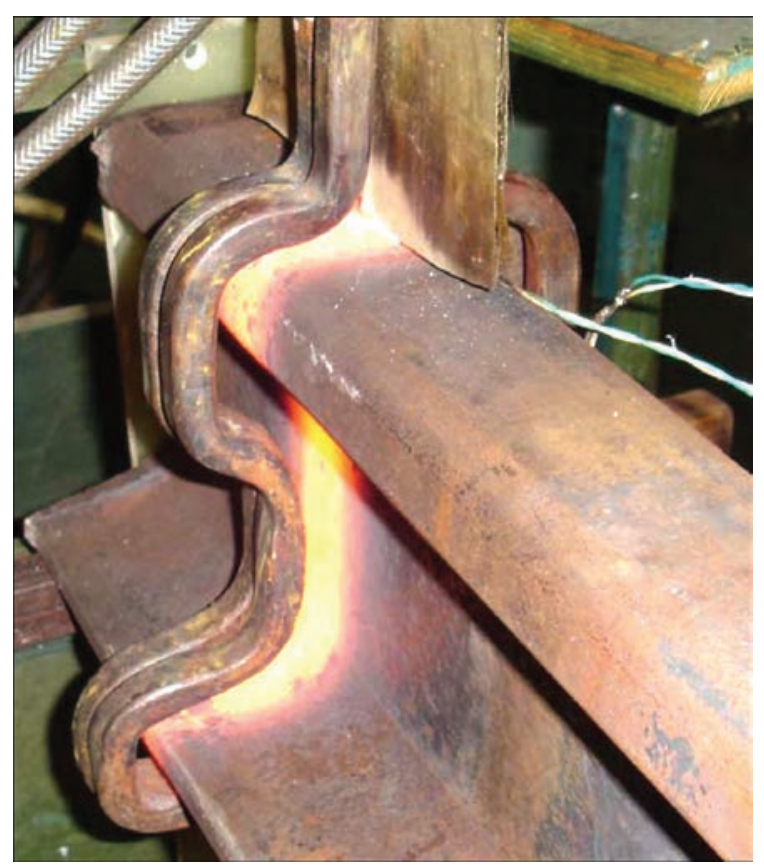

Figure 1. Performance of bulk HT of the welded butt joint of a railway rail of R65 type by split inductor without magnetic circuits

ed butt joints of railway rails, the test sample of onepiece inductor without magnetic circuits (Figure 1) for rail-welding enterprises and materials of works [2, 15-17] were taken as the base.

The design of a split inductor without magnetic circuits with electric contact for joining the two inductor branches (Figure 2) was developed, in which, compared to the inductor in Figure 1, the distances between the rail side surfaces and the inductor were reduced and equalized. Such an inductor is designed to perform surface HT of rails, as it can quickly and uniformly heat a narrow zone around the entire perimeter of the rail to uniform small depth by higher frequency currents (more than $6 \mathrm{kHz}$ ). The inductor is designed to perform HT in rail-welding enterprises and on the track.

A design of a split inductor without magnetic circuits or electric contact between the two parts of the inductor (Figure 3) was developed, in which, compared to the inductor in Figure 2, the distances between the side surfaces of the rail and the inductor were corrected, in order to ensure uniform bulk heating of all the rail parts. The inductor is designed to perform bulk HT in rail-welding enterprises and on the track.

This inductor design greatly simplifies its manufacture and use and improves the reliability of its operation, as the electric contact between its branches is absent. However, due to large distances between the rail side surfaces and the inductor and greater length of induction wires, the inductance and resistance of the inductor increase, leading to greater electric losses

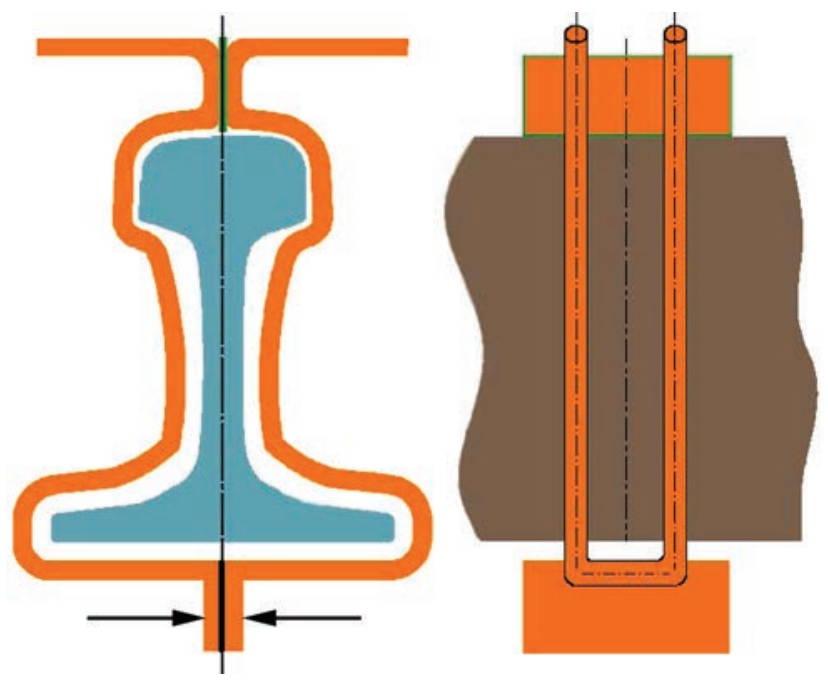

Figure 2. Design of a split inductor without magnetic circuits with electric contact for closing inductor branches, designed for conducting surface HT of narrow surfaces of rails

and the need to increase the capacitance, that compensates the system inductance, and this leads to its higher price during production and operation.

A design of the split inductor without magnetic circuits was proposed, in which the task of uniform bulk heating of all the main parts of the rail is solved comprehensively. The design has different distances between the side surfaces of the rail and the inductor, but much smaller than in the design in Figure 3. Unlike the previously considered designs, this inductor has different configuration in the longitudinal direction of the rail (Figure 4). The design contains higher reliability electric contact with greater area of the surfaces being joined, which are removed beyond the inductor working zone. The inductor is designed to perform bulk HT in the rail-welding enterprises and on the track. This inductor design for uniform bulk
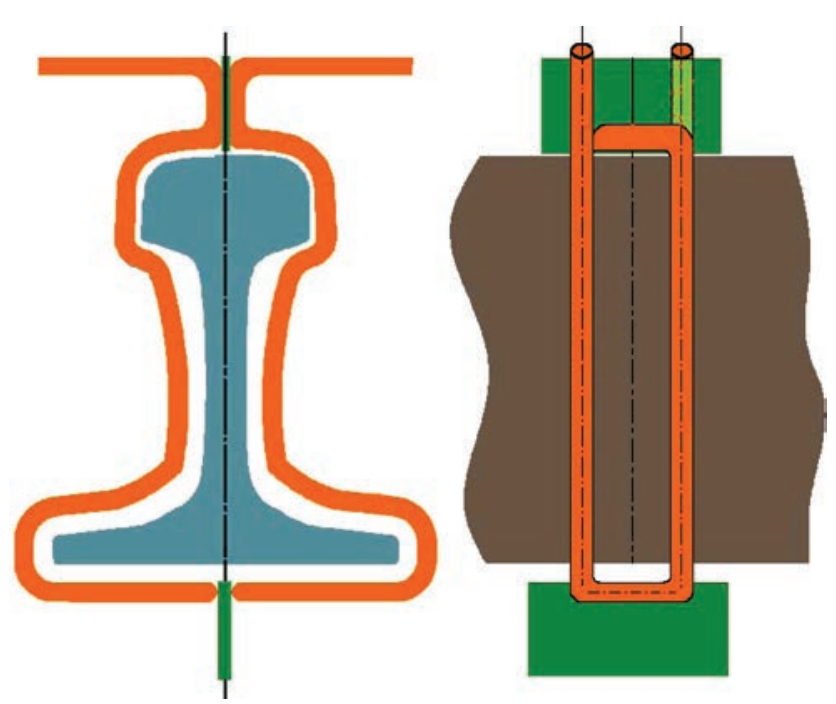

Figure 3. Design of a split inductor without magnetic circuits or electric contact between the inductor halves, designed for bulk HT of railway rails 


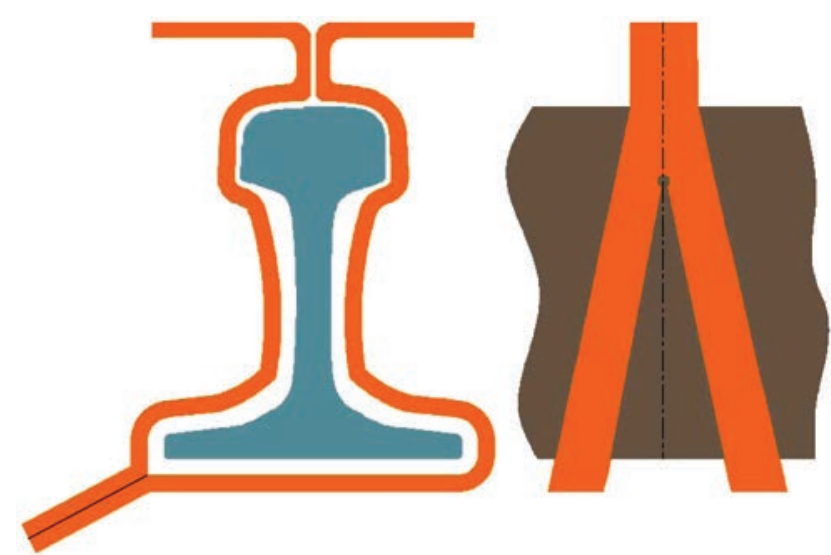

Figure 4. Design of a split inductor without magnetic circuits with higher-reliability electric contact taken out of the working zone, for closing the inductor branches, which is designed to conduct bulk HT of railway rails

heating of rail parts was defined as the priority one for implementation.

The procedure of work [18] and the data of earlier conducted experiments on performance of bulk HT by the inductor in Figure 1, which was also designed by this procedure, were used for estimated calculation of the parameters of split inductor without magnetic circuits (Figure 4).

The following parameters were taken as the base ones: $f$ is the induction current frequency; $S$ is the the cross-sectional area of the rail elements and their percentage value $S_{\%}$ of the total cross-sectional area; $l$ is the length of the rail areas around the perimeter.

Based on the dependencies between the electromagnetic characteristics [18] and geometrical parameters of railway rail of $\mathrm{R} 65$ type, which is to be heat-treated, calculation of the electromagnetic and geometrical parameters of «inductor-rail» system was performed, using the dependence of specific surface power $p$ on magnetic field strength $H$ at frequency $f=2.5 \mathrm{kHz}$ [18], which is close to that of the avail- able power source TPChT-160/2.4 and similarity of distribution of the strength of the magnetic field [19], which forms at distance $\delta$ between the surface of the object being heated and the inducing conductor.

The main parameters of the system have been determined and calculated: $S_{s}, M$ are the surface area of the rail elements which are heated, and their weight; $H, p$ are the magnetic field strengths and specific powers on the heating surfaces of rail elements; $\Delta$ is the depth of magnetic flux penetration into the rail elements; $\delta$ is the distance (nonmagnetic gap) between the heated surfaces of the rail elements and the inductor; $P$ are the powers applied to the rail elements at heating.

The listed parameters at the start of heating, when the rail metal has magnetic properties, are shown in Table 1.

Proceeding from the rail configuration, the highest magnetic field strength should be created in the most massive area of the surface - the rail head. On smaller bodies and thinner areas, the magnetic field strength should be lowered.

A test laboratory sample of this inductor (Figure 5) from sheet copper with reinforcement by water-cooled tubes was manufactured, which allows conducting bulk HT of the welded butt joint of the rails.

The inductor ensures a more concentrated distribution of the magnetic field in the rail head, due to a continuous conductor over its surface and small clearance (gap) between the conductor and the rail. Above the rail web and foot the inductor conductors are made in the form of two parallel branches, the area of which becomes smaller towards the foot, thus reducing the heated area under them. In the foot area, the conductors are also removed from each other that enables heating to be performed in the area of the thinnest end portions of the foot - the base points. In terms of

Table 1. Parameters of the induction system at heating of R65 rail

\begin{tabular}{|c|c|c|c|c|}
\hline Parameters & Head & Web & Foot & Rail \\
\hline Cross-sectional area $S, \mathrm{~cm}^{2}$ & 28.19 & 23.57 & 30.89 & $82.65[6]$ \\
\hline Cross-sectional area $S_{\%}, \%$ & 34.1 & 28.5 & 37.4 & 100.0 \\
\hline Heating area under the inductor, $S_{a}, \mathrm{~cm}^{2}$ & 79.1 & 124.7 & 129.0 & 332.8 \\
\hline Length around the perimeter, $\mathrm{cm}$ & 18.5 & 29.0 & 30.0 & 77.5 \\
\hline Rail element mass $M, \mathrm{~kg}$ & 8.375 & 5.940 & 8.066 & 22.381 \\
\hline Distance between the inductor and surface $\delta, \mathrm{cm}$ & $0.8-1.0$ & $2.4-2.8$ & $2.6-3.2$ & - \\
\hline Magnetic field strength $H, \mathrm{~A} / \mathrm{cm}$ & 1200.0 & 765.5 & 740.0 & - \\
\hline Specific surface power $p, \mathrm{~W} / \mathrm{cm}{ }^{2}$ & 290 & 145 & 130 & - \\
\hline Penetration depth $\Delta, \mathrm{cm}$ & 0.120 & 0.095 & 0.090 & - \\
\hline Applied power $P, \mathrm{~kW}$ & 22.944 & 18.081 & 16.770 & 57.775 \\
\hline
\end{tabular}




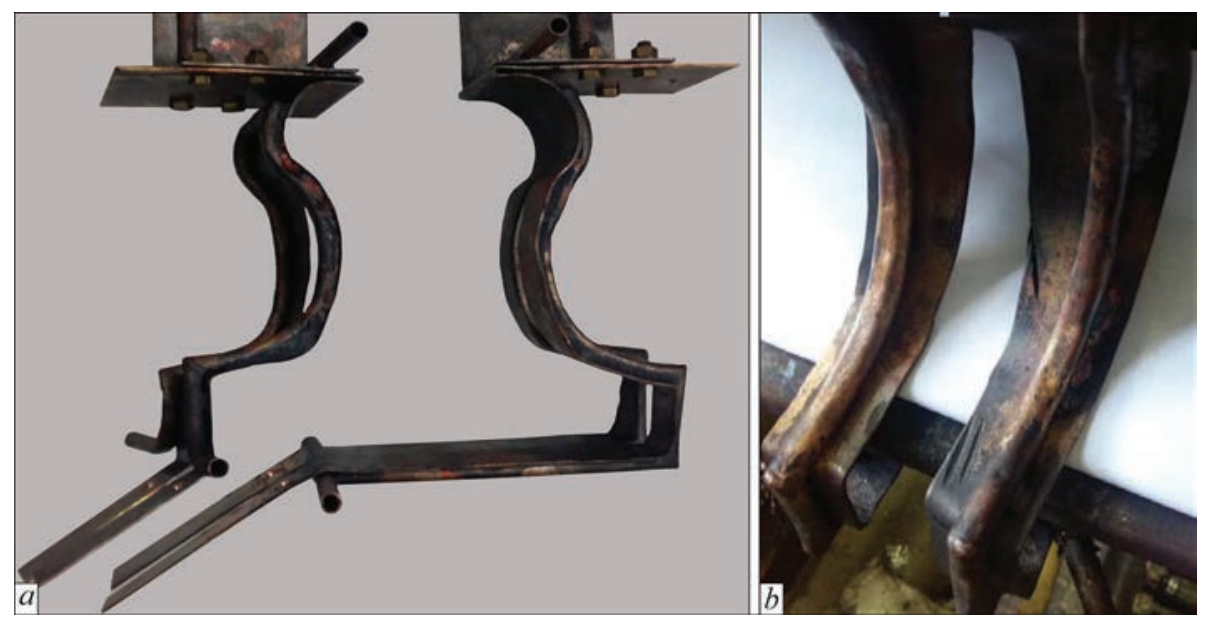

Figure 5. Laboratory test sample of a split inductor without magnetic circuits

design, the gap between the inductor conductors and the rail is made with its increase from the head to the web and foot. Such an inductor design allowed uniform heating to be performed.

Conducting experiments on performance of induction bulk HT of the welded butt joint of the railway rail demonstrated achieving almost simultaneous and uniform heating of parts of different weight and area, namely the head and foot and quite close to them heating of the web center, without its overheating. It should be noted that the temperature at the ends of the rail base points after passing the phase transformation point $A_{c 3}$ (Curie point) stabilized, and practically did not rise further on, because of complete disappearance of the metal magnetic properties, which is associated with the magnetic field penetration into the zone of the volume of base point ends, that lead to reduction of the density of eddy currents, which heat the metal of base point ends, that is not critical as the base point ends are no the most loaded elements of the rail.

It is experimentally confirmed that the power applied during performance of induction bulk HT to each part of the rail, is close to the power determined by calculations.

Bulk HT of the welded butt joint of the rails by a split inductor without magnetic circuits was performed in a narrow zone $(40 \mathrm{~mm})$ on both sides from the transverse weld. Rail heating was conducted in the laboratory equipment, which included: power source - thyristor frequency of $160 \mathrm{~kW}$ power and $2.4 \mathrm{kHz}$ current frequency (TPChT-160/2.4) converter: matching single-phase high-frequency transformer TZ-800 (hardening transformer), battery of cosine capacitors for compensation of the reactive power; and test inductor.

Monitoring of electric parameters of the unit was performed as follows: digital multimeters UNI-T
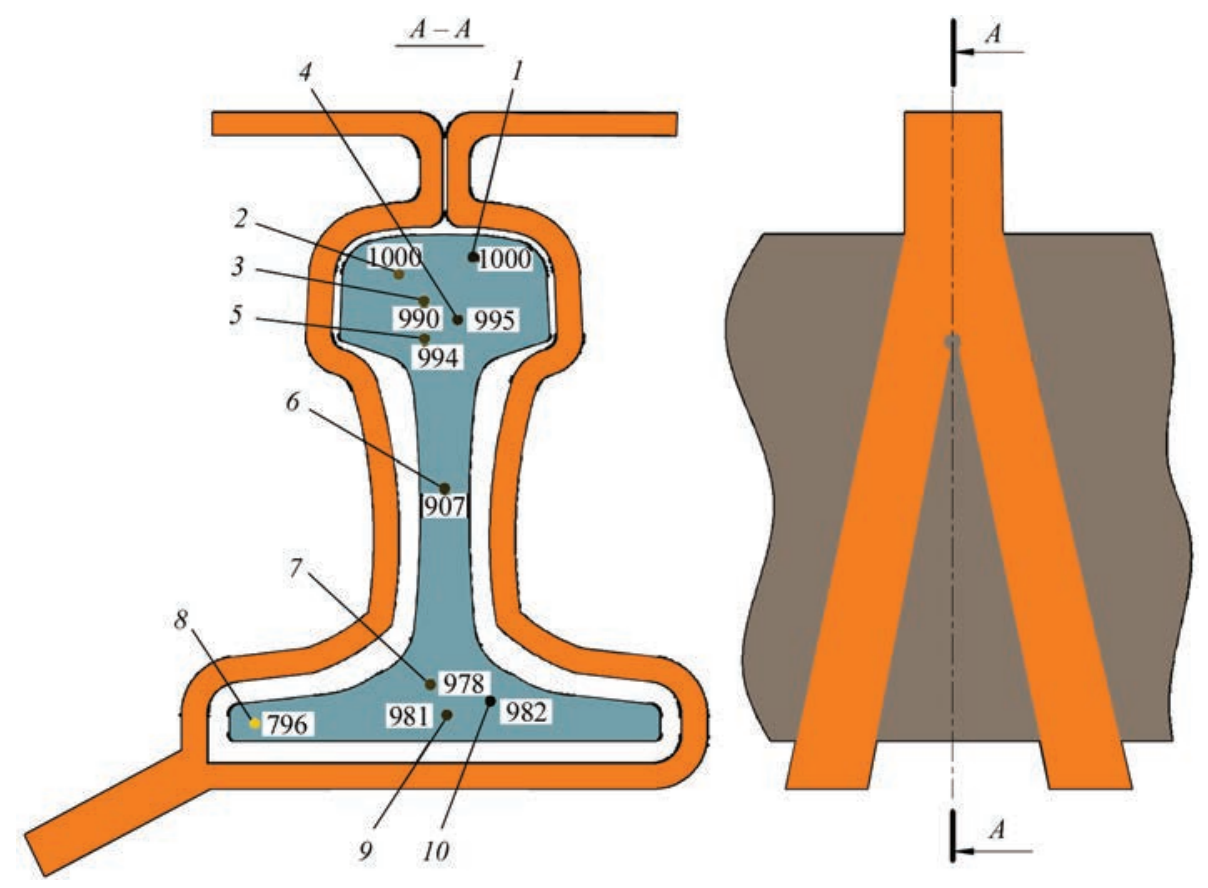

Figure 6. Scheme of location of 10 thermocouples in the conditional cross-section of the rail 


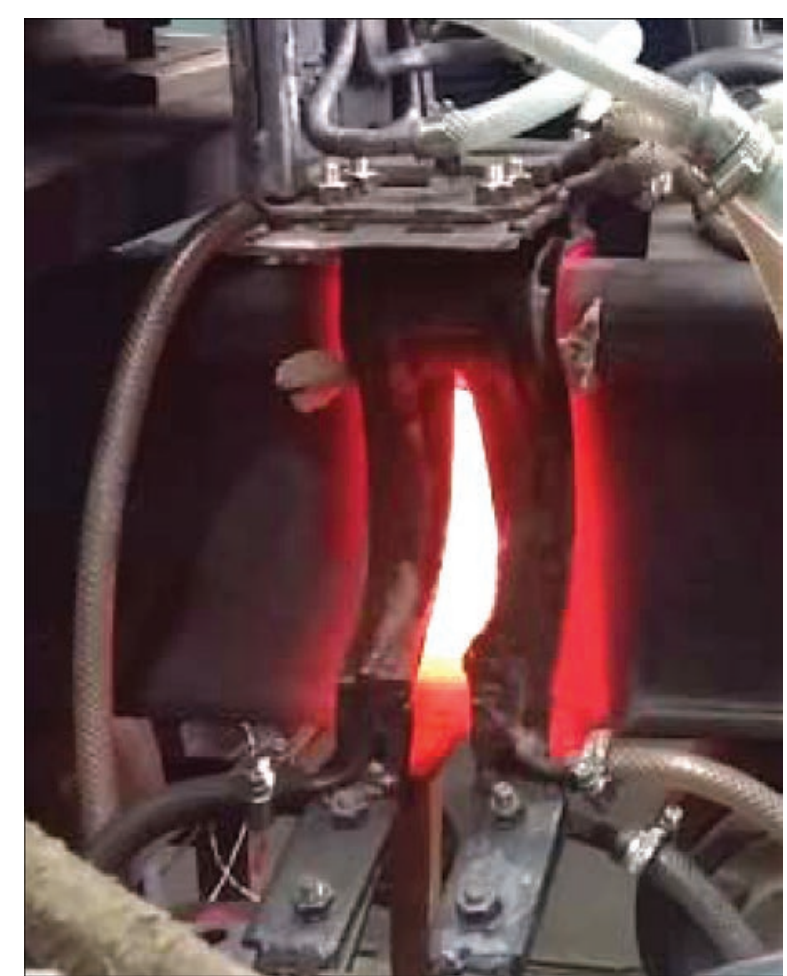

Figure 7. Heating of welded butt joint of R65 rail by a test split inductor without magnetic circuit

UT70V and Velleman DMV1090; phase meter F2-1; Rogowski belt.

Measurement of temperature field in the rail weld was performed by sensors in the form of chromel-alumel thermoelectric converters (thermocouples) of $\mathrm{K}$ type of $0.75 \mathrm{~mm}$ diameter. Thermocouples were welded to the rail, using low-power capacitor welding source. Four thermocouples 1-4 were placed in the rail head (Figure 6), at the depth of 6, 12, 19 and $25 \mathrm{~mm}$ from the rolling surface, respectively; thermocouple 5 was installed in the place of head transition

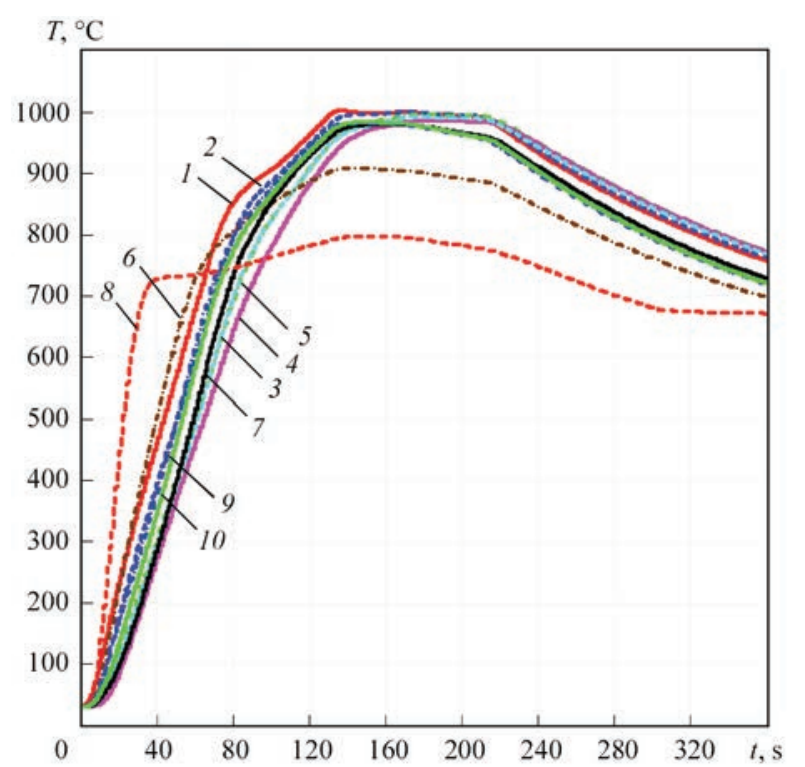

Figure 8. Dependencies of temperature $T$ on time $t$ in points $1-10$ (thermocouple numbers) in the conditional cross-section of the rail to the web; 6 - at $9 \mathrm{~mm}$ depth in the narrowest part of the weld; 7 - at the depth of $22 \mathrm{~mm}$ in the place of the web transition to the foot; 8 - at $10 \mathrm{~mm}$ depth at the end of the rail base point; 9 and 10 - in the rail foot at the depth of 10 and $14 \mathrm{~mm}$, respectively.

Conversion of the thermocouple signal took place due to connection of 10-channel ADC ISP-DAS M-7018 and galvanic decoupling block ISP-DAS i-7561U. Visualization of the results of temperature measurement in time was performed on the computer monitor, using a special program of measured data processing.

Figure 7 showed the welded butt joint of R65 rail heated by a test split inductor without magnetic circuit.

Dependencies of temperature $T\left({ }^{\circ} \mathrm{C}\right)$ in points $1-10$ of the conditional cross-section of the rail on time $t(\mathrm{~s})$ are given in Figure 8, and the numerical temperature values in these points are given in Table 2.

Experimental data show the ability of the developed inductor to heat the surface layers of the rail head up to the temperature of $1000{ }^{\circ} \mathrm{C}$, which is even higher than metal normalizing temperature of $825-875^{\circ} \mathrm{C}$, at relatively uniform distribution of the temperature field in the main working areas of the rail volume.

Maximum temperature of $1000{ }^{\circ} \mathrm{C}$ was reached during time $t_{1}=135 \mathrm{~s}$, which was taken as the start of the process of soaking at this temperature up to $t_{2}=215$ $\mathrm{s}$ and was continued $\Delta t=t_{2}-t_{1}=80 \mathrm{~s}$. Then the inductor was switched off and the heating process stopped. Rail cooling occurred under natural conditions.

In the temperature curves (Figure 6), their smooth inflection can be observed from the start of heating up to time $t_{1}$, when the temperature in different sections of the rail rises abruptly at the rate $v_{\mathrm{mg}}=7.3-20.1^{\circ} \mathrm{C} / \mathrm{s}$ (mean value of $10.5^{\circ} \mathrm{C} / \mathrm{s}$ ) (Table 2 ), and then its increase slows down and the heating rate drops to $v_{\text {nmg-t } 1}=0.8-4.1{ }^{\circ} \mathrm{C} / \mathrm{s}$ (mean value of $3.1{ }^{\circ} \mathrm{C} / \mathrm{s}$ ). Abrupt temperature rise is observed at the start of heating, when the rail metal is in the magnetic state, and the depth of magnetic field penetration into the surface layers is minimum, and the density of eddy currents, which heat the met$\mathrm{al}$, is maximum. After the temperature has passed through the Curie point (phase transition point $A_{c 3}$, approximately $770{ }^{\circ} \mathrm{C}$ for steel), the metal layers by the depth are gradually becoming nonmagnetic, depth of magnetic field penetration into the metal becomes greater, and the density of eddy currents in it smoothly becomes smaller, that leads to slowing down of the heating process and, usually, to the need to increase the power from the source. In different areas and in different volumes of the rail this process proceeds in different ways, depending on the state of the magnetic and nonmagnetic metal, during the heating process. 
Table 2. Temperature values in points 1-10 of the conditional cross-section of the rail

\begin{tabular}{|c|c|c|c|c|c|c|c|c|c|c|}
\hline \multicolumn{10}{|c|}{ Thermocouple numbers (Figure 6) } & \multirow{2}{*}{ Mean value } \\
\hline 1 & 2 & 3 & 4 & 5 & 6 & 7 & 8 & 9 & 10 & \\
\hline \multicolumn{11}{|c|}{ Temperature $T_{1},{ }^{\circ} \mathrm{C}$ of the start of the soaking process, reached during heating time $t_{1}=135 \mathrm{~s}$} \\
\hline 1000 & 990 & 962 & 943 & 962 & 906 & 970 & 794 & 979 & 977 & 948 \\
\hline \multicolumn{11}{|c|}{ Temperature $T_{2},{ }^{\circ} \mathrm{C}$ at the end of the soaking process, which is achieved during heating time $t_{2}=215 \mathrm{~s}$} \\
\hline 985 & 985 & 984 & 981 & 985 & 882 & 955 & 772 & 950 & 951 & 943 \\
\hline \multicolumn{11}{|c|}{ Temperature difference $\Delta T=\left|T_{2}-T_{1}\right|,{ }^{\circ} \mathrm{C}$ on the boundaries $t_{1}$ and $t_{2}$ of range $\Delta t$ of soaking time $\left(\Delta t=t_{2}-t_{1}=80 \mathrm{~s}\right)$} \\
\hline 15 & 5 & 22 & 38 & 23 & 24 & 15 & 22 & 29 & 26 & 22 \\
\hline \multicolumn{11}{|c|}{ Maximum temperature $T_{\max },{ }^{\circ} \mathrm{C}$ in soaking time range $\Delta t$} \\
\hline 1000 & 1000 & 990 & 995 & 994 & 907 & 978 & 796 & 981 & 982 & 962 \\
\hline \multicolumn{11}{|c|}{ Minimum temperature $T_{\text {min }},{ }^{\circ} \mathrm{C}$ in soaking time range $\Delta t$} \\
\hline 985 & 985 & 962 & 943 & 962 & 882 & 955 & 772 & 950 & 951 & 935 \\
\hline \multicolumn{11}{|c|}{ Difference between the maximum and minimum temperature $\Delta T_{\max -\min }=\left|T_{\max }-T_{\min }\right|{ }^{\circ} \mathrm{C}$, in soaking time range $\Delta t$} \\
\hline 8 & 8 & 28 & 45 & 27 & 23 & 23 & 21 & 30 & 27 & 24 \\
\hline \multicolumn{11}{|c|}{ Temperature difference $\Delta T_{1000{ }^{\circ} \mathrm{C}-\max }=\left|T_{1000^{\circ} \mathrm{C}}-T_{\max }\right|,{ }^{\circ} \mathrm{C}$ in soaking time range $\Delta t$} \\
\hline 0 & 0 & 10 & 5 & 6 & 93 & 22 & 204 & 19 & 18 & 38 \\
\hline \multicolumn{11}{|c|}{ Temperature difference $\Delta T_{1000{ }^{\circ} \mathrm{C}-\min }=\left|T_{1000{ }^{\circ} \mathrm{C}}-T_{\min }\right|,{ }^{\circ} \mathrm{C}$, in soaking time range $\Delta t$} \\
\hline 15 & 15 & 38 & 57 & 38 & 118 & 45 & 228 & 50 & 49 & 65 \\
\hline \multicolumn{11}{|c|}{ Metal heating rate in the magnetic state $v_{\mathrm{mg}},{ }^{\circ} \mathrm{C} / \mathrm{s}$} \\
\hline 10.8 & 9.5 & 8.5 & 7.3 & 8.5 & 11.5 & 9.0 & 20.1 & 9.9 & 9.7 & 10.5 \\
\hline \multicolumn{11}{|c|}{ Metal heating rate under the impact of the nonmagnetic state up to the start of the soaking process $v_{\mathrm{nmg}-\mathrm{t}},{ }^{\circ} \mathrm{C} / \mathrm{s}$} \\
\hline 2.7 & 3.0 & 4.1 & 3.6 & 4.1 & 2.0 & 3.7 & 0.8 & 3.4 & 3.6 & 3.1 \\
\hline \multicolumn{11}{|c|}{ Rate of temperature change during soaking, $v_{\Delta t},{ }^{\circ} \mathrm{C} / \mathrm{s}$} \\
\hline 0.2 & 0.1 & 0.3 & 0.5 & 0.3 & 0.3 & 0.2 & 0.3 & 0.4 & 0.3 & 0.3 \\
\hline
\end{tabular}

In massive parts of the rail, such as the head, the foot and places of the web transition to the head and the foot, the heating process occurs smoothly at rates $v_{\text {mg }}=7.3-11.5^{\circ} \mathrm{C} / \mathrm{s}$ and $v_{\text {nmg-t } 1}=2.0-4.1^{\circ} \mathrm{C} / \mathrm{s}$ (Table 2), without any significant inflections of the temperature curves, which during the entire duration of heating are located in clusters, that is the consequence of correctly determined geometrical parameters of the inductor. The rate of temperature change during soaking is equal to $v_{\Delta 1}=0.1-0.5^{\circ} \mathrm{C} / \mathrm{s}$ (mean value of $0.3^{\circ} \mathrm{C} / \mathrm{s}$ ).

The rail base points are thin and heat the fastest at the beginning, but at their complete heating above the Curie point, the rise of temperature in them becomes considerably slower, as the depth of magnetic field penetration coincides with base point thickness, current density becomes smaller, as does the power consumed in their heating. Slowing down of the heating is observed also in the rail web center. More over, these areas, more than others, are affected by the cooling process due to convection and radiation, in connection with the larger cooling area per a unit of metal mass.

During soaking at the temperature, the difference in the temperatures in different areas of the rail is small (Table 2), that is the difference between the temperatures at the start $T_{1}$ and at the end $T_{2}$ of the soaking range is $\Delta T=\left|T_{2}-T_{1}\right|=5-38^{\circ} \mathrm{C}$ (mean value of $22^{\circ} \mathrm{C}$ ), between their maximum $T_{\text {max }}$ and minimum $T_{\text {min }}$ values it is $\Delta T_{\text {max-min }}=\left|T_{\text {max }}-T_{\text {min }}^{\text {max }}\right|=8-45^{\circ} \mathrm{C}$ (mean value of $24^{\circ} \mathrm{C}$ ), and between limit temperature of $1000{ }^{\circ} \mathrm{C}$ and maximum and minimum temperature values it is $\Delta T_{1000{ }^{\circ} \mathrm{C}-\max }=\left|T_{1000{ }^{\circ} \mathrm{C}}-T_{\max }\right|=0-204{ }^{\circ} \mathrm{C}$ (mean value of $38{ }^{\circ} \mathrm{C}$ ), $\Delta T_{10000^{\circ} \mathrm{C}-\min }=\left|T_{1000{ }^{\circ} \mathrm{C}}-T_{\text {min }}\right|=$ $=15-228{ }^{\circ} \mathrm{C}$ (mean value of $65^{\circ} \mathrm{C}$ ). If we ignore the temperature in the rail base points, then the upper limit values of temperature difference will be even smaller.

Thus, the developed split inductor without the magnetic circuits, ensures the temperature in the main rail areas, acceptable for bulk heating of the rail welded butt joints. 
Further studies should focus on producing a split inductor without the magnetic circuits for surface HT of incomplete recrystallization zones that form after performance of bulk HT.

\section{Conclusions}

1. Modern development of railway transportation is going along the path of construction of continuous track with application of new high-strength rails from alloyed steels of higher strength and wear resistance. Stringent requirements are made also of welded butt joints of the rails as an integral part of the continuous track. Achieving metal normalizing, reducing unfavourable residual stresses in the welded joint zone due to performance of HT and improvement of its quality is an urgent task.

2. Implementation of the proposed concept of bulk and surface induction heat treatment of the HAZ of welded butt joints of the rails will allow producing normalized metal structures, which will promote improvement of metal characteristics.

3. Based on the conducted calculations and experiments, analysis of the features of the geometrical forms and weights of the rail in its different areas was the basis for development of split inductors without magnetic circuits for the possibility of conducting bulk and surface induction heat treatment.

4. Conducted experiments on performance of heating of a welded butt joint of rail of R65 type by a test sample of the developed split inductor of a complex shape without magnetic circuits at current frequency of $2.4 \mathrm{kHz}$ showed acceptable for bulk heat treatment of rails values of heating uniformity, limit temperatures and rates of heating the main working areas of the rail, both on the surface, and in-depth of the narrow heating zone of $40 \mathrm{~mm}$.

5. Development of a test sample of a complex-shaped split inductor without magnetic circuits by the performed calculations and the conducted experiments on heating the welded butt joint of rail of R65 type, confirmed the correctness of the calculation model of the «inductor-workpiece» induction system.

1. Gubatyuk, R.S. (2019) Heat treatment of welded joints of high-strength railway rails (Review). The Paton Welding J., 2, 41-48.
2. Taras, P., Fireteanu, V. (2010) Inductors for continuous induction heating of rails. Induktsionnyj Nagrev, 14(4), 21-26 [in Russian].

3. Skoblo, T.S., Sapozhkov, V.E., Aleksandrova, N.M., Sidashenko, A.I. (2014) Quality of thermally-hardened rails and rail bases. Investigations. Theory. Equipment. Technology. Operation. Ed. by T.S. Skoblo. Kharkov, LLC Shchedra Sadyba Plus [in Russian].

4. Pantelejmonov, E.A., Pismenny, A.A. (2015) Inductor for continuous heating in hardening of railway rail head. The $\mathrm{Pa}$ ton Welding J., 3-4, 74-76.

5. Panov, V.I. (2018) Evaluation of technological heredity of metal of solid structures before their repair welding. Svarshchik, 1, 9-11 [in Russian].

6. (2005) DSTU 4344:2004: Normal rails for full-gauge railway. General specifications. Kyiv, Gospotrebstandart Ukrainy [in Ukrainian].

7. (2013) http://magnit-m.ru/catalog/ustanovki-induktsionnogonagreva-tvch/termoobrabotka-svarnykh-relsovykh-stykov/ uin-001-100-rt-p

8. (2013) http://magnit-m.ru/catalog/ustanovki-induktsionnogonagreva-tvch/termoobrabotka-svarnykh-relsovykh-stykov/ uin-001-100-r-tsm

9. Zhan Xinwei, Wang Shuqing, Shao Yangdao, at. al. (2015) Non-contact type opening/closing split induction heating device for rail welded joints. China Pat. CN 201510540567.

10. Ding Wei, Song Hongtu, Li Li, at. al (2012) Heat treatment device of welding joint of steel rail. China Pat. CN 201120285569.

11. Pysmennyi, O.S., Pysmennyi, P.O., Prokofiev, O.S., Yukhymenko, R.V., Gubatyuk, R.S. (2012) Induction installation for heat treatment of rail welded joints. Ukraine Pat. on utility model UA 75027 [in Ukrainian].

12. Panteleimonov, E.O. (2017) Complex for heat treatment of railway rail welded joints in situ. Ukraine Pat. on utility model 114593 [in Ukrainian].

13. Pysmennyi, O.S., Panteleimonov, E.O., Rymar, S.V., Gubatyuk, R.S. (2017) Induction device for heat treatment of railway rail welded joints. Ukraine Pat. on utility model 116086 [in Ukrainian].

14. Panteleimonov, E.O., Gubatyuk, R.S. (2016) Induction device for heat treatment of railway rail welded joints. Ukraine Pat. On utility model 109123 [in Ukrainian].

15. Zhan, X., Wang, S. (2005) Research on the improvement of rail head hardening. Technology on railway. Proc. of the Eastern Asia Society for Transportation Studies, 5, 263-271.

16. Slukhotsky, A.A., Ryskin, S.G. (1974) Inductors for induction heating. Leningrad, Energiya [in Russian].

17. Rezanov, V.M., Fedin, A.V., Bashlykov, A.V. ((2013) Differential hardening of rail welded joints. Vestnik VNIIZhT, 2, 28-34 [ in Russian].

18. Shamov, A.N., Bodazhkov, V.A. (1963) Design and operation of high-frequency installations. Moscow, Leningrad, Mashgiz [in Russian].

19. Bar, I.G., Polevoj, S.V. (1989) Repair of live overhead power lines. Moscow, Energoatomizdat [in Russian].

Received 22.03.2020

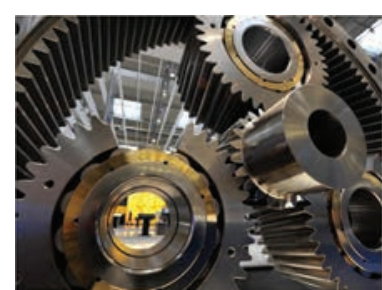

Zaporozhye Industrial Forum

08-10 September, 2020, Zaporozhye, Ukraine

26th International Specialized Exhibition of Industrial Solutions

https://expo.zp.ua/zpf/ 


\title{
ADDITIVE TECHNOLOGIES OF POLYMER MATERIALS (Review)
}

\author{
O.P. Masiouchok, M.V. Iurzhenko, R.V. Kolisnyk and M.G. Korab \\ E.O. Paton Electric Welding Institute of the NAS of Ukraine \\ 11 Kazymyr Malevych Str., 03150, Kyiv, Ukraine. E-mail: office@paton.kiev.ua
}

\begin{abstract}
The paper gives the analysis of the state of the art of 3D technologies of polymer materials, which is based on publications presented both in open sources as well as in a wide range of scientific and technical journals, including the own experience of the authors in 3D printing using thermoplastic and thermosetting polymers. The history of additive technologies, state of the art and trends of the development of the market of three-dimensional printing are considered. The classification of the most widespread in the world technologies of additive manufacturing of products from polymer materials depending on the methods of processing plastics is offered, their short description is given, their features, advantages and disadvantages are presented. 27 Ref., 1 Table, 6 Figures.
\end{abstract}

Ke yw ords : additive technologies, 3D printing, polymer materials

The current pace of industrial development requires the choice of production technologies that can be implemented in the shortest possible terms with the involvement of minimal monetary investments to obtain high-quality products as a result. Nowadays these requirements are met by additive technologies (Additive Manufacturing, Additive Fabrication or AM-, AF-technologies), which find an increased application in all spheres of human life and are one of the most interesting and promising areas of industrial production $[1,2]$. The additive technologies are also called the technologies of layer-by-layer synthesis, 3D printing, 3D technologies, rapid prototyping, layer-by-layer modeling, digital production, etc.

The generalized term «additive» is accepted to denote a group of technologies that allow layer-by-layer creation of three-dimensional objects based on the data of CAD (Computer-Aided Design) model by gradual adding a source material to the future product, which differs from traditional methods of a part forming when an excess material is removed from the workpiece array applying mechanical treatment. The CAD model is a digital mock-up of the object, which should be formed with the use of additive technologies in the 3D printer. The three-dimensional CAD model can be both developed according to the own design applying the method of computer designing, as well as to create from the data collected by means of 3D-scanner.

The essence of Additive Manufacturing (AM) can be illustrated as follows.

The key feature of 3D printing is a significant reduction in the duration of a process chain from the idea or drawing to the process of manufacturing a product, and at the same time a reduction in labor, material and power consumption of manufacturing. Thus, additive manufacturing makes it possible to create final functional products directly from the designer or engineer through the computer and the printer without the use of additional technological operations.

Although 3D printing is considered to be one of the major discoveries of the XXI century, in fact, additive technologies appeared in 1984, when the American researcher Charles W. Hull, founder of the Company 3D Systems, developed the technology of layer-by-layer «growing» of physical three-dimensional objects from a photopolymer composition [3]. The technology was called «stereolithography» (STL). The author received a patent for his invention only in 1986, and a year later, the engineer presented to the public his industrial device for three-dimensional printing [4]. As far as the term «3D printer» appeared only in 1993, the machine of Charles Hull was called a «stereolithography apparatus.» Around the same time, other 3D printing technologies began to be developed. In 1985, Michael Feygin proposed the technology of lamination called LOM (Laminated Object Manufacturing), which allows binding individual layers of material using a special bead heated to a certain temperature [5]. In 1986, Carl Decard, an associate of the University of Texas, applied for a patent describing the process of rapid prototyping of products using the technology of SLS (Selective Laser Sintering) [6], the essence of which consists in layer-by-layer sintering of the powder material by a laser beam. In 1989, Scott Crump, later the founder of Stratasys, announced the development of fused deposition modeling (FDM) technology. When using this technology, the formation 
Basic methods and technologies of additive manufacturing from polymer materials

\begin{tabular}{|c|c|c|}
\hline $\begin{array}{l}\text { Method of forming } 3 \mathrm{D} \\
\text { products }\end{array}$ & 3D printing technology & $\begin{array}{l}\text { Essence of technology or the principle of creating } \\
\text { 3D objects }\end{array}$ \\
\hline Extrusion & $\begin{array}{l}\text { Fusing deposition modeling (FDM) or fused filament } \\
\text { fabrication (FFF) }\end{array}$ & $\begin{array}{c}\text { Successive deposition of layers of molten } \\
\text { thermoplastic polymer material, which reproduce } \\
\text { the contours of the digital model }\end{array}$ \\
\hline \multirow{4}{*}{ Photopolymerization } & Stereolithography (SLA or SL) & $\begin{array}{l}\text { Use of photopolymer resins solidifying under } \\
\text { the action of ultraviolet radiation }\end{array}$ \\
\hline & Digital light processing (DLP) & $\begin{array}{l}\text { Use of photopolymer resins solidifying when } \\
\text { illuminated by a digital LED projector (DLP) }\end{array}$ \\
\hline & Polyjet & \multirow{2}{*}{$\begin{array}{c}\text { Layered solidification of liquid photopolymer materia } \\
\text { under the action of ultraviolet radiation }\end{array}$} \\
\hline & Multi jet modeling (MJM) & \\
\hline \multirow{3}{*}{ Granulation } & Selective laser sintering (SLS) & $\begin{array}{c}\text { Successive sintering of layers of powder material } \\
\text { using high power lasers }\end{array}$ \\
\hline & Selective heat sintering (SHS) & $\begin{array}{l}\text { Melting of thermoplastic powder layers by means } \\
\text { of a thermal radiator }\end{array}$ \\
\hline & $\begin{array}{l}\text { Color jet printing (CJP) (formerly known as } \\
\text { three-dimensional printing - 3DP) }\end{array}$ & $\begin{array}{l}\text { Layer-by-layer gluing and painting of composite } \\
\text { powder bases on plastics }\end{array}$ \\
\hline Lamination & $\begin{array}{l}\text { Manufacturing of objects by the method } \\
\text { of LOM — laminated object manufacturing } \\
\text { or PSL — plastic sheet lamination }\end{array}$ & $\begin{array}{l}\text { Layer-by-layer gluing of film materials with } \\
\text { the subsequent formation (cutting) of model } \\
\text { by means of a laser beam or the cutting tool }\end{array}$ \\
\hline
\end{tabular}

of the object is carried out in layer-by-layer depositing, in other words by surfacing of a molten thread of thermoplastic material, which is extruded through the extrusion head onto the cooled platform. Then the process of development of the new technologies and improvement of the existing ones was accelerated and in 1993 a breakpoint came, which made additive methods of manufacturing products to be widely available, and the term «3D printing» to be known around the world. The students Jim Bradt and Tim Anderson of the Massachusetts Institute of Technology, who were operating on a dissertation on powder-based inkjet printing, introduced layer-by-layer synthesis into a conventional desktop printer [8]. In 1995, Tim and Jim founded the Company Z Corporation, which launched the technology at the market. In 2012, the technology was acquired by the Company together with the 3D systems Corporation. Today, under its brand the former models of $\mathrm{Z}$ Corporation are sold worldwide.

Nowadays, the market of three-dimensional printing is growing rapidly and replenished with new models of unique production equipment, the possibilities of which are almost limitless. Printed parts and assemblies of aircraft, printed car body, printed residential construction, printed clothing, printed medical implants represent far not the whole list of achievements of modern additive technologies. However, the most interesting thing is that it is possible to print using almost any materials: polymers, engineering plastics, composite powders, different types of metals, ceramics, sand, concrete, wood, and recently even food and biological substances [9-11]. Due to the availability and practicality 3D printing with the use of different types of plastic is the most common today.
All the technologies of 3D printing by plastic (Table) are based on four basic methods of processing polymer materials used in the industry for manufacturing of plastic products: extrusion, photopolymerization, granulation and lamination.

The most widespread 3D printing technologies which are used in everyday life (in the office) and industry are the formation of products applying layer-by-layer surfacing (FDM) and stereolithography (SLA). But, nevertheless, each of the abovementioned technologies finds its consumer, and also has advantages and features that arouse interest. Let us review each 3D printing technology in more detail.

FDM/FFF 3D printing. FDM layer surfacing is the most widespread 3D printing technology in the world, based on millions of 3D printers from the cheapest to industrial 3D printing systems. To create products applying FDM method of 3D printing, filament is used made of various thermoplastic materials, which are delivered in the form of coils. The filament can be of two standard diameters: 1.75 and $3 \mathrm{~mm}$ depending on the printer specification [12].

As in all 3D printing technologies, the first step in making a physical object is construction of a digital 3D model. The 3D model in STL format is transmitted to the 3D printer software. The program automatically (or manually by operator) places the model in the virtual space of the operating chamber. Then the program, if necessary, calculates the elements of auxiliary structures - supporting structures for overhanging elements of the object and calculates the required amount of consumables, as well as the time for "growing» the prototype. Before starting the process of printing, the model is automatically divided into horizontal layers and the ways of moving extruder (print head) are cal- 

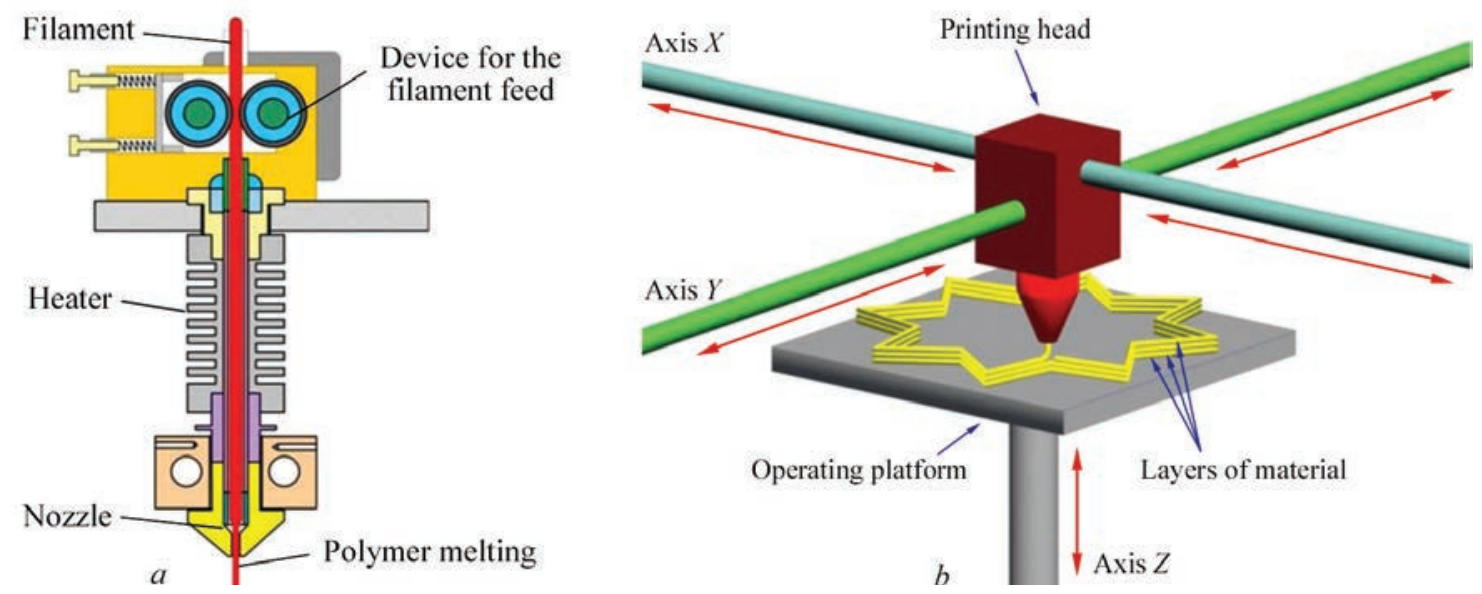

Figure 1. Scheme of extruder of FDM 3D printer $(a)$ and the process of creating a three-dimensional model $(b)$ by it [13]

culated. Extruder represents a device equipped with a mechanical drive for supplying filament, a heating element for its melting and a nozzle through which a direct extrusion-ejection of a molten polymer material on the surface of a product is carried out (Figure 1, a).

The received settings are saved, the model is converted into the control code for the $3 \mathrm{D}$ printer. Then the filament from the coil is unwound for its introduction into the extruder and directly the process of 3D printing is started: the extruder melts the filament and with a high accuracy in thin layers supplies the melt of the polymer material onto the operating surface of the 3D printer according to the printing algorithm and CAD of 3D-model. After deposition the layer, the polymer material is cooled and solidified, and the platform on which the object is formed is lowered to a level equal to the thickness of the deposited layer. The movement of the head and the platform in 3 planes (Figure $1, b$ ) is set by an algorithm developed in advance with the help of a special software.

After the process of product manufacturing is completed, the auxiliary structures are removed (manually or dissolved in a special solution), and the finished product can be used in a printed form or subjected to any method of further processing.

The main advantages of FDM 3D prinitng are ease of using and the absence of special requirements for the room (suitability for using in the office); low cost of FDM printers and consumables; the possibility of using a wide range of types of plastic, depending on the needs and colors.

The main disadvantages of the technology are the need in creating supporting structures for overhanging elements, which after completion of printing have to be removed; low separating capacity, which leads to layering of the surface of the manufactured model; presence of thermal shrinkage is possible, which leads to a change in the size of a product after cooling.

SLA 3D printing. Stereolithography is not only one of the first 3D technologies of additive manufac- turing in the world, but also one of the most pretentious [14-16]. That is why it is most in demand in the medical field, for example, for manufacture of implants, etc. As a consumable it uses liquid photopolymer resin. Under the influence of laser radiation on those parts of the photopolymer that correspond to the walls of the specified object, their layer-by-layer solidification and the formation of the finished product occur.

SLA 3D printing as well as printing by the FDM method, in parallel with construction of the object demands using of the supporting structures, which serve for fixation of a part of a product to the base of the platform and prevent deformation of the manufactured model in the presence of overhanging elements in it. There are two basic structures of stereolithographic 3D printers: conventional, which is used more often in industrial devices, and the so-called «3D SLA upside down printing», which is less common and found mainly in desktop 3D printers.

In the conventional variant of the SLA 3D printer the laser is located above, and the operating platform gradually lowers down (Figure 2). In a tank filled with a special liquid (mixture of photopolymer and reagent-solidifier), which looks like epoxy resin, a mesh platform is immersed to a depth of not more than 0.05$0.13 \mathrm{~mm}$ (this is precisely the thickness of one layer). After that, the laser is activated, as a result of which the liquid solidifies on certain parts of the material and sticks to the platform. Thus, the 3D printer creates the first layer of the product. Each layer represents a 2D image that is traced by a laser, according to the data embedded in a three-dimensional digital model. Then, the platform is lowered by one step, equal to the thickness of one layer, down (in the $Z$ coordinate) and after leveling the surface of the liquid material, the laser is reactivated, continuing to build the next layer on the $X-Y$ coordinate axes. The cycles of forming layers are repeated before construction of a product.

The principle of 3D printing process used in desktop 3D printers is identical, with the only difference 


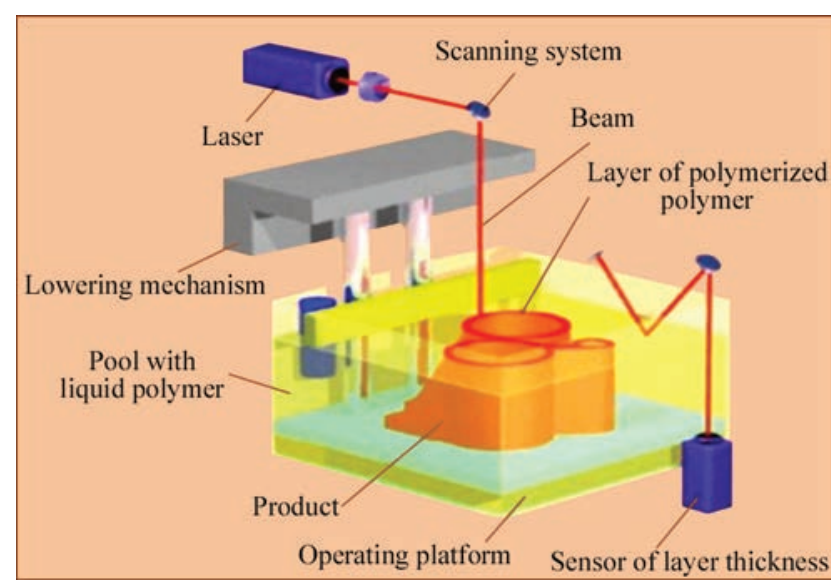

Figure 2. Scheme of SLA 3D printing process [17]

that the laser is located under the container with a photopolymer, and during construction of products, the platform does not lower, but gradually rises.

The feature, which is common to both variants, is that a product should be washed in special solutions to complete 3D printing, as well as irradiated with ultraviolet light. The first is required for the final cleaning of the manufactured model from photopolymer remnants, and the second for complete solidification of a product.

The main advantages of SLA 3D printing are high accuracy of construction of the finished product; the obtained model has a high compressive strength and ability to withstand temperatures of up to $100{ }^{\circ} \mathrm{C}$; ability of producing complex models with preservation of small elements of decor; small amount of wastes; wide selection of consumables.

The main disadvantages of the technology are the massiveness of the equipment (large size and weight); high cost of the equipment and consumables; lack of possibility to use different materials in one cycle; shrinkage of the material during solidification, resulting in low flexural and impact strength; the need in ultraviolet treatment of the product after printing.

DLP 3D printing. Based on the SLA 3D printing method, several other methods of additive technologies were developed, one of which is DLP 3D printing. The difference between these methods is that instead of a laser, DLP 3D printers use a digital LED projector, which illuminates the entire layer simultaneously and not gradually like a laser in stereolithography does $[18,23]$. It is assumed that DLP printing allow reproducing objects faster. However, this difference is not so great as to replace SLA 3D printers from the market of 3D printing.

As in SLA technology, there are two variants of devices for DLP 3D printing: in one the construction of the object occurs from the bottom-up (the operating platform is lowered), and in the other on the contrary - the construction of the object occurs from the top-down (the operating platform rises).
The main advantages of DLP 3D printing: higher printing speed as compared to SLA 3D printers; high printing accuracy; large selection of consumables; affordable cost of equipment due to the use of DLP projectors in printers, which are much cheaper than laser systems (as in SLA).

The main disadvantages of the technology: accuracy of printing is inferior to the accuracy of SLA 3D printing and depends not only on the 3D printer, but also on the used material (the more it is filled with pigments and light blockers, the more accurate products will be printed from it) and the environment (during polymerization namely in DLP printers a lot of heat is released, which leads to the acceleration of chemical reactions); the need for additional irradiation of the product after printing for final solidification.

Multi-jet 3D printing (polyjet and MJM 3D printing). 3D printing using PolyJet and MJM technology is similar to printing with a conventional inkjet 2D printer, but instead of using ink, layer-by-layer spraying of liquid light-sensitive polymer materials takes place on a special inner pad with a subsequent irradiation of each layer with ultraviolet light $[19,23]$. MJM and PolyJet technologies are almost indistinguishable from each other. The difference in names is predetermined by the corresponding patents: Multi Jet Modeling technology belongs to the Company 3D Systems, and PolyJet — to the competing Company Stratasys.

With the help of a printhead equipped with nozzles, from which liquid consumables: the model material - material A and the support material — material $\mathrm{B}$ (Figure 3) are sprayed in thin layers in accordance with the computer CAD 3D model. Each layer is polymerized by the light of an ultraviolet lamp immediately after deposition. The layers are deposited to each other to create the specified three-dimensional model. As a result, a full-color three-dimensional object is produced that can be used immediately after the printing process is completed without additional surface treatment. The material of the supporting structures for the overhanged elements of the future model, used in the printing process, is easily removed after printing mechanically or washed off with water or dissolved in a special solution (for PolyJet 3D printing) or melted in a special furnace (for MJM 3D printing).

The main advantages of multi-jet 3D printing (PolyJet and MJM) 3D are high accuracy $(0.016-0.085$ $\mathrm{mm}$ ) and speed of building models with a complex geometry, excellent physical and mechanical properties of products; easy removal of supports, absence of contact with liquid photopolymer and simple replacement of heads; possibility of surface treatment (gluing, grinding, painting, priming, deposition of various coatings, etc.); ability to print with different materials during manufacture of a single 3D model in a single 
working cycle; possibility of application in the office; high speed of manufacturing of large-scale projects.

The main disadvantage of the technology is the high cost of 3D printing.

SLS 3D printing. Selective laser sintering is one of the methods of 3D printing, which is widely used in expensive professional 3D printers and is characterized by high quality of products [21]. With its help it is possible to achieve the result close to the reproduction of products by injection molding. This procedure allows creating fully finished products of complex geometric shapes within a matter of hours, which explains its popularity among industrial organizations around the world.

The process of SLS printing consists in layer-by-layer sintering of powder material particles to form a physical object according to the specified CAD model. Sintering of the material occurs under the influence of a beam of one or more lasers (Figure 4).

Before the start of the construction process, a special section of the 3D printer is filled with consumables, after which the process of $3 \mathrm{D}$ printing is started. It is interesting that immediately before reproduction, the consumables are heated almost to the melting point, which facilitates and accelerates the operation of the SLS installation.

With the help of a laser installation and a scanning mirror, the laser beam is directed to the necessary areas of powder, sintering them together. After sintering the first layer, a special mechanism adds a thin layer of powder on the top of it, and the process takes place again until a complete construction of the product. In the process of printing, the platform of the operating chamber is constantly lowered (the step is equal to the thickness of the printed layer). Thus, the area of interaction between the material and the laser beam is always on the same level, and the reproduction of the object occurs from the bottom-up.

The SLS process does not require a construction of special support structures. Here, in capacity of supporting structures for construction a model of a complex geometry an unused powder is used, which after removal of the finished product is cleaned and can be reused for printing.

The main advantages of SLS 3D printing technology are the ability of creating complex models of high strength and quality (almost without visible layer-by-layer structure on the models); no need in constructing supports; high speed and efficiency of printing: SLS printers do not require a full melting of particles of the material that allows them to work much faster than other powder 3D printers; the process is almost waste-free - unused material (up to $90 \%$ of powder) can be reused for printing.

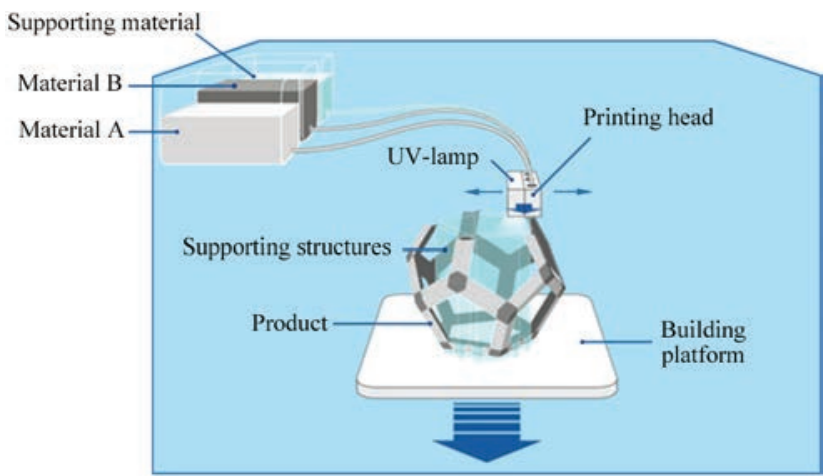

Figure 3. Scheme of PolyJet 3D printing process [20]

The main disadvantages of the technology are the complexity, cumbersomeness and a high cost of equipment; possible contamination during manufacturing: the powder is volatile and in case of careless handling it rises into the air, clogging the surrounding space and getting into the human lungs; it requires a long-term preheating of the powder, as well as time for cooling the finished model before removing the powder remnants; the complexity of processing the product after printing (annealing) in the special furnace for final sintering of the powder; shrinkage of a part after annealing sometimes reaches the values of $30 \%$ (and on average 8-10\%) from the initial volume.

SHS 3D printing. Selective heat sintering is a 3D printing technology that is similar to selective laser sintering. The only significant difference is the use of an infrared radiation source instead of a laser for melting layers of thermoplastic powder [19, 23].

The process of SHS 3D printing is as follows: onto a plate made of quartz glass (mask), using a special material that reflects infrared radiation, a pattern is applied corresponding to the inverted cross-section of the current layer of the object. Then, the required amount of consumables for construction of one layer is supplied to the operating platform. The powder is spread with a special roller, and its excess is removed.

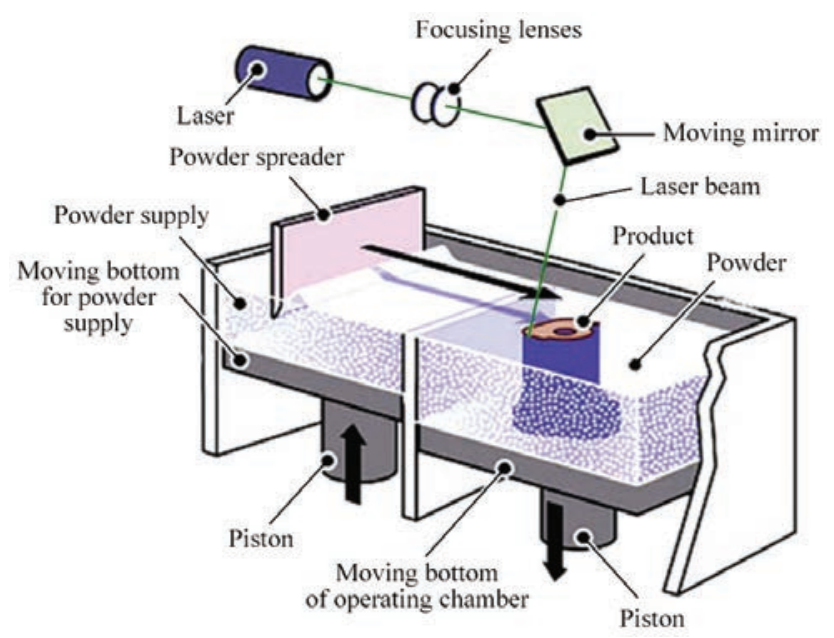

Figure 4. Scheme of SLS 3D printing process [22] 
The quartz plate is located between the construction area and the radiation source. Once everything is ready, the sintering of the first layer begins. As far as the radiation goes through the plate, those its parts that reflect the radiation do not leave a trace on the operating platform. The remaining parts of the powder are sintered between each other. Upon completion of the first layer, the operating platform is lowered to the level of one layer, then the next portion of powder is deposited, the old pattern of the quartz plate is removed and a new one is deposited. This is how the whole model is built. After the end of 3D printing, a product is removed from the 3D printer, it is removed from the platform and cleaned of excess material. If necessary, the further processing is performed.

The main advantages of SHS 3D printing technology are high printing speed; the cost of SHS of the 3D printer and the cost of 3D printing on it is many times lower as compared to SLS with 3D printers; no need in construction of supports; the material left after printing can be reused, which reduces the cost of the process; the ability to create products with a complex geometry.

The main disadvantages of the technology are a low power efficiency, due to which the choice of consumables in this technology is much smaller; the need in additional annealing of the obtained products to achieve a higher strength; a lower strength of finished products as compared to the products made applying other industrial technologies.

CJP 3D printing. Color inkjet 3D printing allows a quick creation of both monochrome and colored objects from a composite powder [23]. As consumables two types of material are used - basic and binding. The basic material is powder plastic, which is used to form layers of the product, while the binder in the form of an adhesive substance simultaneously glues together the particles of the material in the required places in accordance with the computer 3D model and paints them in a preliminary specified color. First, the polymer powder is uniformly distributed in a thin layer over the entire platform plane of the operating chamber of

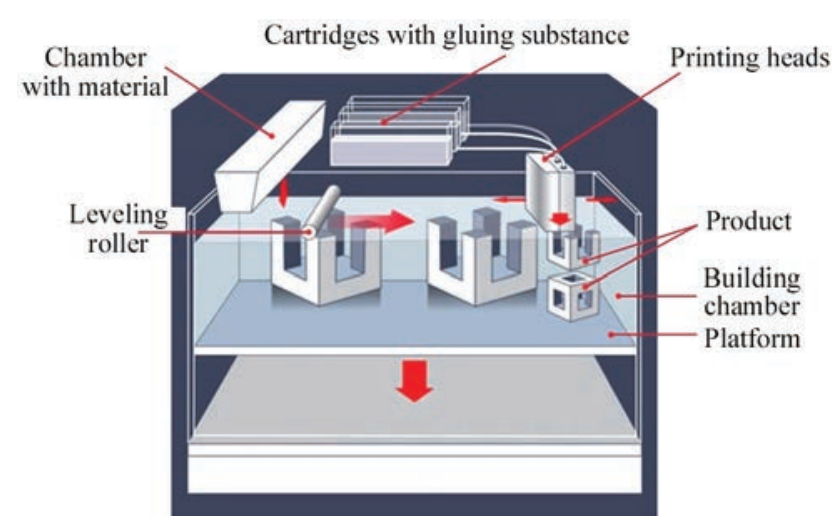

Figure 5. Scheme of CJP 3D printing process [24] the 3D printer (Figure 5), then a binder is applied to it and the platform is shifted down to the thickness of the layer (in the range from 0.089 to $0.102 \mathrm{~mm}$ ). Then the process is repeated and as a result of subsequent cycles the finished product is formed layer-by-layer.

The powder, which is not used during the printing process to form a model (does not glue together), acts as a supporting structure, which allows creating objects with a complex geometry. At the end of 3D printing cycle, the same residual powder can be collected and reused. After the formation of a product is completed, a polymer powder remains on its surface, for the removal of which a cleaning chamber is provided in the $3 \mathrm{D}$ printer, which operates with the help of a compressed air. Then, the formed product is impregnated with cyanoacrylate, better known as «superglue» to increase strength and long life, as well as to achieve brighter colors.

The main advantages of the technology SHS 3D printing are low cost of manufacturing prototype due to a low cost of the material and its waste-free use; high speed of 3D printing and quality of models; available color palette reaches 390000 shades; the accuracy of construction surfaces with various degrees of complexity ranges from 0.4 to $0.1 \mathrm{~mm}$; the wall thickness ranges from $0.5 \mathrm{~mm}$, the layers are in the range from 0.089 to $0.102 \mathrm{~mm}$; the prototypes are easily polished, glued and painted; lack of supporting structures.

The main disadvantages of the technology are that the models have a hygroscopic surface of high roughness and products require a careful processing after molding due to their brittleness.

LOM 3D printing. Manufacturing of three-dimensional objects by the method of lamination consists in layer-by-layer gluing of materials in the specified coordinates (from a computer 3D-model) with the subsequent cutting of remainders [23, 25]. As the consumables usually polyvinylchloride (PVC) film is used with a thickness of $0.15 \mathrm{~mm}$ in five colors: semi-transparent (amber), red, blue, cream, black. The product is formed on a special substrate of a movable (up and down) platform, which is supplied with consumables from a roll or in a separate sheet, distributed under a certain pressure and heated to the desired temperature by a roller (Figure 6). After that, the contour of the first layer of the model is cut with a laser. After that, the platform is lowered to the height of one layer, the roll is rotated (or a new sheet is applied) and the next layer of material is applied on the top of the first layer, on the lower part of which the binder is usually applied. Due to heating and depositing under pressure, a gluing (lamination) of layers occurs. The process of cutting layers and applying new sheets of material is repeated until the complete formation of a final product. 
At the end of the 3D printing process, a part is removed from the 3D printer and cleaned of scraps. Then, if necessary, additional mechanical treatment: grinding, varnishing, painting is carried out.

The main advantages of LOM 3D printing technology are the possibility of full-color printing with a high resolution along the $X$ and $Y$ axes; availability and cheapness of consumables; for models with overhanging or horizontally protruding elements the formation of supporting structures is not required.

The main disadvantages of the technology are the extremely limited choice of materials for creating models; insufficiently high strength of products in the plane of layers - there is a risk of delamination; increased surface roughness; the thickness of the layer depends entirely on the thickness of the used sheet material, due to which the model is formed rough, and mechanical treatment for smoothing is not always available, as it can lead to delamination; a large amount of consumables (trimmings) goes to waste; manufacturing with increased fire hazard and smoke emission.

\section{Conclusion}

According to analysts, the prospects for today are such that in the near future, three-dimensional printing will be used in all areas of human activity [27]. Therefore, it is not surprising that the pace of development of additive technologies is rapidly increasing every year and today in the dynamics of development the market of additive technologies is ahead of other industries.

1. Diyachenko, V.A., Chelpanov, I.B., Nikiforov, S.O., Hozonhonova, D.D. (2015) Materials and processes of additive technologies (rapid prototyping). Ulan-Ude, BNC SO RAN, Russia [in Russian].

2. Ligon, S.C., Liska, R., Stampfl, J. et al. (2017) Polymers for $3 \mathrm{D}$ printing and customized additive manufacturing. Chem. Rev., 117, 10212-10290.

3. Bourella, D.L., Beaman, J.J., Leub, M.C., Rosenc, D.W. (2009) A brief history of additive manufacturing and the 2009 roadmap for additive manufacturing: Looking back and looking ahead. RapidTech US-Turkey Workshop on Rapid Technologies, 2009, Istanbul.

4. Hull, C.W. (1986) Apparatus for production of three dimensional objects by stereolithography. USA Pat. 4575330A.

5. Feygin, M. (1986) Apparatus and method for forming an integral object from laminations. USA Pat. 872102.

6. Deckard, C.R. (1989) Method and apparatus for producing parts by selective sintering. USA Pat. 4863538A.

7. Crump, S.S. (1992) Apparatus and method for creating three-dimensional objects. USA Pat. 5121329A.

8. Bredt, J.F., Suh, N.P., Waldman, F.A. (1995) Three-dimensional printing techniques. USA Pat. 5387380.

9. Zarek, M., Layani, M., Cooperstein, I. et al. (2016) 3D printing of shape memory polymers for flexible electronic devices. Adv. Mater., 28, 4449-4454.

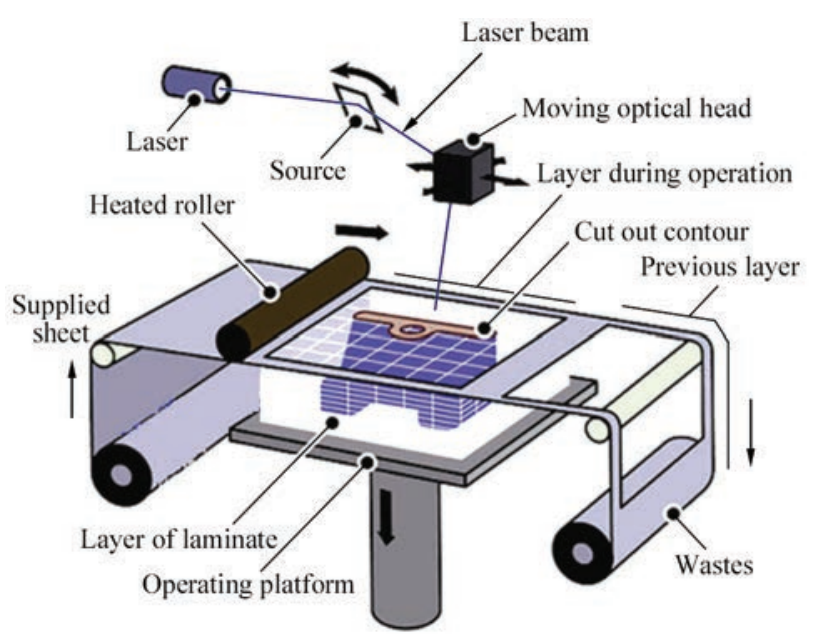

Figure 6. Scheme of LOM 3D printing process [26]

10. Salmi, M., Paloheimo, K.S, Tuomi, J. et al. (2013) Accuracy of medical models made by additive manufacturing (rapid manufacturing). J. of Cranio-Maxillofacial Surgery, 41(7), 603-609.

11. https://www.orgprint.com/wiki/3d-pechat/sfery-primenenija-3D-pechati

12. Turner, B.N., Strong, R., Gold, S.A. (2014) A review of melt extrusion additive manufacturing processes: I. Process design and modeling. Rapid Prototyping J., 0(3), 192-204.

13. http://3dtoday.ru/wiki/3dprint_basics/

14. Kazemi, M., Rahimi, A. (2015) Supports effect on tensile strength of the stereolithography parts. Rapid Prototyping, 21, 79-88.

15. Jacobs, P.F. (1992) Rapid prototyping \& manufacturing: fundamentals of stereolithography. Society of Manufacturing Engineers, New York, USA.

16. Zhang, X., Jiang, X., Sun, C. (1999) Micro-stereolithography of polymer and ceramic microstructures. Sensor Actuat APhys., 77-149.

17. http://3dprofy.ru/stereolitografi ya-sla/

18. Gibson, I., Rosen, D.W., Stucker, B. (2010) Additive manufacturing technologies. New York, Springer.

19. Kazmer, D. (2017) Three-dimensional printing of plastics. In: Applied plastics engineering handbook. $2^{\text {nd }}$ Ed. Amsterdam,William Andrew Publ., 617-634.

20. http://3d.globatek.ru/3d_printing_technologies/polyjet/

21. Peyre, P., Rouchausse,Y., Defauchy, D. , Régnier, G. (2015) Experimental and numerical analysis of the selective laser sintering (SLS) of PA12 and PEKK semi-crystalline polymers. J. Mater. Proc. Technol., 225, 326-336.

22. https://3dprinter.ua/additivnye-tehnologii-chto-jeto/

23. Zlenko, M.A., Nagajcev, M.V., Dovbysh, M.V. (2015) Additive technologies in mechanical engineering: Manual for engineers. Moscow, GNC RF FGUP NAMI [in Russian].

24. http://blog.iqb-tech.ru/cjp-technology

25. Antonova, V.S., Osovskaja, I.I. (2017) Additive technologies: A Tutorial. St.-Petersburg, VShTJe SPbGUPTD Russia [in Russian].

26. https://3d-expo.ru/ru/article/izgotovle-nie-obek-tov-metodom-laminirovaniya-lom-78841

27. Androshchuk, G.O. (2017) Additive technologies: perspectives and problems of 3D printing. Nauka, Tekhnologiï, Innovatcii, 1, 68-77. 


\section{EBW INSTALLATIONS FOR GRANULAR METALLURGY}

Installations for granular metallurgy are designed for degassing, filling and vibration compaction of granules in

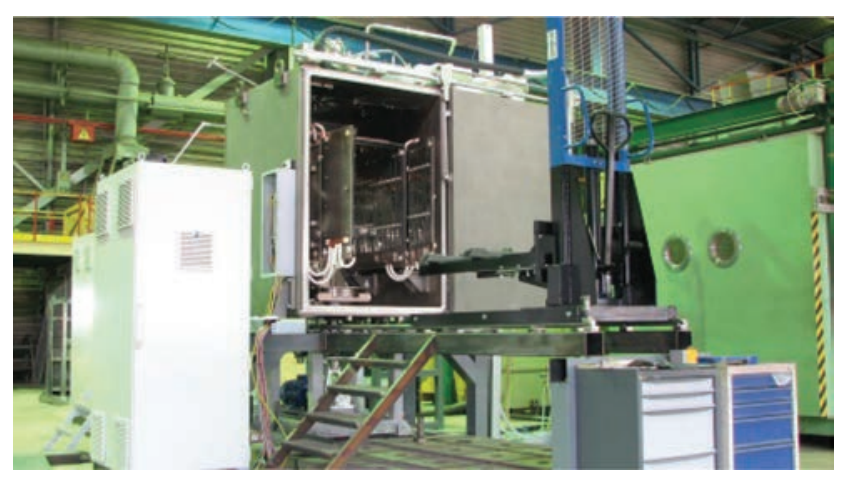

capsules with a subsequent sealing applying electron beam welding.

In the installations the following technological operations are performed:

- heating and degassing of products (capsules) to remove adsorbed moisture and gases from the inner and outer surfaces;

- degassing of granules when filling a product;

- vibrocompaction of granules in a product during filling process;

- electron beam welding of the plug, installed in the neck of a product;

- cooling of a filled and sealed product in vacuum.

The E.O. Paton Electric Welding Institute produces three standard sizes of installations for granular metallurgy: KL168, KL114 and KL139.

Basic characteristics of installation KL139

\begin{tabular}{|c|c|c|}
\hline & Description of parameter & Value \\
\hline 1 & $\begin{array}{l}\text { Overall dimensions of installation, } \mathrm{mm} \text { : } \\
\text { length } \\
\text { width } \\
\text { height }\end{array}$ & $\begin{array}{l}7980 \\
4470 \\
3140\end{array}$ \\
\hline 2 & Weight of installation, $\mathrm{t}$ & 10 \\
\hline 3 & $\begin{array}{l}\text { Inner dimensions of vacuum chamber, mm: } \\
\text { length } \\
\text { width } \\
\text { height }\end{array}$ & $\begin{array}{l}1500 \\
1300 \\
1854\end{array}$ \\
\hline 4 & $\begin{array}{l}\text { Maximum dimensions of product to be welded, mm of a cylinder type } \\
\text { diameter } \\
\text { height } \\
\text { of a disc type (vertical position) } \\
\text { diameter } \\
\text { width }\end{array}$ & $\begin{array}{l}600 \\
650 \\
800 \\
400\end{array}$ \\
\hline 5 & Weight of product to be welded, $\mathrm{kg}$, $\max$ & 1000 \\
\hline 6 & Depth of weld, mm, not less than & 6 \\
\hline 7 & Working vacuum in the vacuum chamber, Pa, not worse than & $2,66 \cdot 10^{-3}$ \\
\hline 8 & Working vacuum in the gun, $\mathrm{Pa}$, not worse than & $6,67 \cdot 10^{-3}$ \\
\hline 9 & Leakage into an empty and clean chamber, $\mathrm{Pa} \cdot 1 / \mathrm{s}(\mathrm{mm} \mathrm{Hg} \cdot 1 / \mathrm{s})$, not more than & $5(0,0375)$ \\
\hline 10 & Time for evacuation of the vacuum chamber (up to $2.66 \cdot 10^{-3} \mathrm{~Pa}$ ), min, not more than & 30 \\
\hline 11 & Temperature of product heating, ${ }^{\circ} \mathrm{C}, \max$ & 600 \\
\hline 12 & Amplitude of product vibration, $\mathrm{mm}$, max & 2 \\
\hline 13 & Range of product vibration frequency, $\mathrm{Hz}$ & $5-30$ \\
\hline 14 & $\begin{array}{l}\text { Power unit with high-voltage power source of } 6 \mathrm{~kW} / 60 \mathrm{kV} \text { : } \\
\text { accelerating voltage, } \mathrm{kV} \\
\text { range of welding current control, } \mathrm{mA}\end{array}$ & $\begin{array}{c}60 \\
1-100 \\
\end{array}$ \\
\hline 15 & Cycle of preparation, heating, filling and welding of one product, working shifts & $1-2$ \\
\hline 16 & $\begin{array}{l}\text { Technical parameters provided by the Customer: } \\
\text { - power supply - in accordance with the standard of Germany DIN EN } 60204 \text {, item } 4.3 \\
\text { - power consumption, } \mathrm{kV} \cdot \mathrm{A} \text {, not more than } \\
\text { - consumption of cooling water, } 1 / \mathrm{h} \\
\text { - temperature of cooling water at the inlet, }{ }^{\circ} \mathrm{C} \\
\text { - pressure of cooling water, } \mathrm{kg} / \mathrm{cm}^{2} \text {, not less than } \\
\text { - pressure of compressed air, } \mathrm{kg} / \mathrm{cm}^{2} \text {, not less than } \\
\text { - room temperature, }{ }^{\circ} \mathrm{C} \text {, not more than } \\
\text { - humidity, } \% \text {, not more than } \\
\text { - presence of air conditioning } \\
\text { - presence of crane with a load-carrying capacity of at least } 1.5 \mathrm{t}\end{array}$ & $\begin{array}{c}380 \mathrm{~B}, 50 / 60 \text { Гц } \\
120 \\
5340 \\
15-20 \\
3 \\
5 \\
30 \\
70 \\
+ \\
+ \\
\end{array}$ \\
\hline
\end{tabular}

